Portland State University

PDXScholar

5-18-1973

\title{
Digital Computer Solution of Electromagnetic Transients in Large Power Systems
}

Bijan Navidbakhsh

Portland State University

Follow this and additional works at: https://pdxscholar.library.pdx.edu/open_access_etds

Part of the Electrical and Electronics Commons, Numerical Analysis and Scientific Computing Commons, and the Power and Energy Commons

Let us know how access to this document benefits you.

\section{Recommended Citation}

Navidbakhsh, Bijan, "Digital Computer Solution of Electromagnetic Transients in Large Power Systems" (1973). Dissertations and Theses. Paper 1757.

https://doi.org/10.15760/etd.1756

This Thesis is brought to you for free and open access. It has been accepted for inclusion in Dissertations and Theses by an authorized administrator of PDXScholar. Please contact us if we can make this document more accessible: pdxscholar@pdx.edu. 
AN ABSTRACT OF THE THESIS OF Bijan Navidbakhsh for the

Master of Science in Applied Science presented May 18, 1973.

THte: Digital Computer Solution of Electromagnetic

Transients in Large Power Systems.

APPROVED BY MEMBERS OF THE THESIS COMMTTTEE

Thomas J. Ké⿱一𧰨lilian, Chairman

Jạck C. Rijley

Chamberlain I. Foes

This thesis is an introduction to the solution of electromagnetic transients by a combination of the Bergeran method of characteristics and the application of trapezoidal male of integration.

Three test examples solved by digital computer illustrate the step by step solution and computer programming.

To compare this method with the Iaplace transformation technique, a test problem solved by both methods and also digital computer is illustrated. In conclusion, the advantages and disadvantages of both methods are compared. 
TO THE OFFICE OF GRADUATE STUDIES:

The members of the Comittee approve the thesis of Bijan Navidbakhsh presented May 18, 1973.

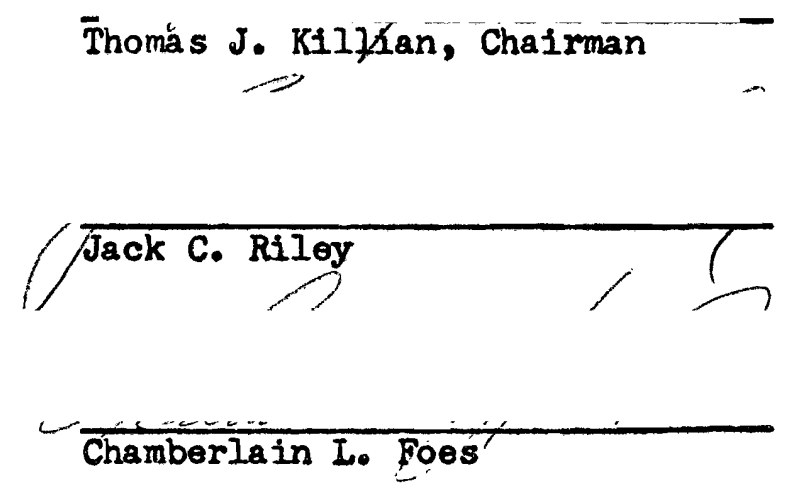

APPROVED8

Nan-Teh Hsu, Head, Department of Applied Science

Detid T. Clark, Dean of Graduate Studtes and Research

May 18, 1973 
DIGITAL COMPUTER SOLUTION OF ELECTROHAGHETIC

TRANSIENTS IN LARGE POWER SYSTEMS

by

BIJAN NAVIDBAKHSH

A thesis submitted in partial fulfillment of the requirements for the degree of

\author{
MASTER OF SCIENCE \\ in \\ APPLIED SCIENCE
}

Portland State University

1973 
TO MY

PARENTS 
TABLE OF CONTENTS

PAGE

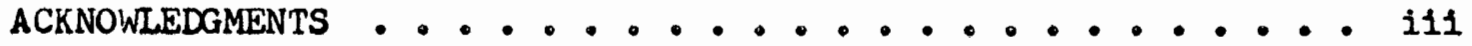

\section{CHAPTER}

I INTRODUCTION $\cdot$. . . . . . . . . . . . . I I

II BERGERON METHOD .................. 3

Distributed-Constant Transmission Ifine . . . 7

Transmission Iine with a Non-Linear

Resistor ................. 8

Lumped Elements . . . . . . . . . 11

Lumped Inductance ........... 11

Iumped Capacitance and Series Lumped

Circuit .............. 13

III DIGITAL COMPUTER TECHNIQUE . . . . . . . . . . 14

Node Equations ............... 14

Trapezoidal Rule of Integration . . . . . 16

DIGITAL COMPUTER SOLUTION OF ELECTROMAGNETIC

TRANSIENTS •. . . . . . . . . . 17

Lossless Iine . . . . . . . . . 18

Test Case No. 1 . . . . . . . . . . 22

Inductance ................... 38

Capacitance ............. 40

Resistance ............. 4 I

Series R - I - C Branch ......... 4 I

Test Case No. 2 ............ 45

Nonlinear and Time Varying Parameters . . 68

Past History Current I ......... 93 
CHAPTER

PAGE

LAPLACE TRANSFORMATION TECHNIQUE . . . . 94

Test Case No. 4 ......... 96

IV COMPARISON AND CONCLUSION .......... 108

Comparison of Both Techniques ...... 108

Conclusion ............ 110

REFERENCES ....................... 111 


\section{ACKNOWLEDGMENTS}

This thesis was suggested and motivated by Dr. Thomas J. Killian, my thesis advisor, to whom I wish to express apy apreciation for giving of his time and assistance.

Special thanks are due to Dr. Hermann W. Dommel at Bonneville Power Administration, who helped in providing me with the facilities to complete this thesis."

Thanks are also extended to Dr. Nan-Teh Hsu of the Applied Science Department at Portland State University. 
CHAPTER I

INTRODUCTION

The objective of this thesis is to present an introduction to a combination of the Bergeron method of characteristics and the trapezoidal rule of integration to the digital computer solution of transients in electric circuits. This method has been used both in Europe and here at the Bonneville Power Administration. 1,2

Since this method has not been generally available to students of electrical engineering, this paper discusses the method with complete details for transient and steady state problems involving both lumped and distributed parameter.

Chapter two discusses the Bergeron method applied to distributed parameters of transmission lines. The graphical solution with examples presents the general method and how it can be applied to a digital computer solution.

The first part of chapter three begins with the node equations and the trapezoidal rule of integration used in the digital computer

$I_{\mathrm{H}}$. Prinz and $\mathrm{H}$. Dommel, wberspannungsberechnung in Hochspannungsnetzen", presented at the Sixth Meeting for Industrial Plant Managers, Munich, Germany, 1964.

2 "Digital Computer Solution of Electromagnetic Transients in Single and Multiphese Networks", I.E.E.E. Transactions on Power Apparatus and Systems, Vol. Pas-88, pp. 388-399, April 1969 
solution. The Bergeron method applied to distributed parameters of lossless line by digital computer is introduced; the equations and equivalent impedance network of a line are derived.

The trapezoldal rule of integration is applied for lumped parameters, the equation describing the relation of voltage and current are determined and the equivalent impedance network for each lumped parameter is obtained. Finally, the digital solution of a system with one nonlinear element is discussed. Three detailed examples are presented: the first, a lossless line with distributed parameters, the second, a circuit with lumped parameters, and the third, a system with a nonlinear parameter.

Chapter three consists of the example of a relatively simple problem by both the conventional Laplace transformation technique and the described computer transient program.

Chapter four includes the comparison of both techniques and the conclusion. 
CHAPTER II

BERGERON METHOD

The method of characteristics with the aid of the trapezoidal rule of integration can be generalized in a method capable of solving transients in any notwork with distributed as well as lumped parameters.

In order to understand the method of characteristics, in the following paragraphs we shall discuss the Bergeron method, which will perform the character of the method of characteristics and some graphical example which enables us to understand the concept of our main objective--the digital computer solution of electromagnetic transient. The trapezoidal rule of integration will be described in the course of this paper.

In about 1930 the Bergeron method was originally devised by Louis Bergeron and 0 . Schnyder. This method is by no means new and it has been used as an ald for the calculation and determination of the transient phenomena in hydraulic systems. The Bergeron method has been used extensively in the field of hydraulios and the contributions to this field are well known. Recently there have been attempts to apply this method to electrical systems. The method is essentially a graphical process and this naturally will develop drawing errors. However, these orrors can be eliminated by the use of a digital computer.

In this method transmission lines may be considered exactly with- 
out having the equivalent networks of lumped elements and the essential nature of the line is retained. This can be considered one of the advantages of this method. Another advantage is that complex forcing functions such as sinusoids and exponentials can be handled exactly, while in other methods these types of functions have to be approximated and simulated in different forms. The method is also capable of handIIng circuits with lumped, resistive, inductive, and capacitive elements. Non-linear elements cause little difficulty.

There are fundamental mathematical equations for all wave motion. There are a number of different types of solutions for these equations. One of these solutions is that the basis of the Bergeron method is such that it is exact and does not rely on mathematical series for its expression. Since transients are often discontinuous, this is an important point.

Let'us now continue our discussion on relation of voltage and current on a lossless line. The following two equations describe the reletion of voltage and current on a transmission line.

$$
\begin{aligned}
& -\partial \theta / \partial x=I \cdot \partial i / \partial t \\
& -\partial I / \partial x=c \cdot \partial \theta / \partial t
\end{aligned}
$$

wheres

$$
\begin{aligned}
& e=\text { voltage to ground } \\
& 1=\text { Iine current } \\
& t=\text { time } \\
& I=\text { Iine inductance per unit length } \\
& C=\text { Iine capacitance per unit length }
\end{aligned}
$$




$$
x=\text { distance on the transmission line }
$$

We may introduce two notations, $Z$ and $a$.

where:

$$
\begin{aligned}
z= & \text { surge impedance of the line } \\
a= & \text { velocity of propagation of the } \\
& \text { disturbance }
\end{aligned}
$$

Theif relations with $I$ and $C$ ares

$$
\begin{aligned}
& Z=\sqrt{I / C} \\
& a=1 / \sqrt{I \cdot C}
\end{aligned}
$$

By substitution of one equation for another we obtain two equations of roltage and current as follows:

$$
\begin{aligned}
& \partial^{2} i / \partial x^{2}=1 / a^{2} \cdot \partial i / \partial t^{2} \\
& \partial^{2} \theta / \partial x^{2}=1 / a^{2} \cdot \partial^{2} \theta / \partial t^{2}
\end{aligned}
$$

The classicel solution of these two equations iss

$$
\begin{aligned}
& i=F_{1}(x-a t)+F_{2}(x+a t) \\
& i=Z \cdot F_{1}(x-a t)-Z \cdot F_{2}(x+a t)
\end{aligned}
$$

Here $F_{1}$ and $F_{2}$ are some functions and voltage and current are functions of time.

We can think of the expressions $(x+a t)$ and $(x-a t)$ as waves travelIng in the negative and positive direction, respectively. Now by some manipulation of equations (5) and (6) we will see the principle of Bergeron method clearly.

Let us multiply equation (5) by $Z$ and first add it, then subtract it from equation (6). The result will be the two following equations: 


$$
\begin{aligned}
& e+z \cdot 1=2 Z \cdot F_{1}(x-a t) \\
& e-z \cdot i=-2 Z \cdot F_{2}(x+a t)
\end{aligned}
$$

If the two expressions ( $x-a t)$ and $(x+a t)$ in equation (7) and (8) are constant, the left hand side of the two equations will also be constant.

Now if we think of an observer who travels along the line with a constant velocity $n_{2} "$ in the positive $x$ direction, then this observer would tell us that the expression $\theta+2 . i$ appears constant to him.

If we express this in physical terms, we may understand the concept of two equations (7) and (8) thoroughly. This simply can be expressed so that if we think of an observer who is able to travel along the line with the traveling wave, at the same speed as the wave is moving, and at the same time is able to measure the voltage and current flowing, he would see that the relation of voltage and current is $+2.1=$ constant

The result of the above discussion permits us to write equations (7) and (8) 28 the following forms

$$
\begin{aligned}
& e+2 \cdot 1=\text { Constant } \\
& e-z \cdot 1=\text { Constant }
\end{aligned}
$$

Equations (9) and (10) are the equations of two straight lines in the voltage and current plane with the slopes of $+Z$ and $-Z$, respectively. This is the basic idea of the Bergeron method.

In order to formulate the principle of this method we have to express another point. 
Let us assume two observers are moving along a transmission line, one in positive and the other in negative direction. As they are moving along the line they meet each other at a point where the voltage and current that one observer is measuring is the same as the other.

Equations (9) and (10) are called the "characteristics" of the preceeding differential equations. From this we may say that the Bergeron method is the extension of the "Method of Characteristic".

In order to see the practical aspect of this method we illustrate some examples as follows:

\section{Distributed-Constant Transmission line}

Consider the distributed-constant transmission line AC and point $B$ between $A$ and $C$ as shown in $f_{1 g}$. (1)a

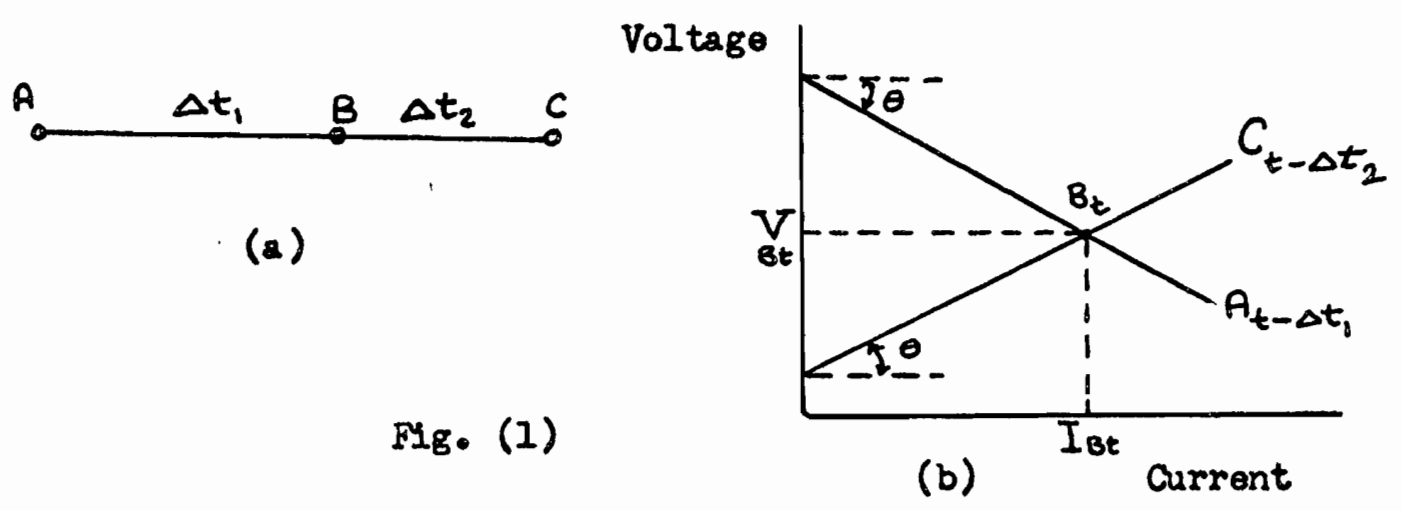

$\Delta t_{1}$ and $\Delta t_{2}$ represent the transit time for sections $A B$ and $B C$, respectively. This means $\Delta t_{1}$ unit of time takes the wave travel from $A$ to $B$ and $\Delta t_{2}$ unit of time from $B$ to $C$.

Now if some observer at time $\left(t-\Delta t_{1}\right)$ starts traveling from point A toward point B with wave velocity, he would see the relation of voltage and current along the line as follows: 


$$
\theta+Z_{.1}=K_{1}
$$

Here $K_{1}$ is constant.

If another observer starts traveling from point $C$ toward point $B$ with wave velocity, he would see the relation of voltage and current along the IIne as follows:

$$
\theta-2.1=K_{2}
$$

Suppose by some means the voltage and current at point $A$ at time $\left(t-\Delta t_{1}\right)$ and at point $C$ at time $\left(t-\Delta t_{2}\right)$ are known. By having this information equations (11) and (12) can be solved for $K$ (constant) and consequently the points and lines $A_{\left(t-\Delta t_{1}\right)}$ and $C_{\left(t-\Delta t_{2}\right)}$ can be plotted In voltage and current plane as shown in fig. (I)b. The slopes of the lines $A\left(t-\Delta t_{1}\right)$ and $C\left(t-\Delta t_{2}\right)$ are $-Z$ and $+Z$, respectively.

Now if we go beck to our observers, we see that they will meet each other at point $B$ at time $t$ and both register the same value for voltage and current. Consequently, by having the past history we are able to determine voltage and current at any point and at any instant of time.

Transmission Line with a Non-Linear Resistor

Let us turn our attention to a more complicated and practical example. Consider the system shown in fig. (2). There is a transmission line terminated by a non-linear resistor. The characteristic of the resistor and the parameters of the line are known. For this example the line is considered to be. lossless.

The non linearity of an element in a system causes some complexity as far as the Bergeron method is concermed. The transient 
voltage across the resistor and the transient current at the source are desired while a step voltage is applied at the point $A$ at time zero.

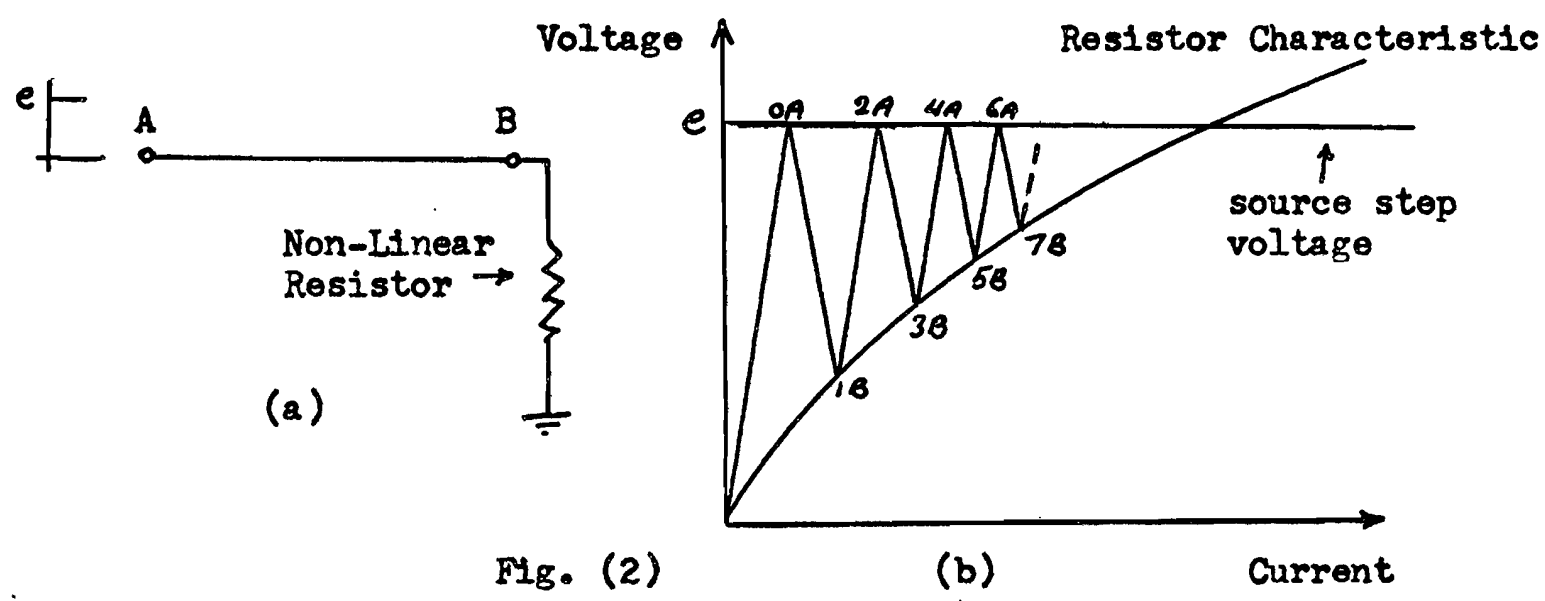

One very important advantage of the Bergeron mothod is that it enables us to compute current and voltage simultaneously. In spite of other methods there is no need for separate computation to determine the transient current. This advantage will appear in the digital computer solution of electromagnetic transient which shall be discussed in full details in further sections. The Bergeron diagram for this system is shown in fig. (2)b.

Let us consider an observer moving at the wave speed up and down along the transmission line. Every time this observer travels the distance $\mathrm{AB}$ or $\mathrm{BA}$ it takes him one time unit. Here the time unit corresponds to the transit time of the line. Suppose he is leaving the recelving end $B$ at a time -1. This means one time unit before the step voltage is applied at $A$. We shall notice in the following paragraph that it is necessary to have some information of the past history in a 
short period of transit time.

Consider equations (11) and (12). Every time the observer travels the distance $A B$ and $B A$ we should be able to show the straight lines corresponding equations (11) and (12), respectively. He will reach A at time zero just as the step is applied. We know voltage and current at time $-i$ at $B$ is zero. From this equation (11) becomes a straight line with the form of $\theta=21$ passing the origin and intersecting the step voltage $\theta$ at point $O A$ in Bergeron diagram at time zero. The slope of this line is $+Z$ where $Z$ is the line surge impedance. This line is represented by $0, O A$ as shown in $\mathrm{flg}$. (2)b. Now at point oA (o represents time zero and A represents terminal A in fig. (2)a) we know voltage and current at time zero. In the next step when the observer travels from $A$ to $B$ we know already the past history for the next step time +1 . The equation describes the relation of voltage and current at this time is equation (12). This is a line pessing through point of with the slope of $-Z$ and intersecting the resistor characteristic at point 1B. The characteristic of his travel from time -1 until time +1 is the Iine 0 , $O A$ and $O A, 1 B$.

The intersection of the IIne oA, 1B with a line representing the characteristics of the reststor tells us the required voltage and current at $B$ at time +1 . We may notice that the characteristics of the resistor can take any degree of complexity without really making the problem more complicated.

To continue the solution of this problem for further steps, the 
observer simply continues his travel back and forth along the transmission line and the diagram is built up as shown in fig. (2)b.

\section{Lumped Elements}

Since the Bergeron method is not our main objective and it is only to give us a basic background for our further discussion in chapter two, we limit ourselves to a brief description of the handling of lumped elements in the Bergeron method.

Important elements in power systems are of course lumped Inductive and capacitive components. There must be some methods which are able to handle lumped elements in power systems. One of these methods is presented by the Bergeron method. The one possible disadvantage in this case is that the results must be a little approximated. The approximation taken in this method is quite controllable and the result obtained by the Bergeron method is not worse than those from other processes.

To show the process of the method a lumped inductance example is illustrated as follows:

\section{Lumped Inductance}

Consider a transmission Iine terminated by a lumped inductance as shown in fig. (3)a. Let us assume some disturbance is applied at $A$ and the voltage and current at $B$ is known at time $t$. Since we know the required information of $B$ at thme $t$, the point $B_{t}$ can be plotted in fig. (3)b. 
The voltage across an inductance is given by:

$$
\theta=I \cdot d i / d t
$$

This will be handled by using finite differences rather than differentials, therefore let $d t=h$.

We want to find the voltage at point $B$ at time $t+h$. The point $B_{t+h}$ must be on the straight Iine characteristic $A_{t+h-\Delta t,} B$ seen by an observer leaving $A$ at time $t+h-\Delta t$, where $\Delta t$ is the transit time from $A$ to $B$. Now if $h$ is small enough that we can assume e varies linearly In this interval, et and et+h are the voltages at point $B$ at time $t$ and $t$ th respectively, then we may write equation (13) in the form of:

$$
\left(\left(\theta_{t}+\theta_{t+h}\right) / 2\right) \cdot h=I \cdot d t
$$

or

$$
\theta_{t+h}=-\theta_{t}+L /(h / 2) \cdot d i
$$

Equation (15) is plotted in fig. (3)b represented by the line Bt, S. The slope of this line is $I /(h / 2)$. This means $\tan 0=L /(h / 2)$.

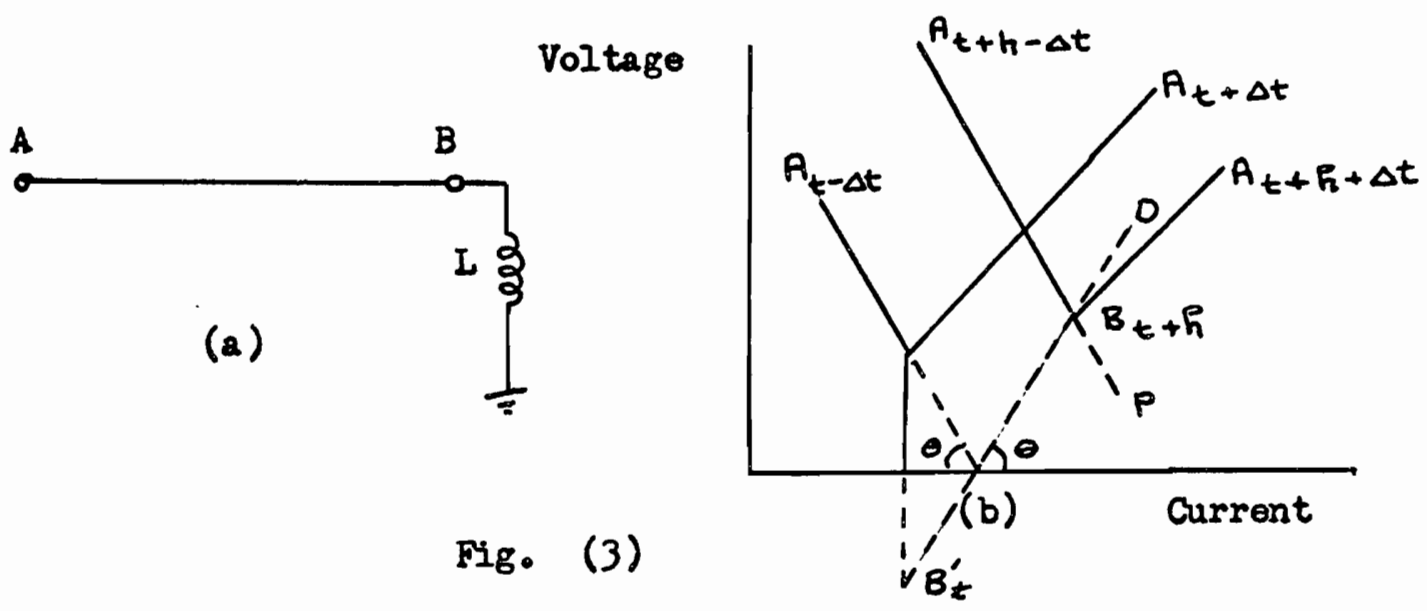

Since we know the angle $\theta$, we can plot the equation of the Iine $B_{t}^{\prime}, S$ and since the point $B_{t}^{\prime}$ is symmetrical with $B_{t}$, the line $B_{t}^{\prime}, s$ can 
be plotted. This Iine intersects the line $A_{t+h-\Delta t}, P$ at the desired point $B_{t+h}$.

The complete diagram is built up by assuming that an observer travels beck and forth along the transmission line AB. The surge Impedance of such a Iine is $L /(h / 2)$ and transit time is $h / 2$. In this case it might be argued that the inductor has been simulated by a transmission line.

Iumped Capacitance and Series Lumped Circuit

The same process could be done in a case of lumped capacitance. In this case the surge impedance is $h / 20$ and the line transit is $h / 2$.

The series lumped circuit can be handled in the Bergeron method by the method just described, which may be "Cascaded" and this enables us to solve any combination of such elements in any electrical circuit. The Bergeron method provides a powerful tool for the solution of transient voltage and current in electrical engineering. So far this mothod taught us how to determine the transient voltage and current graphically in an electrical circuit. The concept of this method will be applied to our next discussion regarding the digitel computer solution. 


\section{CHAPTER III}

\section{DIGITAL COMPUTER TECHNIQUE}

The computation of the transient voltage and current was discussed by means of the graphical method in the previous chapter. As mentioned before, the disadvantage of this graphical method is the errors made by drawing and the time consumed for the solution of a large power system. However, graphical errors and the problem of time can be eliminated by means of digital computation.*

The important digital computer solutions which are discussed in this chapter are the method of characteristics and the trapezoidal rule of integration. Since node equations play an important role in digital computer solution, these are discussed first and then the trapezoidal rule of integration is presented.

\section{Node Equations}

The system of node equations, applying the Kirchhoff's current law, is an important fundamental base for a digital computer solution of a large power system. In order to derive a general formula for node equations in any electicical circuit, consider the circuit shown in fig. (4). The Kirchhoff's current law states that the sum of the currents at each node is zero.

* Of course, the main purposes of using digital computers are automatic solution and faster facility in obtaining data. 
Applying this lew at node $1,2,3$, and 4 with direction of current as show in fig. (4) (the arrow represents the direction of current), gives

$$
\begin{aligned}
& y_{g}\left(\theta-V_{1}\right)=Y_{a}\left(V_{1}-V_{2}\right)+Y_{c}\left(V_{1}-V_{4}\right) \\
& 0=Y_{a}\left(V_{1}-V_{2}\right)-Y_{b}\left(V_{2}-V_{3}\right)-Y_{\theta}\left(V_{2}-V_{4}\right) \\
& 0=Y_{b}\left(V_{2}-V_{3}\right)-Y_{m}\left(V_{3}-0\right)-Y_{d}\left(V_{3}-V_{4}\right)
\end{aligned}
$$

and for node 4

$$
0=-Y_{p}\left(Y_{4}-0\right)+Y_{d}\left(V_{3}-V_{4}\right)+Y_{c}\left(V_{1}-V_{4}\right) .
$$

Rearranging this equation and letting $Y_{B}{ }^{e}=I_{1}$ gives.

$$
\begin{aligned}
& I_{1}=V_{1}\left(Y_{g}+Y_{a}+Y_{c}\right)-V_{2} Y_{a}-V_{4} Y_{c} \\
& 0=V_{1} Y_{a}-V_{2}\left(Y_{a}+Y_{b}+Y_{e}\right)+V_{3} Y_{b}+V_{4} Y_{a} \\
& 0=V_{2} Y_{b}-V_{3}\left(Y_{b}+Y_{m}+Y_{d}\right)+V_{4} Y_{d} \\
& 0=V_{1} Y_{c}+V_{3} Y_{d}-V_{4}\left(Y_{p}+Y_{d}+Y_{c}\right) .
\end{aligned}
$$

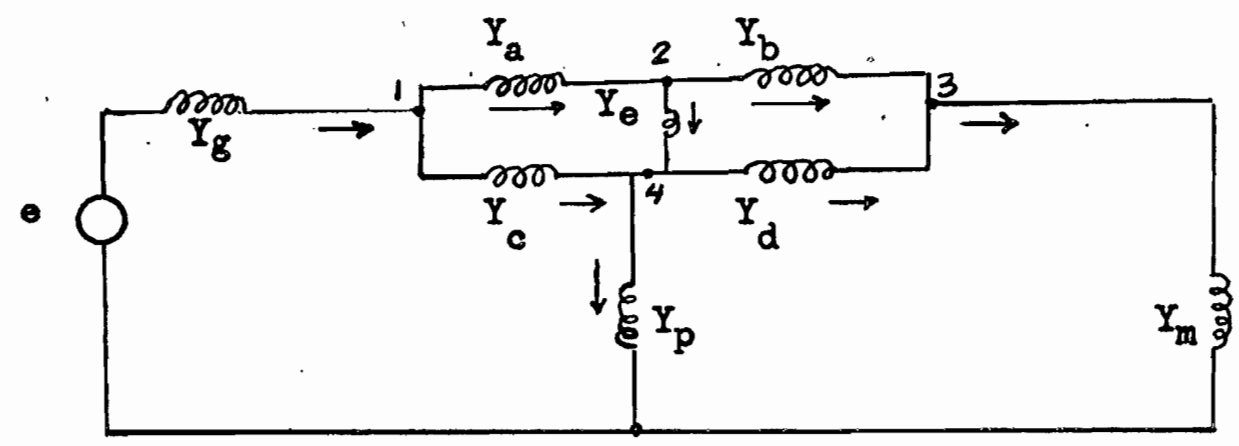

Fig.

(4)

The node voltages $v_{1}, v_{2}, v_{3}$, and $v_{4}$ can be determined by solving the four equations 20 - 23 simultaneously. By knowing these voltages, all branch currents can be found. We should note that the number of equations is one less than the number of nodes.

From the above four equations we can derive the general node equation for any electrical circuit as follows: 


$$
\begin{aligned}
& I_{1}=v_{1} Y_{11}+v_{2} Y_{12}+v_{3} Y_{13}+\ldots \ldots . \cdot v_{n} Y_{1 n} \\
& I_{2}=v_{1} Y_{21}+v_{2} Y_{22}+v_{3} Y_{23}+\ldots \ldots \cdot v_{n} Y_{2 n} \\
& I_{3}=v_{1} Y_{31}+v_{2} Y_{32}+v_{3} Y_{33}+\ldots \ldots . v_{n} Y_{3 n} \\
& I_{n}=v_{1} Y_{n 1}+V_{2} Y_{n 2}+V_{3} Y_{n 3}+\ldots \ldots . v_{n} Y_{n n}
\end{aligned}
$$

In matrix form it is written as:

$$
\text { or } \begin{aligned}
{[I] } & =[Y][V] \\
{[V] } & =[Y]^{-1}[I]
\end{aligned}
$$

where, in our case $n=4$ and $I_{2}, I_{3}$, and $I_{4}$ are zero.

Trapezoidal Rule of Integration

There are a number of ways to integrate a function and one of these is the trapezoidal method which is used in many digital computer solution techniques. In order to see the rule of this integration method, consider function $F$ in Flg. (5) ( $F$ could be any continuous function).

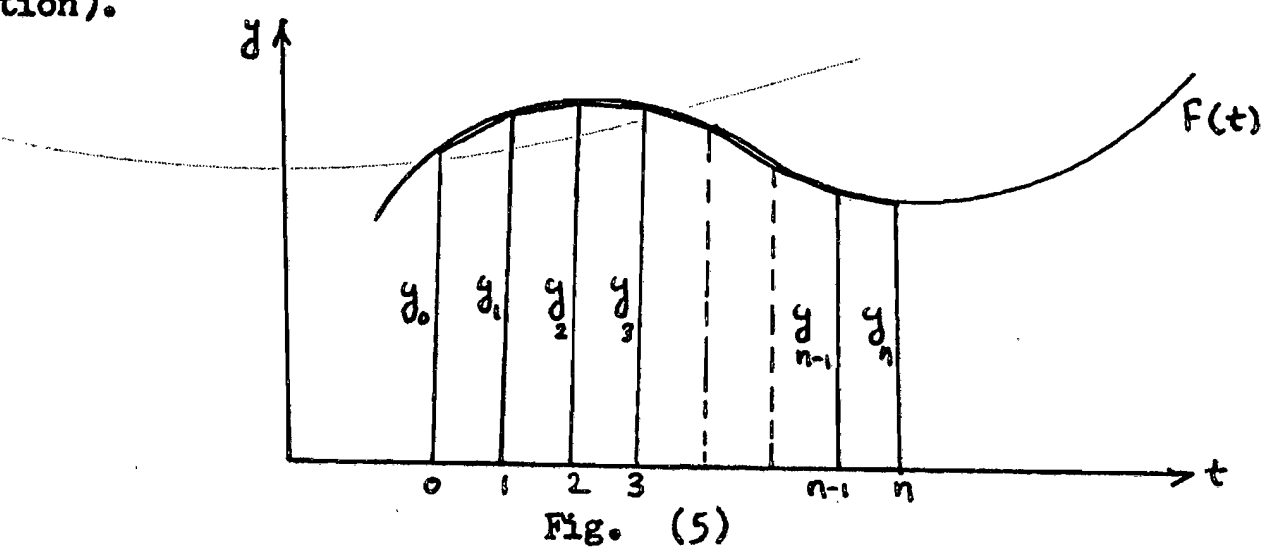

The $t$ axis is equally divided in $n$ smell division and each small 
division is designated by $\Delta$. The area below the curve between zero and $n$ determines the integral of function from 0 to $n$. Let us write the area of each trapezoid under the curve and then by summation of all areas, the integral of $F$ wili. be found.

$$
\begin{aligned}
& A_{1}=(1 / 2)\left(y_{0}+\nabla_{1}\right) \Delta t \\
& A_{2}=(1 / 2)\left(y_{1}+y_{2}\right) \Delta t \\
& A_{n-1}=(1 / 2)\left(y_{n-2}+y_{n-1}\right) \Delta t \\
& A_{n}=(1 / 2)\left(y_{n-1}+y_{n}\right) \Delta t .
\end{aligned}
$$

By adding all areas the total area will be:

$$
A_{t}=(\Delta t / 2)\left(y_{0}+2 y_{1}+2 y_{2}+\cdots+2 y_{n-1}+y_{n}\right)=\int_{0}^{n} F d t
$$

of course one could say this result may not be accurate enough since an approximation is used. This will depend on how small $t$ is. The use of $\Delta t$ will be made more clear in the next pert where the digital computer solution is discussed.

\section{DIGITAL COMPUTER SOLUTION OF ELECTOMAGNETIC TRANSIENTS}

A digital computer solution of transients can be applied to power systems containing long lines with or without Iumped parameters. The process taken in this digital computer solution is a step by step procedure that proceeds along the time axis where each step is designated by $\Delta t$. This short interval of time may be either fixed or variable. Starting with initial condition $t=0$, the state of the system in the 
sequence of steps is found at $t=\Delta t, 2 \Delta t, 3 \Delta t, \ldots \ldots$ up to the maximum time $t_{\max }$ for a particular case. In every state of the process the past history is known. This means when we are solving for time $t$ the previous states $t-\Delta t, t-2 \Delta t, t-3 \Delta t$, and back to the initial conditions are known. In the case of long lines the past history used for time $t$ is $t-\tau$ where $\tau$ corresponds to the travel time of the line. In the case of lumped parameters $\Delta t$ corresponds only to the previous step where it can be any arbitrary length of time. Therefore a limited portion of this "past history" is used for long lines in the method of characteristics and in the trapezoidal rule of integration.

Equivalent impedance network of a Iine and lumped parameters are presented by the equations derived by the method of characteristics for lines and trapezoidal rule of integration for lumped parameters and the record of past history. This will be made clearer as we first discuss lossless lines and the lumped parameter networks.

\section{Lossless Line}

In order to derive an equation by the method of characteristics for lossless line and consequently to build an equivalent impedance network for the line, we have to remind the reader of some material which has been already discussed in chapter two. This also helps us to see that the digital computer solution is actually Bergeron's method for a lossless line.

Consider a lossless line with inductance I and capacitance C per unit length (fig. 6). The relation of voltage and current at a point $x$ along the line is 


$$
\begin{aligned}
& -\partial \theta / \partial x=I(\partial \dot{\partial} / \partial t) \\
& -\partial 1 / \partial x=c(\partial \theta / \partial t)
\end{aligned}
$$

The generel solution, first given by d'Alembert, is:

$$
\begin{aligned}
& i(x, t)=F_{1}(x-a t)+F_{2}(x+a t) \\
& e(x, t)=2 \cdot F_{1}(x-a t)-Z \cdot F_{2}(x+a t)
\end{aligned}
$$

where

$$
\begin{aligned}
& z=\sqrt{I / C} \\
& a=1 / \sqrt{I C} \\
& \underset{\text { Terminal a }}{\longrightarrow} \underset{\text { Terminal b }}{\longrightarrow}
\end{aligned}
$$

Fig. (6) Lossless Line

and by some manipulation which was discussed in chapter two, equations (26) and 27) can be written in the form of:

$$
\begin{aligned}
& e(x, t)+z \cdot i(x, t)=2 Z \cdot F_{1}(x-a t)=\text { constant } \\
& e(x, t)-z \cdot i(x, t)=-2 Z \cdot F_{2}(x+a t)=\text { constant. }
\end{aligned}
$$

As we see equations (24) - (29) are the same as equations (1) - (8) in the previous chapter.

Now with the same imaginary observer as before, who travels along the line, equations (28) and (29) seen by the observer are constant. This means when he travels from $b$ at time $t-\tau$ equation: (28) is equal to equation (29) when he reaches a at time t. If the travel time to get from $b$ to $a$ or $a$ to $b$ is

$$
\tau=1 / a
$$

(1 is the length of the line), then with the same logic we have: 
20

$$
\begin{aligned}
& e_{a}(t)-2 i_{a, b}(t)=e_{b}(t-\tau)+2 i_{b, a}(t-\tau) \\
& e_{b}(t)-2 i_{b, a}(t)=e_{a}(t-\tau)+2 i_{a, b}(t-\tau)
\end{aligned}
$$

$1_{a, b}$ and $I_{b, a}$ can be found from equations $(30)$ and $(31)$ as follows:

$$
\begin{aligned}
& 1_{a, b}(t)=(1 / z) e_{a}(t)+\left(-(1 / z) e_{b}(t-\tau)-1_{a, b}(t-\tau)\right)(32) \\
& 1_{b, a}(t)=(1 / z) e_{b}(t)+\left(-(1 / z) e_{a}(t-\tau)-i_{a, b}(t-\tau)\right) \cdot(33)
\end{aligned}
$$

Consider equation (32); the second term of the right hand side of this equation can be simulated as a source current parallel with $Z$ and let us call this current $I_{a}(t-\tau)$. Therefore equation (32) can be written in the following form:

$$
1_{a, b}(t)=(1 / 2) e_{a}(t)+I_{a}(t-\tau)
$$

where

$$
I_{a}(t-\tau)=-(1 / 2) \theta_{b}(t-\tau)-I_{b, a}(t-\tau) .
$$

Consequently the equivalent impedance network by considering equations (34) for node a is illustrated in fig. (7).

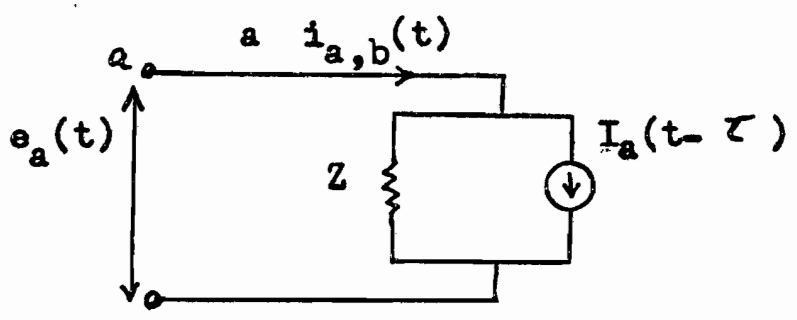

Fig. (7)

Similarly, for node $b$ equation (33) can be written in the form of:

$$
1_{b, a}(t)=(1 / z) e_{b}(t)+I_{b}(t-\tau)
$$

where

$$
I_{b}(t-\tau)=-(1 / z) e_{a}(t-\tau)-1_{a, b}(t-\tau)
$$


and the equivalent impedance network considering equation (36) for node $b$ is shown in $\mathrm{flg}$. (8)

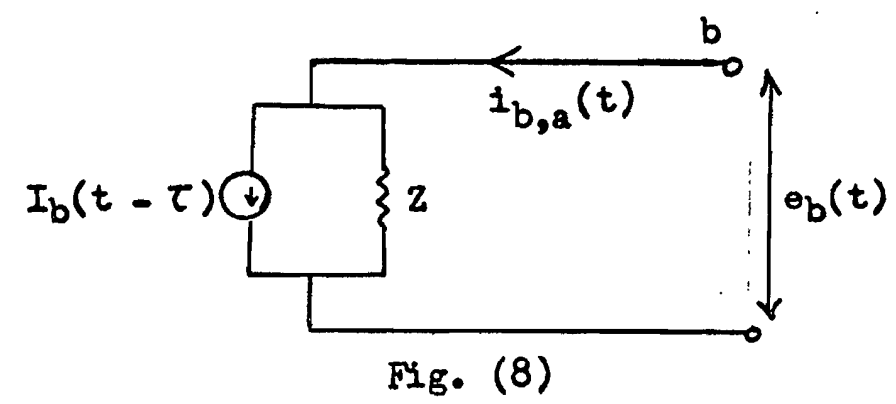

Now, if fig. (7) and (8) are combined in an imaginary box, the complete equivalent impedance network of the line is a two port network as shown in fig. (9).

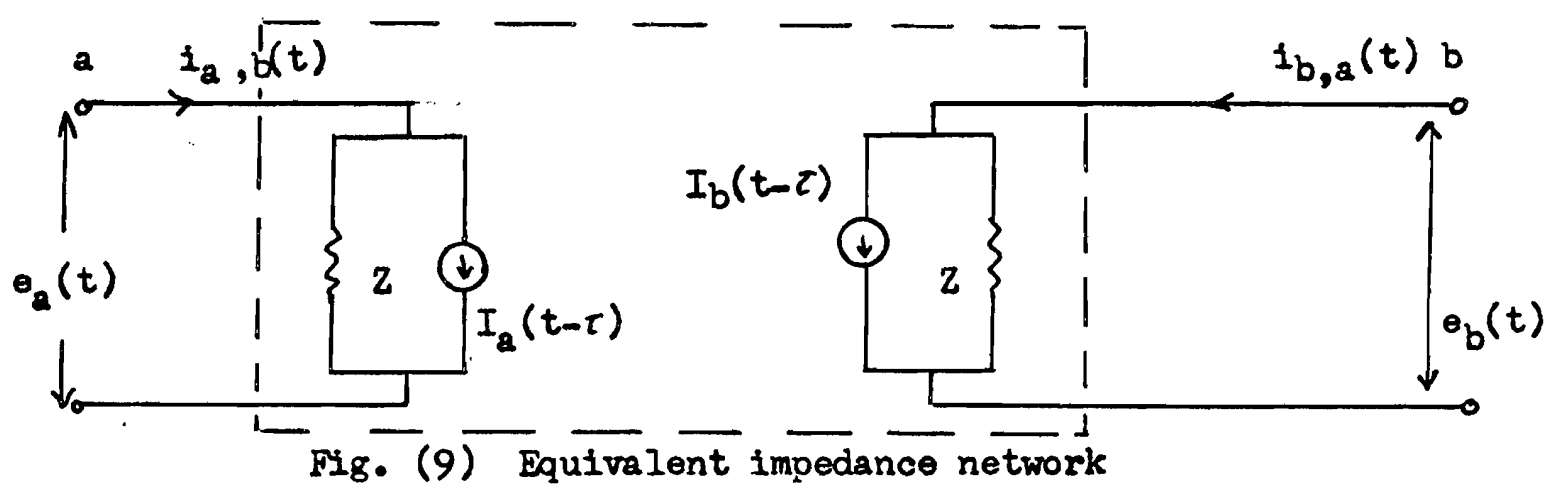

This fully describes the lossless line at its terminals. As the diagram shows, the terminals are not connected; of course the conditions at the other terminal in respect to another are only seen indirectly by means of equations (30) - (33) with a time delay .

Although the method of characteristics can handle lossy lines also, the differential equations produced are not directly integrable. Therefore, losses are neglected at this stage. They may be included later as equivalent lumped resistances. 
In order to indicate the complete procedure a digital computer solution for a lossless line is illustrated in full detail as follows: Test Case No. 1

Consider a series of three different lines, which are terminated by an infinite line. A rectangular voltage impulse, coming from an infinite line, is applied to these lines. This is shown in fig. (10). The voltage at node 4 is desired for maximum time of 20 micro-seconds.* V=1 p.u.

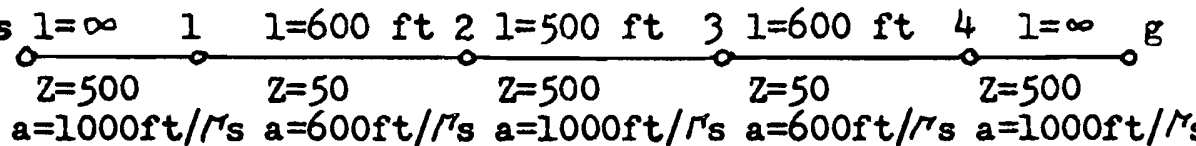
$\mathrm{v}=2 \mathrm{p} \cdot \mathrm{u} \cdot \uparrow$

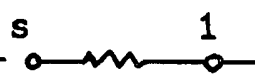
$R=500$
(a)

FIg. (10)
$\tau_{1}=600 \mathrm{ft}(600 \mathrm{ft} / \mathrm{s})=1 / \mathrm{s}$
$\tau_{2}=500 \mathrm{ft} /(1000 \mathrm{ft} / \mathrm{s})=.5 \mathrm{~s}$
$\tau_{3}=600 \mathrm{ft} /(600 \mathrm{ft} / \mathrm{s})=1 / \mathrm{s}$

Infinite line means the travel time on the line is more than the time of study and when a voltage impulse of 1 p.u. is coming over this line, it is represented by voltage impulse of 2 p.u. coming over its

*This problem is taken from L. V. Bewley, Traveling Waves on Transmission Systems, (New York: Dover Publications, Inc., 1951), p. 100. 
equivalent resistance $R=Z$. Infinte line $4, g$ shown in fig. (10)a is represented as a resistance to ground with $R=Z$ as shown in Fig. (10)b.

Given data:

$$
\begin{aligned}
& \text { Excitations } \theta(t)= \begin{cases}0 & t \leqslant 0 \\
2.0 & t>0\end{cases} \\
& \Delta t=.25 / \mathrm{s} \\
& t_{\max }=20 / \mathrm{s}
\end{aligned}
$$

Solution:

The first step is to draw the equivalent network impedance of the system. This could be done by using fig. (9) for each node and the second step is to write node equations for all nodes. For this type of problem (lossless lines) there is no need to put node equations in matrix form, because all equations can be solved independently. (The equivalent impedance network of the system is completely shown in fig. (11).

Node Equations:

Consider each node in fig. (II); the node equations for node I, 2,3 , and 4 are found as follows:

$$
\begin{aligned}
& i_{1,2}-i_{1}(t)=(1 / 50) \theta_{1}+I_{1}^{\prime}\left(t-\tau_{1}\right)-\left(2-\theta_{1}\right) / 500=0 \\
& i_{2,1}+i_{2,3}=(1 / 50) \theta_{2}+I_{2}\left(t-\tau_{1}\right)+(1 / 500) \theta_{2}+I_{2}^{\prime}\left(t-\tau_{2}\right)=0 \\
& i_{3,2}+i_{3,4}=(1 / 500) \theta_{3}+I_{3}\left(t-\tau_{2}\right)+(1 / 50) \theta_{3}+I_{3}^{\prime}\left(t-\tau_{3}\right)=0 \text { (40) } \\
& i_{3,4}+i_{4}=(1 / 50) \theta_{4}+I_{4}\left(t-\tau_{3}\right)+(1 / 500) \theta_{4}=0
\end{aligned}
$$




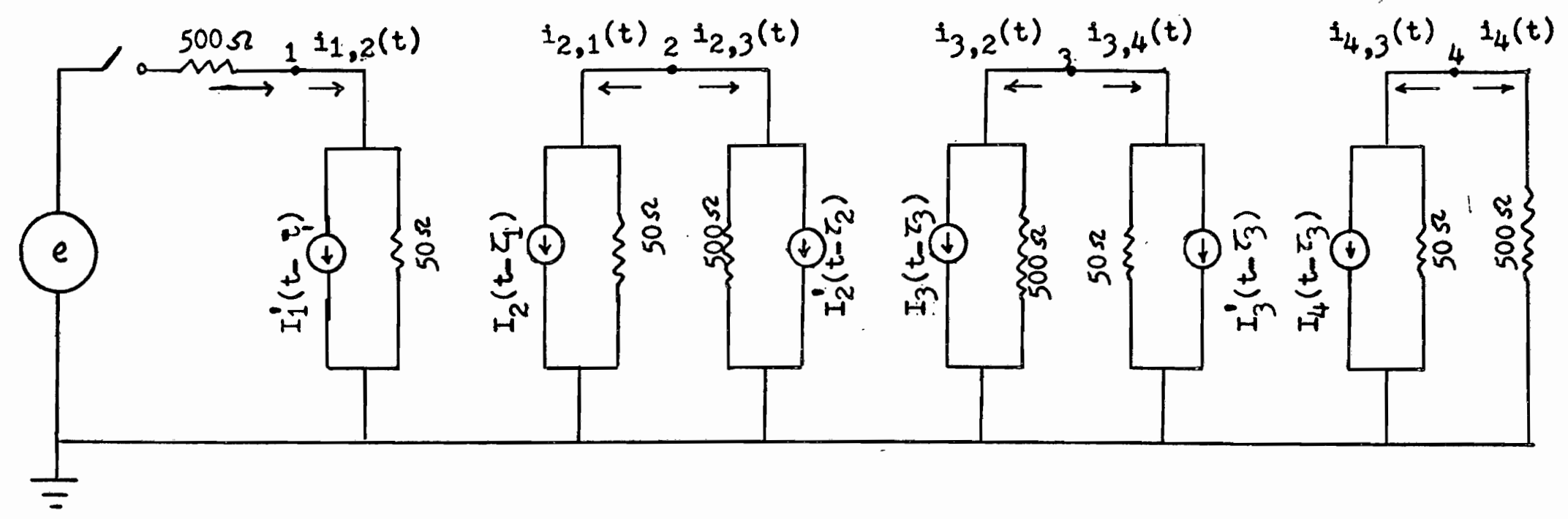

Fig. (11) Equivalent Impedance Network 
Node voltages $\theta_{1}, \theta_{2}, e_{3}$, and $e_{4}$, can be found from equations (38)-(41) in the following form:

$$
\begin{aligned}
& e_{1}(t)=(500 / 11)\left(2 / 500-I_{1}^{\prime}\left(t-\tau_{1}\right)\right) \\
& e_{2}(t)=(500 / 11)\left(-I_{2}\left(t-\tau_{1}\right)-I_{2}^{\prime}\left(t-\tau_{2}\right)\right) \\
& e_{3}(t)=(500 / 11)\left(-I_{3}\left(t-\tau_{2}\right)-I_{3}^{\prime}\left(t-\tau_{3}\right)\right) \\
& e_{4}(t)=(500 / 11)\left(-I_{4}\left(t-\tau_{3}\right)\right)
\end{aligned}
$$

In order to compute the node voltages, we need to compute I and $I^{\circ}$. By considering equations (32) - (35), we have:

$$
\begin{aligned}
& i_{2,1}(t)=(1 / 50) e_{2}(t)+I_{2}\left(t-\tau_{1}\right) \\
& I_{1}^{\prime}\left(t-\tau_{1}\right)=-(1 / 50) e_{2}\left(t-\tau_{1}\right)-i_{2,1}\left(t-\tau_{1}\right) \\
& i_{1,2}(t)=(1 / 50) e_{1}(t)+I_{1}^{\prime}\left(t-\tau_{1}\right) \\
& I_{2}\left(t-\tau_{1}\right)=-(1 / 50) e_{1}\left(t-\tau_{1}\right)-i_{1,2}\left(t-\tau_{1}\right) \\
& i_{3,2}(t)=(1 / 500) e_{3}(t)+I_{3}\left(t-\tau_{2}\right) \\
& I_{2}^{\prime}\left(t-\tau_{2}\right)=-(i / 500) e_{3}\left(t-\tau_{2}\right)-i_{3,2}\left(t-\tau_{2}\right) \\
& i_{2,3}(t)-(1 / 500) e_{2}(t)+I_{2}^{\prime}\left(t-\tau_{2}\right) \\
& I_{3}\left(t-\tau_{2}\right)+-(1 / 500) e_{2}\left(t-\tau_{2}\right)-i_{2,3}\left(t-\tau_{2}\right) \\
& \dot{i}_{4,3}(t)=(1 / 50) e_{4}(t)+I_{4}\left(t-\tau_{3}\right) \\
& I_{3}^{\prime}\left(t-\tau_{3}\right)=-(1 / 50) e_{4}\left(t-\tau_{3}-i_{4,3}\left(t-\tau_{3}\right)\right. \\
& i_{3,4}(t)=(1 / 50) e_{3}(t)+I_{3}^{\prime}\left(t-\tau_{3}\right) \\
& I_{4}\left(t-\tau_{3}\right)=-(1 / 50) e_{3}\left(t-\tau_{3}\right)-i_{3,4}\left(t-\tau_{3}\right)
\end{aligned}
$$

Now we have all the information to write a digital computer program for this system. Digital Computer Program:

Before we write a program, we have to describe some notations used in the program. These notations correspond to the previous nota- 
tions and they are as follows:

$T 1$ = maximum time

$D=t$

$I=\left(T_{\max } / \Delta t\right)=$ units of time

$T=\operatorname{tim} \theta$

$k=\tau_{1}=\tau_{3} \quad$ (In unit of time)

$N=\tau_{2} \quad$ (in unit of time)

$E(n, I)=\theta_{n}(t) \quad n=1,2,3,4$

$R(2, I)=i_{2, I}(t)$

$R(1, I)=1_{1,2}(t)$

$P(2, I)=i_{2,3}(t)$

The program written on the next page is in basic language and has been executed by G. E. Mark II. 
100 DTI $E(4,100), R(4,100), A(3,100), B(4,100), P(3,100)$

110 READ TI,D

$120 \operatorname{READ} E(1,1), A(1,1), A(2,1), B(2,1), E(3,1), E(2,1)$

$130 \operatorname{READ} A(3,1), B(3,1), E(4,1), B(4,1)$

140 PRINT "TIME", "VOLTAGE AT NODE 4"

$150 \mathrm{~J}=\mathrm{I}+\mathrm{TI} / \mathrm{D}$

160 FOR I=2 TO J

$170 \mathrm{~T}=\mathrm{D}^{*}(\mathrm{I}-1)$

$180 \mathrm{~K}=\mathrm{I}-4$

$190 \mathrm{~N}=\mathrm{I}-2$

200 IF T $>\cdot 75$ THEN 210

$204 \mathrm{~K}=1$

$206 \mathrm{~N}=1$

$210 E(I, I)=(500 / 11) *(2 / 500-A(I, K))$

$215 E(2, I)=(500 / 11) *(-B(2, K)-A(2, N))$

$220 \mathrm{R}(2, I)=(I / 50) * \mathrm{E}(2, I)+\mathrm{B}(2, \mathrm{~K})$

$230 \mathrm{~A}(1, I)=-(I / 50) * E(2, I)-R(2, I)$

$240 \mathrm{R}(I, I)=(I / 50) * E(I, I)+\mathrm{A}(I, K)$

$250 \mathrm{~B}(2, I)=-(I / 50) * \mathrm{E}(I, I)-R(I, I)$

$270 E(3, I)=(500 / 1 I) *(-B(3, N)-A(3, K))$

$280 R(3, I)=(I / 500) * E(3, I)+B(3, N)$

$290 \mathrm{~A}(2, I)=-(I / 500) * \mathrm{E}(3, I)-R(3, I)$

$300 \mathrm{P}(2, \mathrm{I})=(I / 500) * \mathrm{E}(2, I)+\mathrm{A}(2, \mathrm{~N})$

$310 \mathrm{~B}(3, I)=-(I / 500) * E(2, I)-P(2, I)$

$330 \mathrm{E}(4, I)=-(500 / I I) * \mathrm{~B}(4, \mathrm{~K})$

$340 R(4, I)=(I / 50) * E(4, I)+B(4, K)$ 
$350 \mathrm{~A}(3, I)=-(1 / 50) * E(4, I)-R(4, I)$

$360 P(3, I)=(1 / 50) * E(3, I)+A(3, K)$

$370 B(4, I)=-(1 / 50) * E(3, I)-P(3, I)$

380 PRINT T,E $(4, I)$

390 NEXT I

400 DATA $20, .25$

410 DATA $.0, .0, .0, .0, .0, .0$

420 DATA $.0, .0, .0, .0$

999 END

The result is printed on the next page. 
TIME

0.25

0.5

0.75

1

$1 \cdot 2.5$

1. 5

$1 \cdot 75$

2

2. 25

2. 5

2. 75

3

3.25

3.5

3. 75

4

$4 \cdot 25$

$4 \cdot 5$

$4 \cdot 75$

5

$5 \cdot 25$

$5 \cdot 5$

$5 \cdot 75$

6

6.25

6.5

6.75

7

$7 \cdot 25$

$7 \cdot 5$

$7 \cdot 75$

8

$8 \cdot 25$

$8 \cdot 5$

$8 \cdot 75$

9

9.25

9.5

9. 75

10

$10 \cdot 2.5$

10.5

10.75

11

11.25

11.5

11.75

12 .
VOLTAGE AT NODE 4

ü

0

0

0

0

0

0

0

0.109982

$0.10988 \%$

$0.10926 ?$

$0.10928 ?$

0.182138

0.182 .138

0.189438

0.18 .2438

$0.3777 \% ?$

0.377722

0.377722

0.377722

0.460081

$0.46008: 1$

0.460081

$0.46,1031$

0.629753

0.629753

$0.6,29753$

0.62 .9753

0.632 .52

0. 63c.52

0.6325 ?

0.63252

0.712729

0. $11: 724$

0.712729

0.712729

0.0367544

$0.03678,4$

0.636784

0.6367811

$0.0,68727$

0. $f .64707$

0.666727

$0.6687 ? 7$

[. $5 \% 3386$

0.593386 


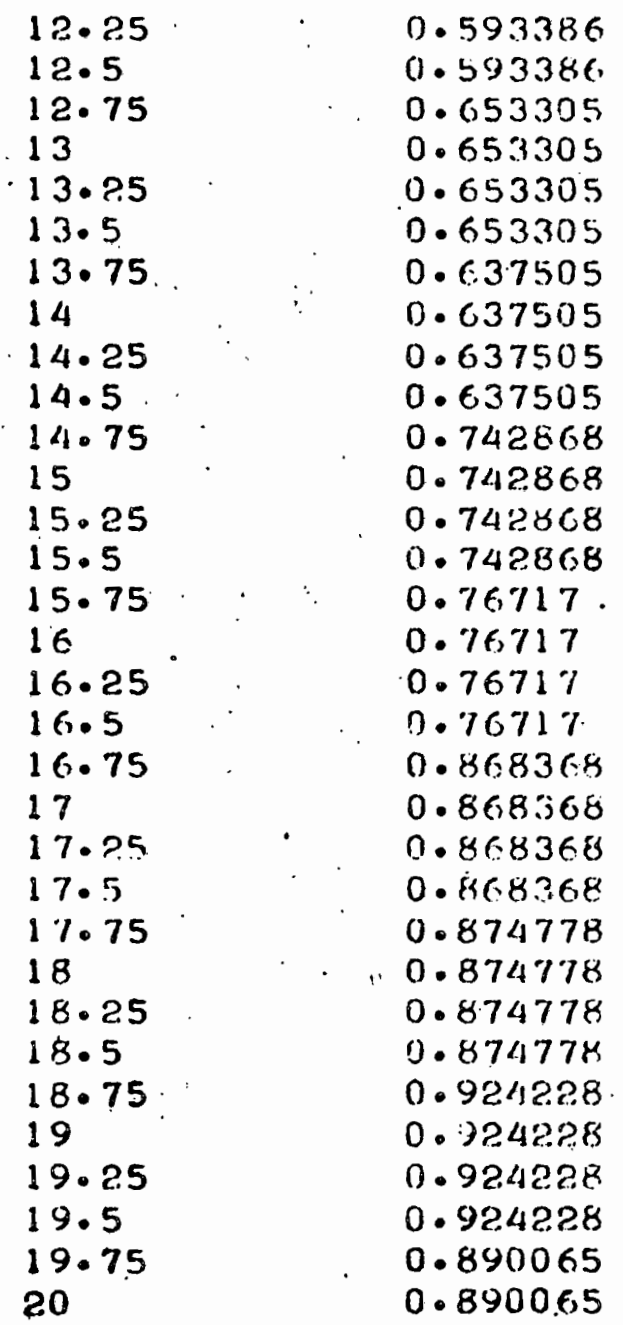




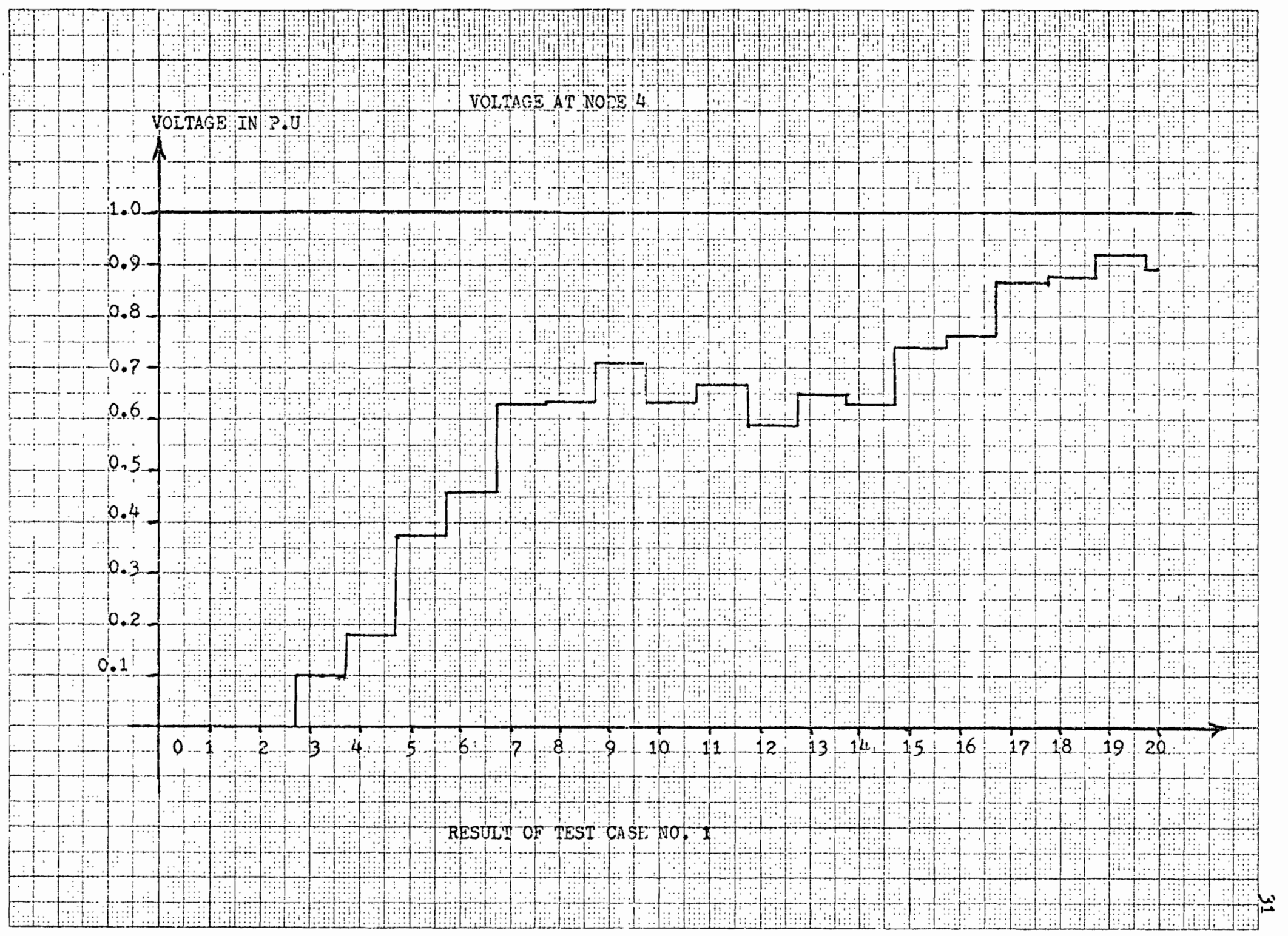


In the previous example a digital computer solution for a lossless line was fully described. In order to see that different types of systems with a lossless line are terminated in a resistor, inductor, or capacitor, some examples of traveling wave on single phase lines will be illustrated.

The following examples are taken from $\mathrm{H}$. Prinz, W. Zaengl and 0. Volaker.*

In most examples, the Iine is assumed to be lossless and the surge impedance for a single phase line with $a R^{\circ}=$ and $G^{\circ}=0$ iss

$$
z=\sqrt{I} / c^{\circ}
$$

and travel time is:

$$
\tau=1 \cdot \sqrt{I^{\prime} C^{\prime}}
$$

where

1 = length of Iine

$I^{\prime}=$ Serles inductance per unit length

$C^{\prime}=$ Shunt capacitance per unit length

1. Line Terminated in $R \quad(R>2)$

Energization is from de source. The result is shown in fig. (12), $a, b, c$, and $d$.

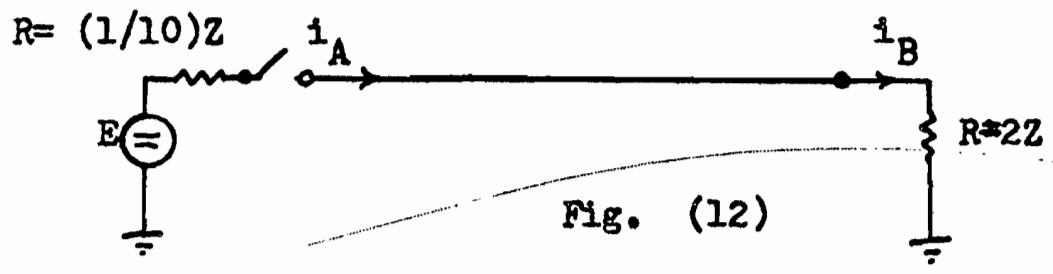

*H. Prinz, W. Zaengl and O. Volaker, "The Method of Bergeron for Solving Traveling Wave Problems" (in German), Bulletín SEV, Vol. 53, (Swiss Association of Electrical Engineering, August, 1962), pp. 725-739. 


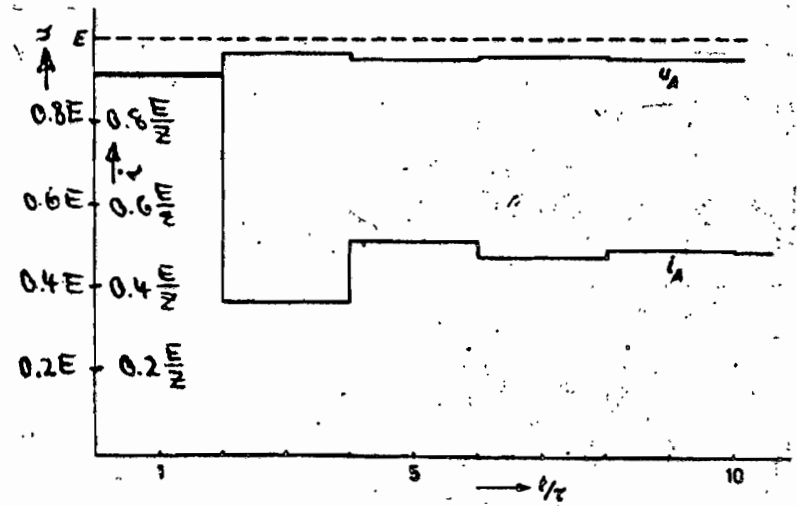

Voltage $u_{A}$ and current $i_{A}$ at sending end.

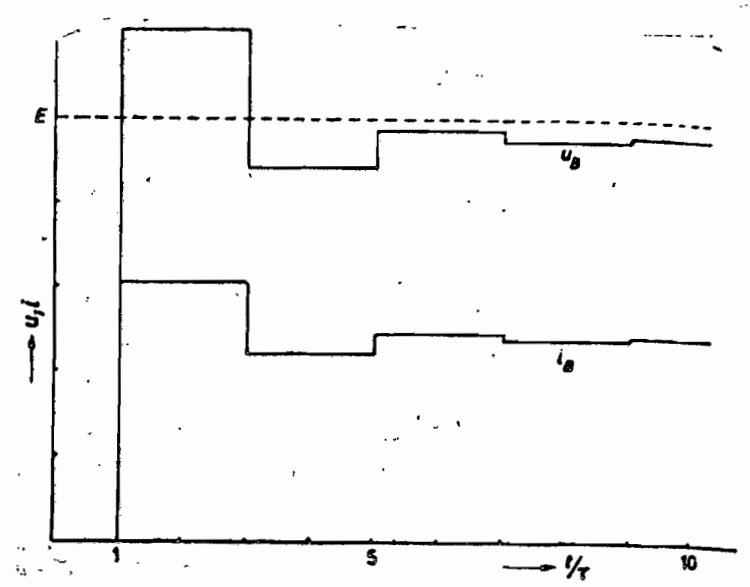

Voltage $u_{B}$ and current $i_{B}$ at receiving end.

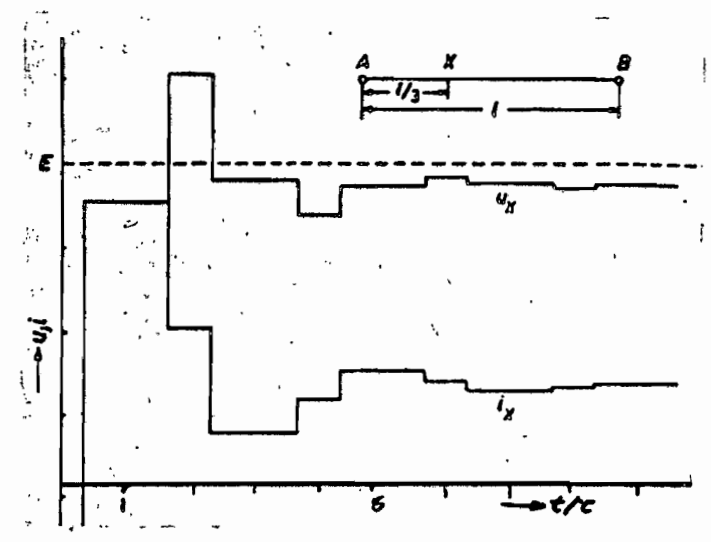

Voltage $u_{X}$ and current $i_{X}$ at $1 / 3$ down the line

\section{Line terminated in $R \quad(R>Z)$}

Energization is $e(t)=K\left(e^{-\alpha t}-e^{-3 t}\right)$ as shown in fig. (13) b. Switch closes at $t=0$.

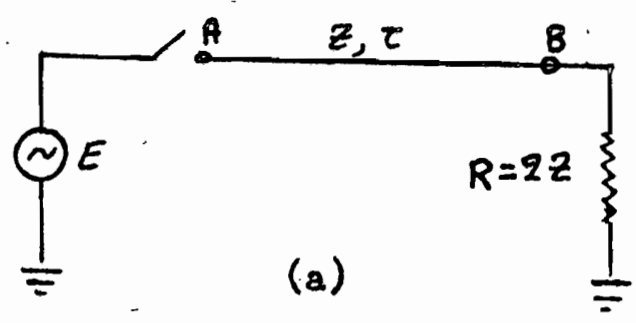

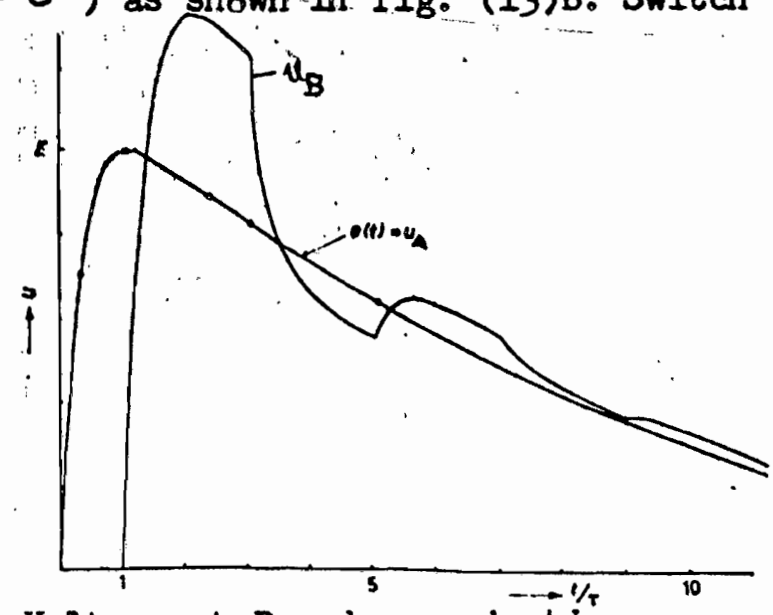

Voltage at $B$ and energization source 
3. Line texminated in $R \quad(R>Z)$, internal resistance $R_{i}=2$ Inergization is from de source.

$\sum_{=}^{R_{i}}$

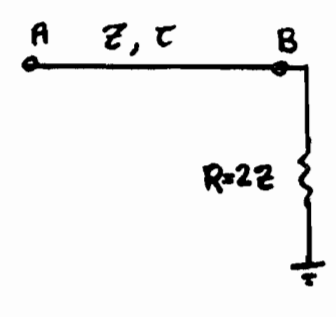

F1g. (14)

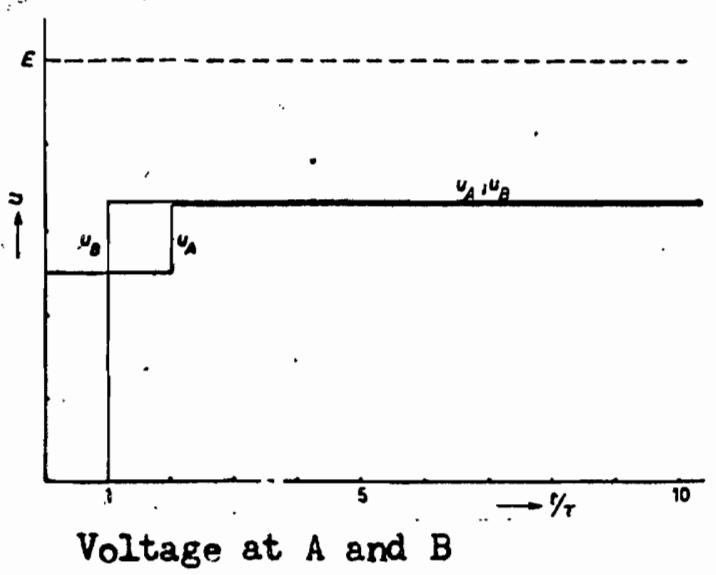

4. Line torminated in $R \quad(R>Z)$, energization from current source

Switch closes at $t=0, i(t)=0$ for $t<0, i(t)=I$ for $t \leqslant 0$

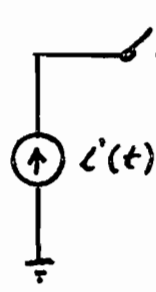

$z, \tau$

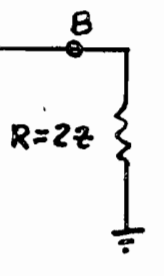

Fig. (15)

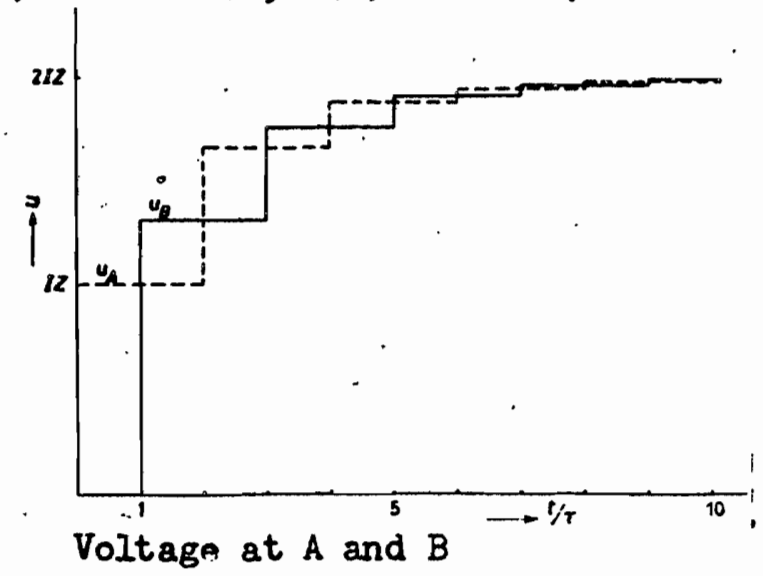

5. Series connection of lines with unequal surge impedance

Switch closes at $t=0, z_{1}=(1 / 10) z_{2}, \tau_{1}=2 \tau_{2}$.
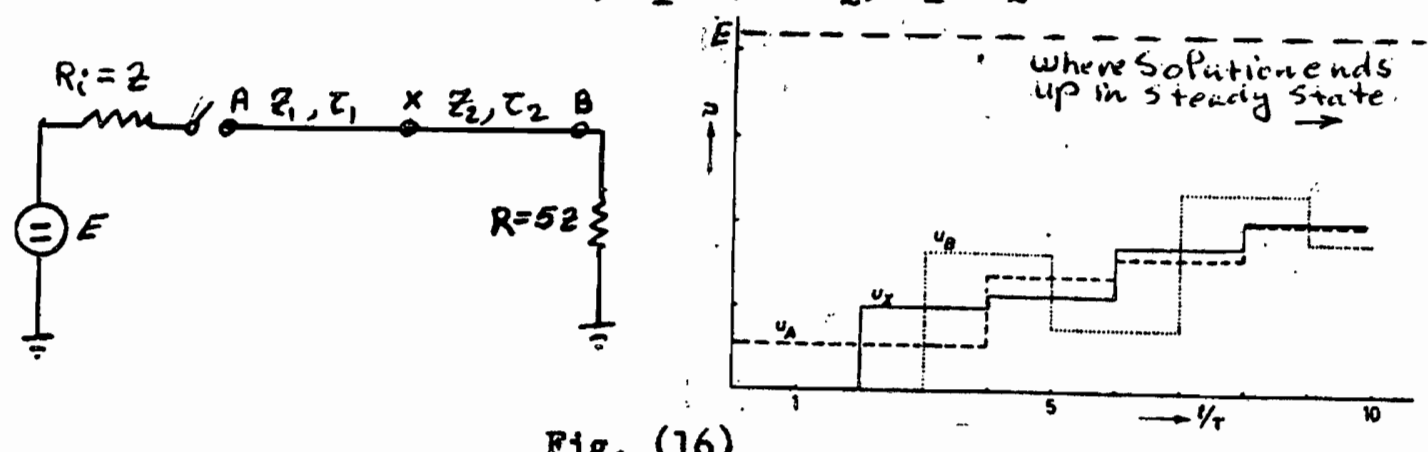

Fig. (16) 
6. Reflections at line junctions

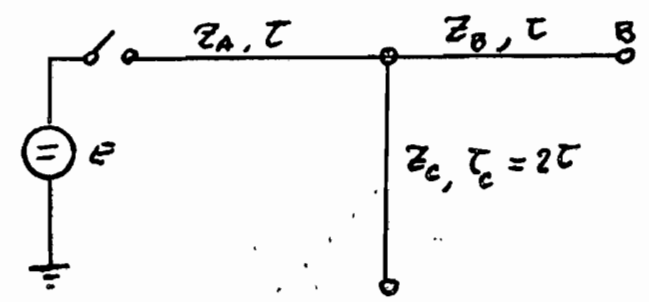

Fi8. (17)

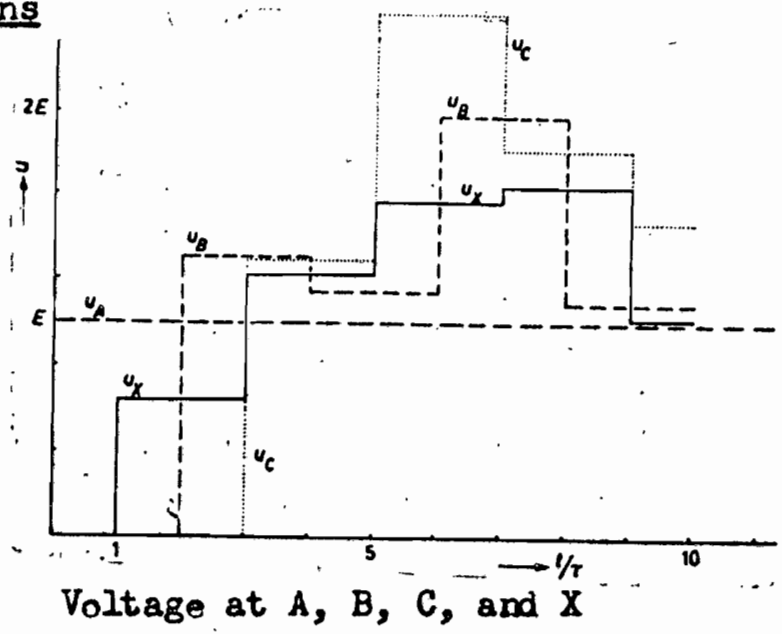

7. Lumped resistance in series with line

$u_{R}$ is voltage across resistance, $z_{B}=2$, and $\gamma_{B}=2 \tau$

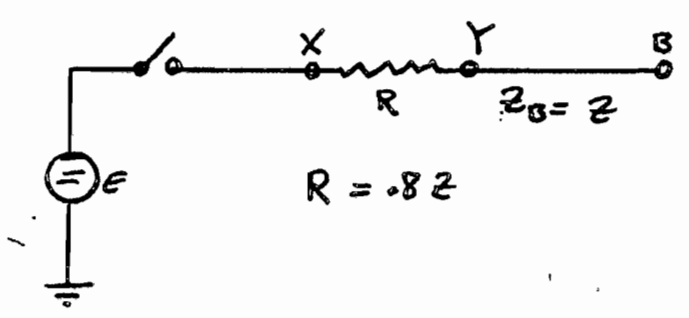

Fig. (18)

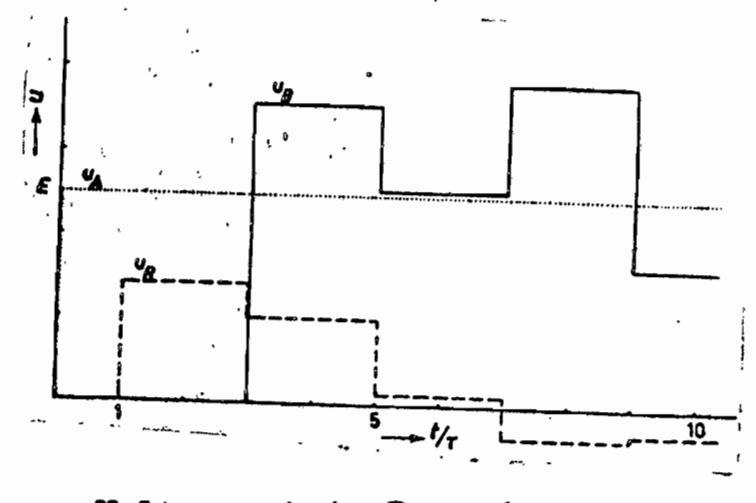

Voltage at $A, B$, and $u_{R}$

8. Lumped shunt resistance

$R=2 Z$
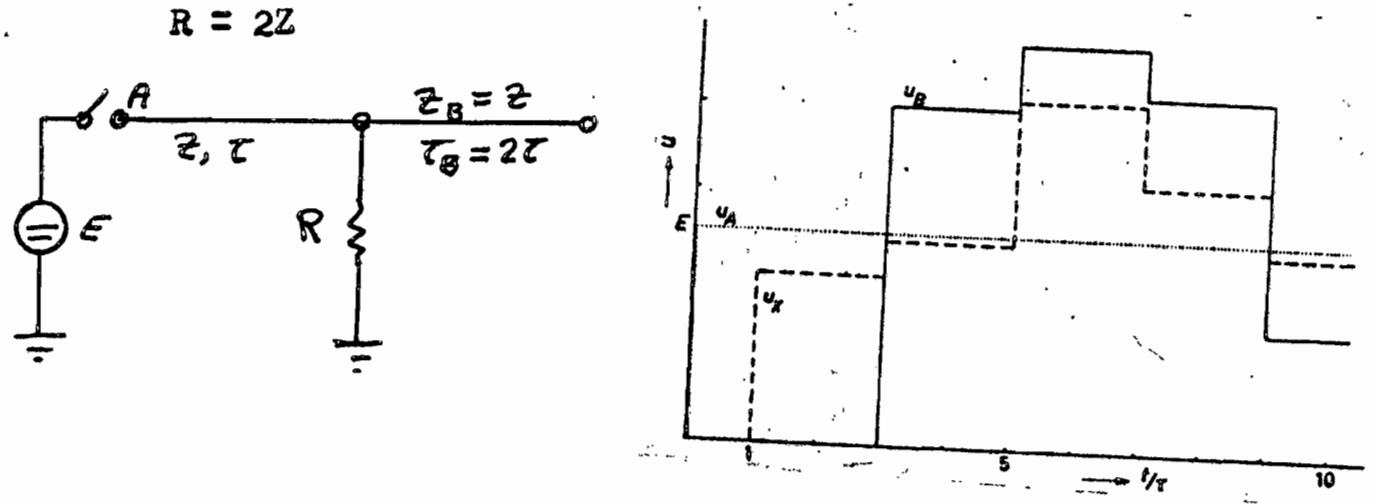

Fig. (19)

Voltage at $A, B$, and $X$ 
2. Line teminated with inductance

Energization is from dc source.

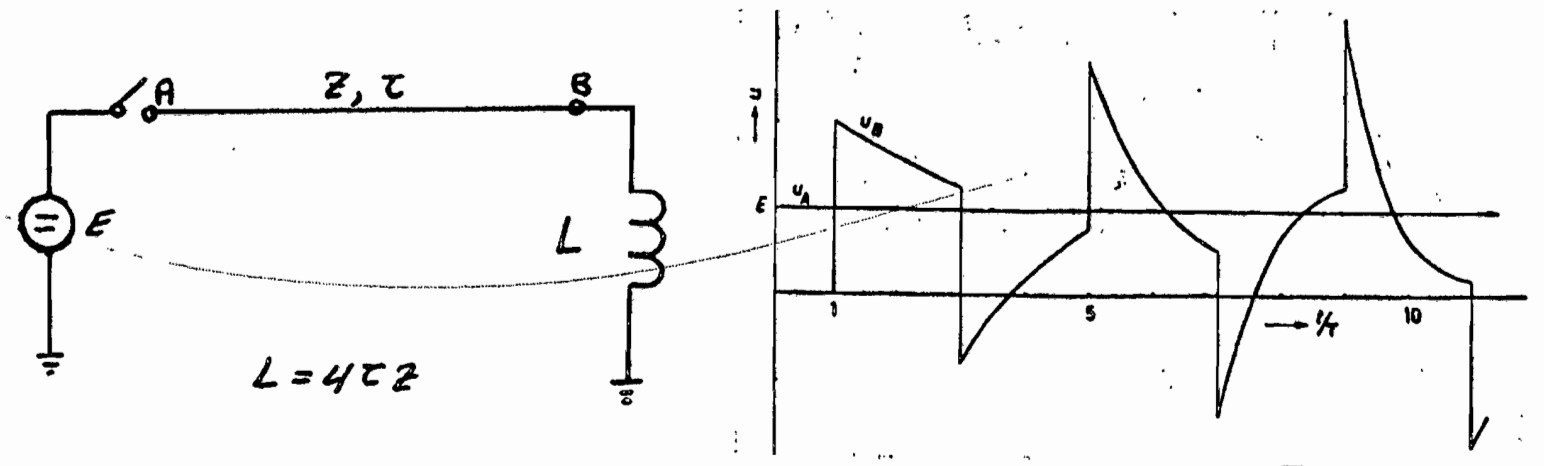

Fig. (20)

Voltage at $A$ and $B$

10. Iine terminated with capacitance

Energization is from de source.
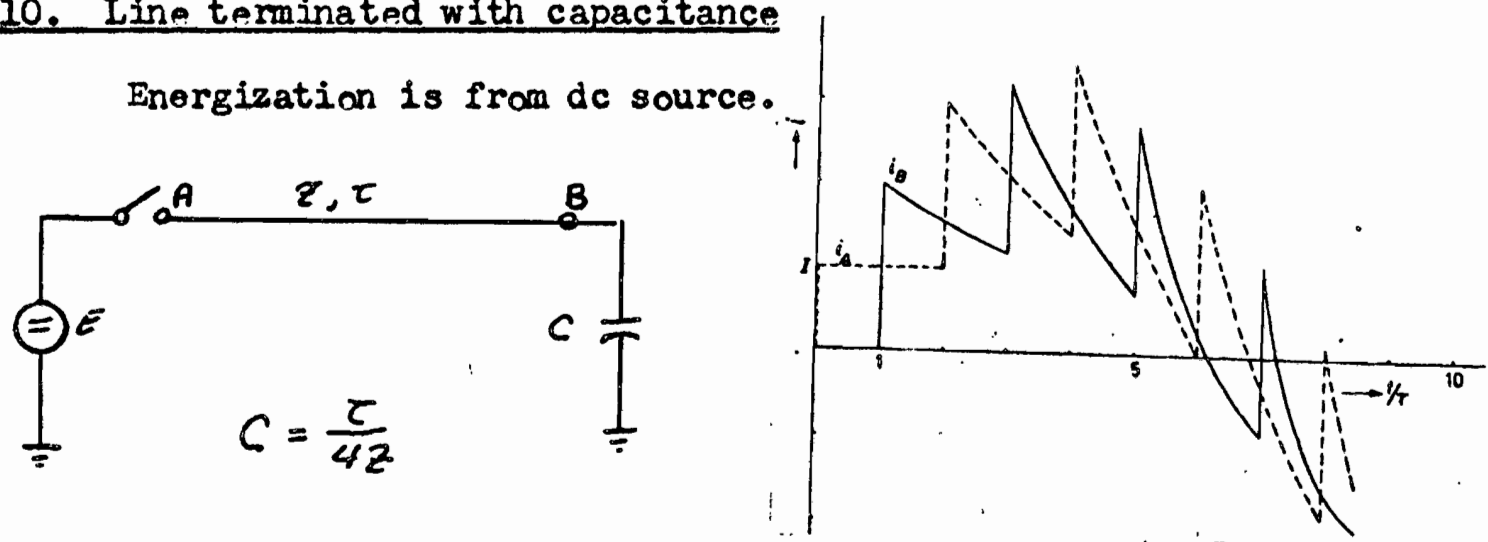

Fig. (21) In contrast to Iumped inductances, sudden' jumps in the current are possible in distributed-parameter lines

11. Lumped series inductance
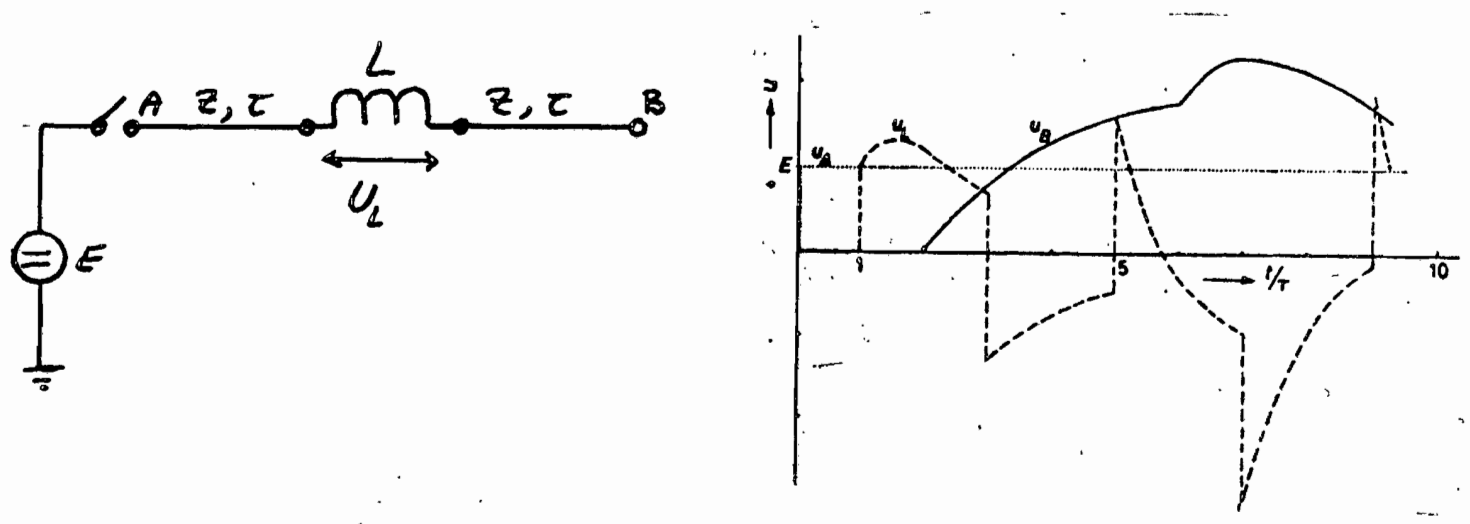

Fig. (22) 
12. Lumped series capacitance

Energization is from dc source.

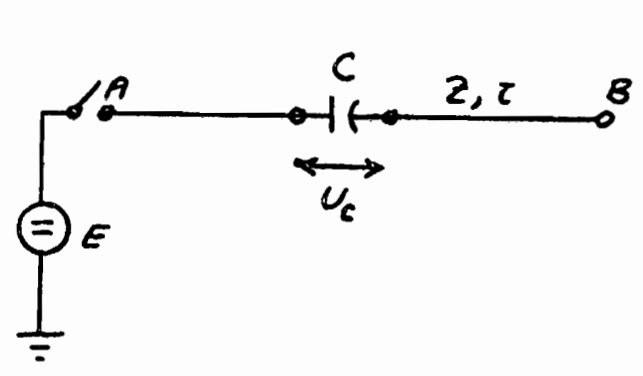

Eig. (23)

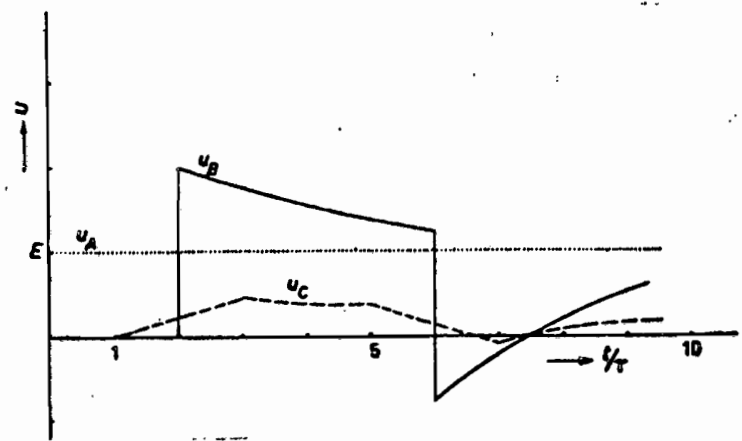

Voltage at $A$ and $B$

13. Shunt inductance in middle of line

Energization is from dc source.
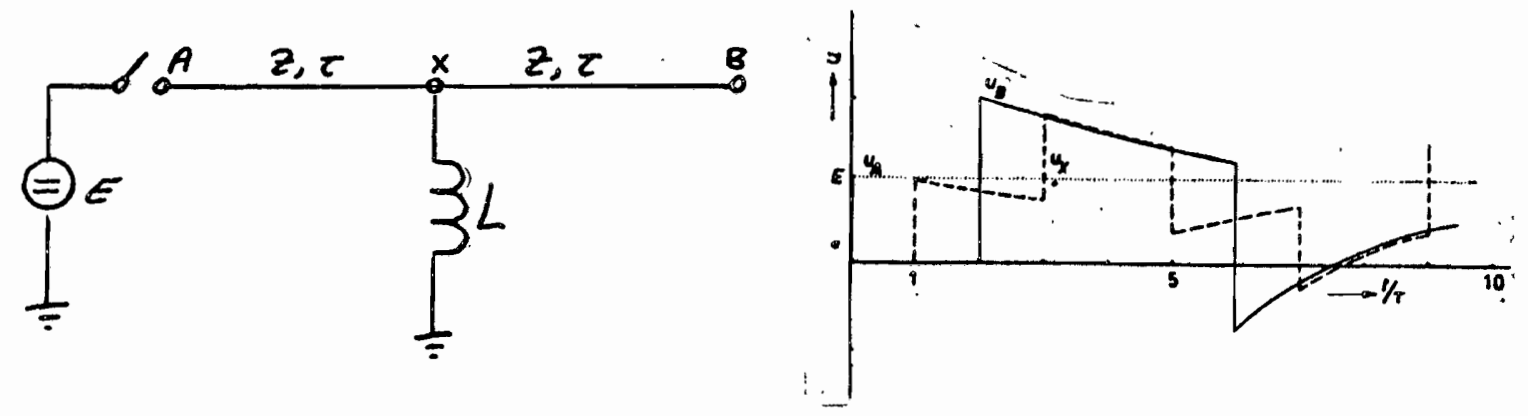

Fig. (24)

Voltage at $A, B$, and $X$

14. Shunt capacitance in middle of line

Energization is from de source.

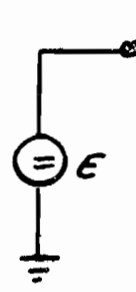

8

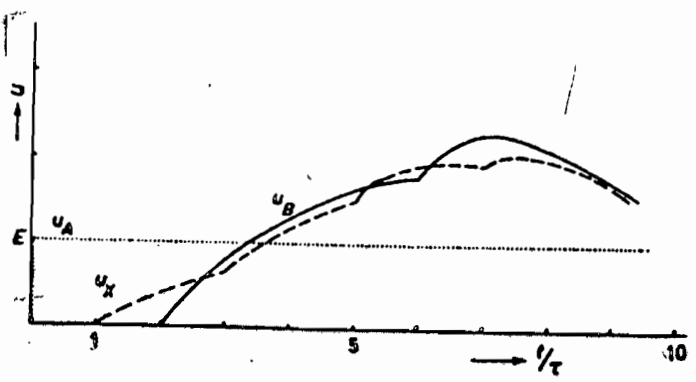

Fig: (25) 
Iumoed pa rameters

Lumped parameters are handled by the use of the trapezoidal mule of integration using digital computers. The impedance network is determined by the equivalent impedance of each element.

Inductance. Consider an inductance between nodes a and b in fig. (26). The voltage across the inductance is

$$
\theta_{a}(t)-\theta_{b}(t)-I\left(d i_{a, b}(t) / d t\right)
$$

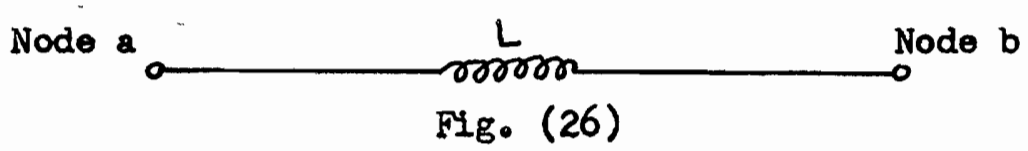

Let us assume that voltage and current at time $t$ - $\Delta t$ are known, and we want to find voltage and current at time t. These are determined by integration of equation (46) from $t$ - $\Delta t$ to the unknown state $t_{0}$ From equation (46) we have:

$$
\begin{aligned}
d i_{a, b}(t) & =(I / I)\left(e_{a}(t)-e_{b}(t)\right) d t \\
\int_{t-\Delta t}^{t} d i_{a, b}(t) & =(I / L) \int_{t-\Delta t}^{t}\left(e_{a}(t)-e_{b}(t)\right) d t \\
i_{a, b}(t) & =(I / L) \int_{t-\Delta t}^{t}\left(e_{a}(t)-e_{b}(t)\right) d t \\
i_{a, b}(t) & =i_{a, b}(t-\Delta t)+(1 / I) \int_{t-\Delta t}^{t}\left(\theta_{a}(t)-e_{b}(t)\right) d t(47)
\end{aligned}
$$

The second term of right hand side of equation (47) can be integrated by using the trapezoidal vule of integration and this gives:

$$
\begin{aligned}
& i_{a, b}(t)=1_{a, b}(t-\Delta t)+(I / L)(\Delta t / 2)\left(\theta_{a}(t)-\right. \theta_{b}(t)+\theta_{a}(t-\Delta t)- \\
&\left.\theta_{b}(t-\Delta t)\right)
\end{aligned}
$$


Rearranging this equation, we have:

$$
\begin{aligned}
1_{a, b}(t)=(\Delta t / 2 L)\left(\theta_{a}(t)-e_{b}(t)\right)+1_{a, b}(t-\Delta t) & +(\Delta t / 2 I)\left(e_{a}(t-\Delta t)-\right. \\
& \left.\theta_{b}(t-\Delta t)\right)(48)
\end{aligned}
$$

Let the second half right hand side of equation (48) be designated by $I_{a, b}(t-\Delta t)$, then equation $(48)$ can be written in the form of:

$$
1_{a, b}(t)=(\Delta t / 2 L)\left(\theta_{a}(t)-\theta_{b}(t)\right)+I_{a, b}(t-\Delta t)
$$

where

$$
I_{a, b}(t-\Delta t)=I_{a, b}(t-t)+(\Delta t / 2 L)\left(e_{a}(t-\Delta t)-\theta_{b}(t-\Delta t)\right) \cdot(50)
$$

Now by considering equations $(49)$ and $(50),(\Delta t / 2 I)$ and $I_{a, b}(t-\Delta t)$ can be simulated in a resistance and source current across the resistor, respectively. Therefore the equivalent impedance network of an inductor can be illustrated as in fig. (27).

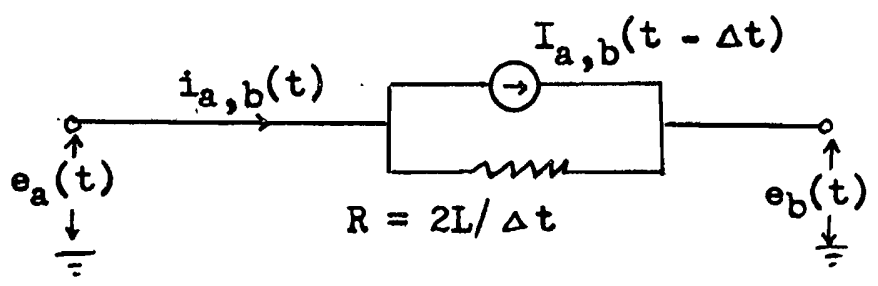

Fig. 27 Equivalent Impedance network

As was mentioned before, the trapezoidal mule produces some error in computation and this error is of order $(\Delta t)^{3}$; now if $\Delta t$ be chosen sufficiently small and cut in half, then the error will be cut in 1/8. The trapezotdal rule of integration used in equation (48) shows that this rule is identical with replacing the differential quotient in (46) by a central difference quotient at midpoint between $t$ and $t-\Delta t$ with assuming that $\theta$ is Iinear during this interval. 


\section{Capscitance}

Consider a capacitor as shown in fig. (28). The voltage across a capacitor in general is:

$$
e(t)=1 / C \int 1 d t+e(0)
$$

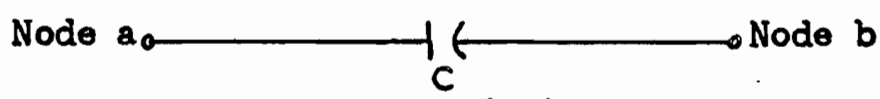

Fig. (28)

We wish to find the voltage across the capacitor at time $(t)$, while we know voltage and current at time $(t-\Delta t)$. Therefore equation (5I) can be written in the following form:

$\theta_{a}(t)-\theta_{b}(t)=1 / C i d t+\theta_{a}(t-t)-\theta_{b}(t-t)$.

Let us apply the trapezoidal rule of integration on equation (52), which yields:

$$
\begin{gathered}
e_{a}(t)-\theta_{b}(t)-(1 / c)(\Delta t / 2)\left(i_{a, b}(t)+i_{a, b}(t-\Delta t)\right)+\theta_{a}(t-\Delta t)- \\
e_{b}(t-\Delta t)
\end{gathered}
$$

Solving equation (53) for $i_{a, b}(t)$, it gives:

$$
\begin{gathered}
i_{a, b}(t)=(2 c / \Delta t)\left(\theta_{a}(t)-\theta_{b}(t)\right)-1_{Q, b}(t-\Delta t)-(2 c / \Delta t)\left(\theta_{a}(t-\Delta t)-\right. \\
\left.\theta_{b}(t-\Delta t)\right)
\end{gathered}
$$

If the second half right side of equation (54) is designated as $I_{a, b}(t-\Delta t)$, equation $(54)$ can be written in the form of:

$$
\dot{i}_{a, b}(t)=(2 c / \Delta t)\left(\theta_{a}(t)-\theta_{b}(t)\right)+I_{a, b}(t,-\Delta t)
$$

where

$$
I_{a, b}(t-\Delta t)=-I_{a, b}(t-\Delta t)-(2 c / \Delta t)\left(e_{a}(t-\Delta t)-e_{b}(t-\Delta t)\right)
$$

Again by considering equations (55) and $(56),(2 \mathrm{c} / \Delta t)$ and 
Now if these four nodes can be reduced to two nodes, it would be easier to solve a system than using 4 nodes. Suppose there is a tencircuit series of $R$ - I - C branches in a system, and if for each element we use one equivalent network impedance, we have to deal with 28 nodes. However, if each of the $R$ - I - C branches can be presented by two nodes and one equivalent resistance, we have to deal with only 10 nodes. This will be illustrated in the next digital computer solution for a series $R$ - I - C branch.

In order to derive an equation describing the relation of voltage and current in a series R - I - C branch, consider fig。 (3I)a. The fundamental equation is:

$$
\theta_{a}-\theta_{b}=R i+I(d i / d t)+I / C \int i d t+\theta_{c}(0)
$$

where $\theta_{c}(0)$ is the initial condition of voltage $\theta_{c}$ across the capacitor. Let us apply the trapezoidal mule of integration to equation (58). We know this rule is equivalent to using central differences; this means $e=L(d i / d t)$ can be replaced by:

$$
(1 / 2)(\theta(t)+\theta(t-\Delta t))=(I / \Delta t)(1(t)-i(t-\Delta t))
$$

This is similar to equation (49). Now the average capacitor voltage between $(t-\Delta t)$ and $(t)$ is:

$$
\theta_{c}(\operatorname{averag\theta })=(I / 2)\left(e_{c}(t)+\theta_{c}(t-\Delta t)\right)
$$

$\theta_{c}=1 / c \int$ idt can be written in the form of $1=c\left(d \theta_{c} / d t\right)$, by the same procedure used for equation $(58), 1=c\left(d e_{c} / d t\right)$ can be written as:

$$
(1 / 2)(1(t)+1(t-\Delta t))=(c / \Delta t)\left(\theta_{c}(t)-\theta_{c}(t-\Delta t)\right)
$$

or

$$
\theta_{c}=(\Delta t / 2 c)(1(t)+1(t-\Delta t))+\theta_{c}(t-\Delta t)
$$


Now let us determine each term of equation (58) step by step at $(t-\Delta t)$ to $(t)$, and then substitute each term in the equation and find the final result which is applicable for our digital computer solution.

$\theta_{a}-\theta_{b}=(1 / 2)\left(e_{a}(t)-\theta_{b}(t)+\theta_{a}(t-\Delta t)-\theta_{b}(t-\Delta t)\right)$

$R i=(R / 2)(i(t)+i(t-\Delta t))$

$I(d 1 / d t)=(L / \Delta t)(i(t)-i(t-\Delta t))$

$(1 / c) \int i d t+\theta_{c}(0)=(1 / 2)\left(\theta_{c}(t)+\theta_{c}(t-\Delta t)=(\Delta t / 4 c)(i(t)+\right.$ $i(t-\Delta t))+e_{c}(t-\Delta t)$

Now substitute each term in equation (58) and multiply by two and reorder; we have:

$$
\begin{array}{r}
\left.\left(e_{a}(t)-e_{b}(t)\right)+\left(e_{a}(t)-\Delta t\right)-e_{b}(t-\Delta t)\right)=1(t)(R+2 L / \Delta t+\Delta t / 2 C) \\
+i(t-\Delta t)(R-2 L / \Delta t+\Delta t / 2 C)+2 e_{c}(t-\Delta t):(59)
\end{array}
$$

Let the following symbols be assigned:

$Y=1 /(R+2 L / \Delta t+\Delta t / 2 C)$

$P=Y(R-2 L / \Delta t+\Delta t / 2 C)$

Then equation (59) becomes:

$$
i_{a, b}(t)=Y\left(\theta_{a}(t)-\theta_{b}(t)\right)+I_{a, b}(t-\Delta t)
$$

where

$$
I_{a, b}(t-\Delta t)=Y\left(\theta_{a}(t-\Delta t)-\theta_{b}(t-\Delta t)-2 \theta_{c}(t-\Delta t)\right)-P i_{a, b}(t-\Delta t)
$$

For computer programing the updating of $I_{a, b}$ can be done

as follows:
a) Compute $H=Y\left(\theta_{a}(t)-\theta_{b}(t)\right)+I_{a, b}(t-\Delta t)$.
This is the new current, but it should not be stored.
b) Compute $e_{c}(t)=\theta_{c}(t-\Delta t)+(\Delta t / 2 c)(i(t-\Delta t)+H)$
c) Update $I_{a, b}(t)=Y\left(\theta_{a}(t)-\theta_{b}(t)-2 \theta_{c}(t)\right)-P H$ 
d) H should be stored into location for current, $i(t)=H$

For past history we should have three values $I_{a}, b, 1$, and $e_{c} \cdot$

By considering equations (60) and (61), the equivalent impedance network for a series $R-I-C$ is as shown in fig. (32).

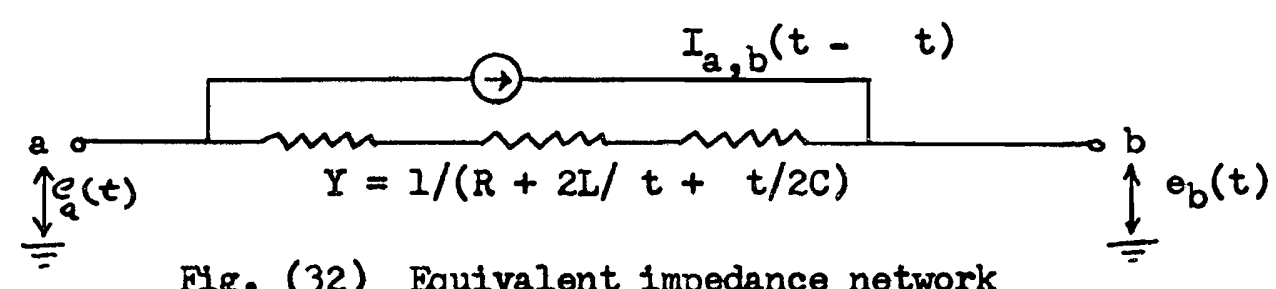

Fig. (32) Equivalent impedance network

When all impedance networks are replaced by each element, the nodal equations for any network can be determined. This was explatned in previous sections. The set of equations can be written in the form of:

$$
[Y] \cdot[\theta(t)]=[1(t)]-[I]
$$

Matrix $[\theta(t)],[i(t)]$, and $[I]$ are colum matrix. Part of the voltage of $[e(t)]$ matrix is known and the other part is unknown. Let $K$ designate the known part and $U$ the unknown part; then we have:

$$
\begin{aligned}
& {\left[\begin{array}{ll}
{\left[Y_{U U}\right]} & {\left[Y_{U K}\right.} \\
{\left[Y_{K U}\right]} & {\left[Y_{K K}\right.}
\end{array}\right]\left[\begin{array}{l}
{\left[e_{U}(t)\right]} \\
{\left[e_{K}(t)\right]}
\end{array}\right]=\left[\begin{array}{l}
i_{U}(t) \\
i_{K}(t)
\end{array}\right]-\left[\begin{array}{l}
I_{U} \\
I_{K}
\end{array}\right]} \\
& \text { Solving for }\left[\theta_{U}(t)\right] \text {, it gives: } \\
& {\left[Y_{U U}\right]\left[e_{U}(t)\right]=\left[I_{T}\right]-\left[Y_{U K}\right]\left[e_{K}(t)\right]} \\
& {\left[\theta_{U}(t)\right]=\left[Y_{U U}\right] \quad\left[I_{T}\right]-\left[Y_{U K}\right]\left[e_{K}(t)\right]} \\
& {\left[I_{T}\right]=\left[i_{U}(t)\right]-\left[I_{U}\right]}
\end{aligned}
$$

or

where

This leads us to the solution of a system of linear equations with a constant coefficient matrix [YUU], and with $\Delta t$ fixed.

A digital computer solution is illustratod in full details on the next page. 
Test Case No. 2

An impulse of rectangular waveform is applied to a voltage divider. This voltage divider has an equivalent circuit as shown in fig. (33). The equivalent circuit is formed of ten equal sections. We wish to determine the oscillation in voltage at low voltage end. Voltage at node 10 and current from node 9 to 10 are desired.*

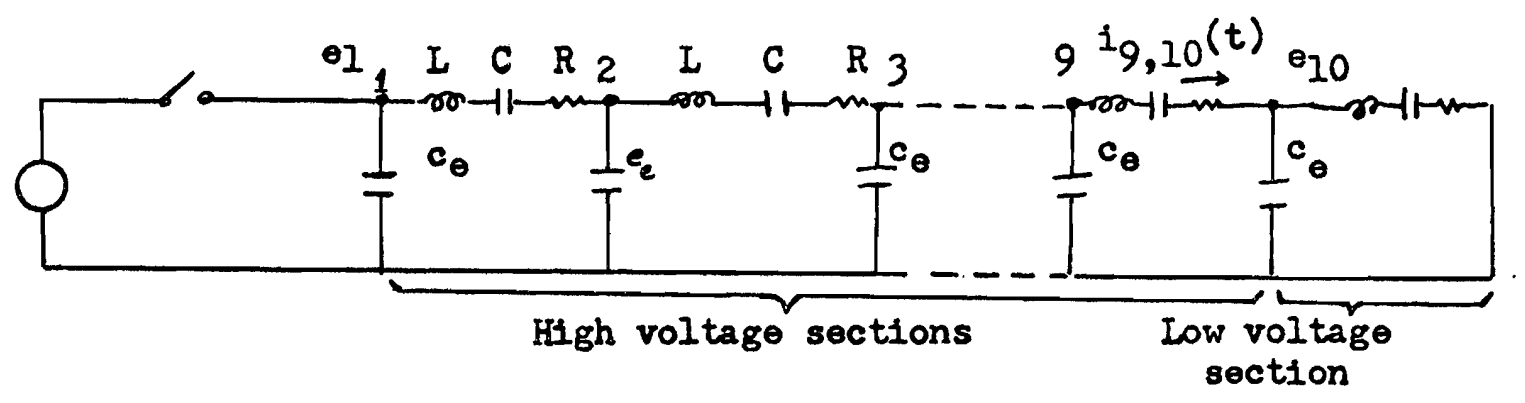

F1g. (33)

Given:

$$
\begin{array}{ll}
C_{e}=10 \mathrm{PF} & \text { Excitation: } \\
L=.5 \Gamma_{\mathrm{H}} & \theta_{1}(t)=1 \text {. for } t>0 \\
C=15 \mathrm{nF} & \theta_{1}(t)=0 \text { for } t \leqslant 0 \\
R=1 \Omega & \\
\Delta t=1 \mathrm{~ns} &
\end{array}
$$

Solution:

By considering fig. (32) for a series $R-L-C$ and fig. (27)

for a capacitor, the equivalent impedance network for the system shown in fig. (33) can be illustrated as in fig. (34) on the next page.

Lot the following symbols be assigned:

$$
\begin{aligned}
& Y=I /(R+2 L / \Delta t+\Delta t / 2 C) \\
& P=Y(R-2 L / t+\Delta t / 2 C)
\end{aligned}
$$

* This problem is taken from Hermann W. Dammel, Habilitation Thesis, submitted to the Munich Institute of Technology, May 1967, p.37. 


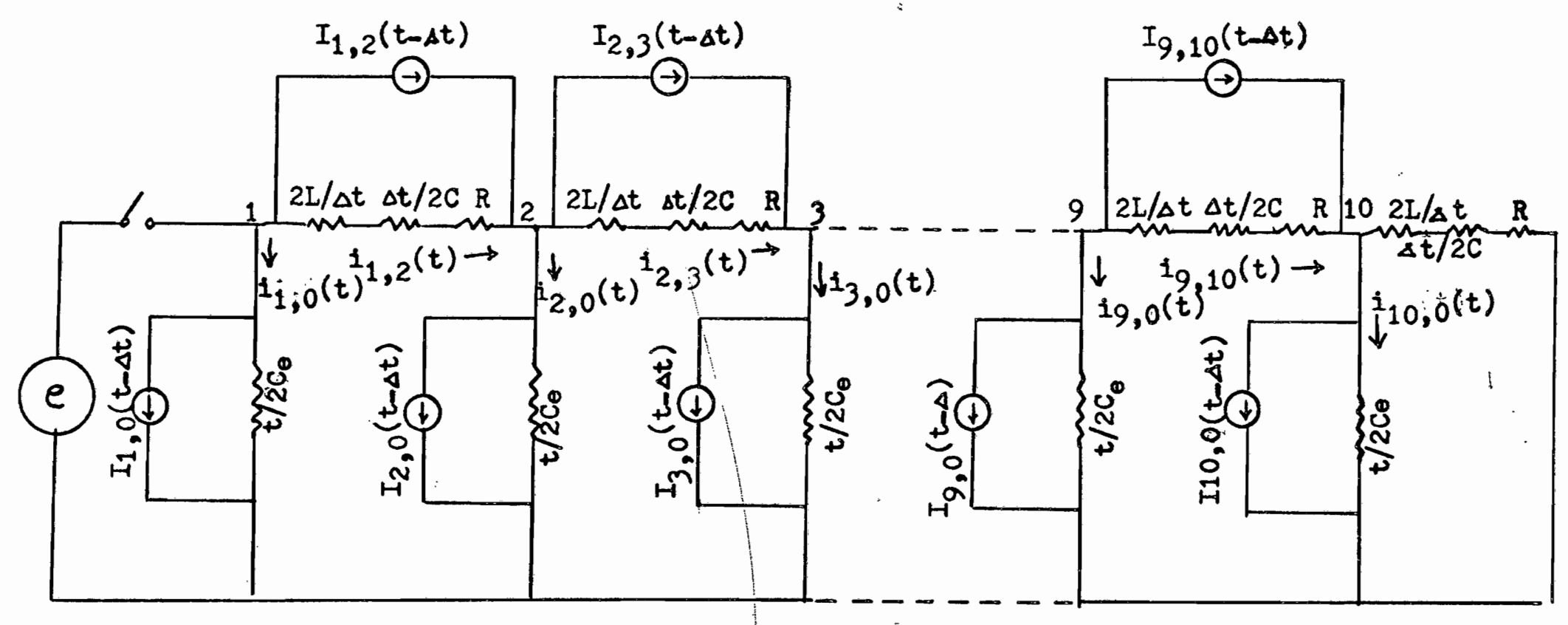

Fig. (34) Equivalent Impedance Network 
Node equations:

Since we know voltage at node 1 , there is no need to write the node equation for this node.

Node No. 2:

$$
-i_{1,2}+i_{2,0}+i_{2,3}=0
$$

according to equations (55) and $(60)$, we have:

$$
\begin{aligned}
& -i_{1,2}(t)=-Y\left(\theta_{1}(t)+\theta_{2}(t)\right)-I_{1,2}(t-\Delta t) \\
& i_{2,0}(t)=2 C_{\theta} / \Delta t\left(\theta_{2}(t)-0\right)+I_{2,0}(t-\Delta t) \\
& 1_{2,3}(t)=Y\left(\theta_{2}(t)-\theta_{3}(t)\right)+I_{2,3}(t-\Delta t)
\end{aligned}
$$

By adding and reordering these equations, it gives:

$$
\begin{array}{r}
-Y \theta_{1}(t)+\left(2 Y+2 C_{\theta} / \Delta t\right) \theta_{2}(t)-Y \theta_{3}(t)-I_{1,2}(t-\Delta t)+I_{2,0}(t-\Delta t)+ \\
I_{2,3}(t-\Delta t)
\end{array}
$$

let:

$$
\begin{gathered}
Y^{0}=2 Y+2 C_{\theta} / \Delta t \\
I_{1}=Y \theta_{1}(t) \\
I_{T 2}=-I_{1,2}(t-\Delta t)+I_{2,0}(t-\Delta t)+I_{2,3}(t-\Delta t)
\end{gathered}
$$

then the node equation for node No. 2 is:

$$
I_{1}=Y^{0} \theta_{2}(t)-Y_{\theta_{3}}(t)+I_{T 2}
$$

Node No. 3:

$$
-1_{2,3}(t)+i_{3,0}(t)+i_{3,4}(t)=0
$$

where

$$
\begin{aligned}
-i_{2,3}(t) & =-Y\left(\theta_{2}(t)-\theta_{3}(t)\right)-I_{2,3}(t-\Delta t) \\
1_{3,0}(t) & =2 C_{0} / \Delta t\left(\theta_{3}(t)-0\right)+I_{3,0}(t-\Delta t) \\
1_{3,4}(t) & =Y\left(\theta_{3}(t)-e_{4}(t)\right)+I_{3,4}(t-\Delta t) .
\end{aligned}
$$

Again, by adding and reordering these equations and letting 


$$
\begin{gathered}
I_{\mathrm{T}}=-I_{2,3}(t-\Delta t)+I_{3,0}(t-\Delta t)+I_{3,4}(t-\Delta t) \text {, It gives: } \\
0=-Y_{\theta_{2}}(t)+Y^{\prime} \theta_{3}(t)-Y_{e_{4}}(t)+I_{T 3}
\end{gathered}
$$

Similarly, for nodes $4,5, \ldots .$. and 10 , we have:

$$
\begin{aligned}
& 0=-Y_{\theta_{3}}(t)+Y^{\prime} \theta_{4}(t)-Y_{\theta_{5}}(t)+I_{24} \\
& \ldots \ldots \ldots \\
& 0=-Y_{8}(t)+Y^{0} e_{9}(t)-Y_{10}(t)+I_{T 9} \\
& 0=-Y \theta_{9}(t)+Y^{\prime} e_{10}(t)+I_{\text {P10 }}
\end{aligned}
$$

In matrix form this can be written as follows:

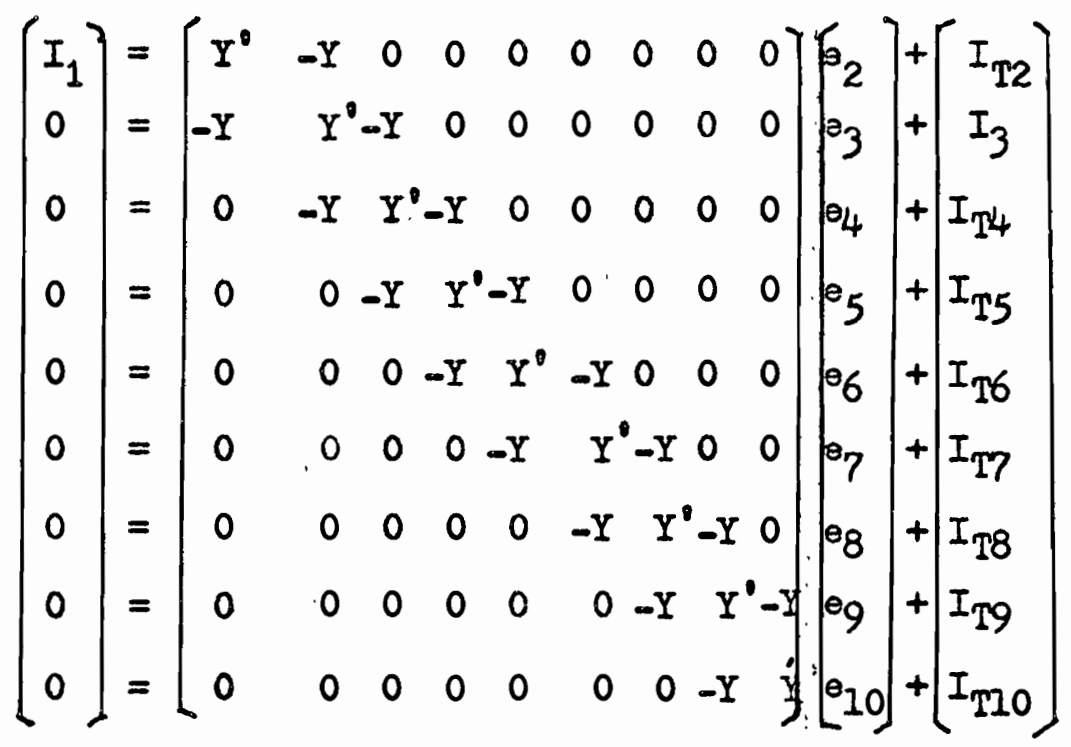

which is:

$$
\begin{aligned}
& {[i]=[Y][\theta]+[I Y]} \\
& {[\theta]=[Y]^{-1}\left([I]-\left[I_{Y}\right]\right)}
\end{aligned}
$$

Now we are ready to write a computer program for this system. Let us first draw a flow chart for the program and then write the 
computer program.

In order to be able to follow the program, let us define the symbols used in the program.

$$
\begin{aligned}
& T=\operatorname{maximum} \text { time } \\
& D=\Delta t \\
& \mathrm{R} 1=\mathrm{R} \\
& I 2=\mathrm{L} \\
& C=\text { series capacitance } \\
& C 1=C_{e}=\text { shunt capacitance } \\
& {[A]=\left[I_{n-1}, n\right]} \\
& {[B]=\left[I_{n, 0}\right] \quad n=1,2,3, \ldots ., 9} \\
& {[c]=\left[I_{n}, n+1\right]} \\
& {[A]-[B]-[C]=\left[I_{T}\right]} \\
& {[z]=[i]} \\
& {[\mathrm{Q}]=[\mathrm{Y}]} \\
& {[\mathrm{W}]=[\mathrm{Y}]^{-1}} \\
& J 1=\operatorname{maximum} \text { time } \\
& R(I, M)=I_{I, I+1} \quad I=1,2,3, \ldots, 9 \\
& \mathbf{M}=1
\end{aligned}
$$

The rlow chart is shown on the next page. 


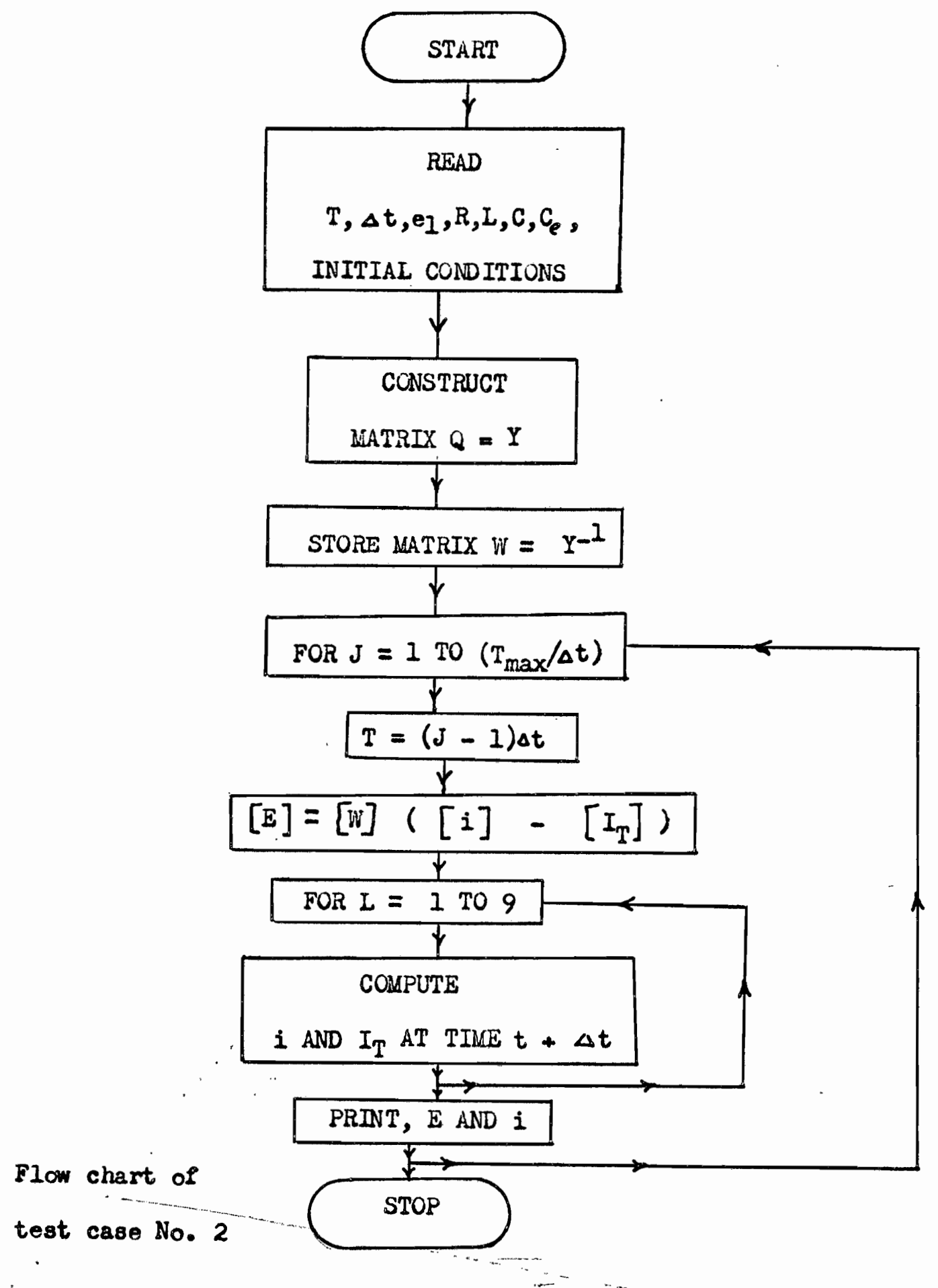


Computer program:

$100 \operatorname{DIM} E(9,1), Z(9,1), A(9,1), B(9,1), C(9,1)$

$110 \operatorname{DIM} V(9,1), R(9,1), I(9,1), T(9,1), P(9,1)$

$120 \operatorname{DTM} W(9,9), F(9,1), G(9,1), H(9,1), Q(9,9)$

130 READ T, D,EI

$140 \mathrm{READ} \mathrm{RI}, \mathrm{I2}, \mathrm{C}, \mathrm{Cl}, \mathrm{Al}, \mathrm{VI}, \mathrm{II}$

$150 \operatorname{MAT} A=Z \operatorname{ER}(9,1)$

$160 \operatorname{MAT} B=Z \operatorname{ZER}(9,1)$

$170 \operatorname{MAT} C=2 \operatorname{ER}(9,1)$

$180 \operatorname{MAT} Z=Z \operatorname{ER}(9,1)$

$190 \operatorname{MAT} I=2 \operatorname{ER}(9,1)$

$200 \operatorname{MAT} V=Z \operatorname{ZER}(9,1)$

$210 \operatorname{MAT} P=Z \operatorname{ER}(9,1)$

220 PRINT "TIME", "CORRENT TO 10", "VOLTAGE AT $10 "$

225 PRINT

$230 \mathrm{Y}=1 /(R I+2 * I 2 / D+D /(2 * C))$

$240 U=Y *(R I-2 * I 2 / D+D /(2 * C))$

$250 \mathrm{YI}=2 * \mathrm{Y}+2 * \mathrm{Cl} / \mathrm{D}$

260 MAT $Q=2 E R(9.9)$

270 FOR K2=I TO 9

280 FOR K3=1 TO 9

290 IF K2 $<>K 3$ THEN 370

$300 \mathrm{Q}(\mathrm{K} 2, \mathrm{~K} 3)=\mathrm{YI}$

$310 \mathrm{~K} 4=\mathrm{K} 3+1$

320 IF $K 4=20$ THEN 380

$330 Q(K 2, K 4)=-Y$ 
$340 \mathrm{k} 5=\mathrm{k} 3-1$

350 IF K5=0 THEN 370

$360 Q(K 2, K 5)=-Y$

370 NEKT K3

380 NEXT K2

390 MAT $W=I N V(Q)$

$400 \mathrm{~J} 1=1+\mathrm{T} / \mathrm{D}$

410 FOR $\mathrm{J}=1$ TO J1

420 MAT $F=A-B$

430 MAT $G=F-C$

440 MAT $H=G+Z$

$450 \mathrm{MAT} E=\mathrm{W}^{*} \mathrm{H}$

460 FOR I $=1$ TO 9

$470 \mathrm{M}=1$

480 IF I $>1$ THEN 550

490 IF J $=$ THEN 520

$500 \mathrm{~S}=\mathrm{E} 1$

510 GO TO 530

$520 \mathrm{~s}=0$.

$530 R(L, M)=Y *(S-E(1,1))+A(1,1)$

540 GO TO 570

550 I1 $=1-1$

$560 R(I, M)=Y *(E(I 1, M)-E(I, M))+A(I, M)$

$570 \mathrm{~V}(I, M)=V(L, M)+(D /(2 * C)) *(I(L, M)+R(L, M))$

580 IF L $>1$ THEN 650

590 IF $\mathrm{J}=1$ THEN 620 
$600 s=E 1$

710 GO TO 630

$610 s=0$.

$630 T(L, M)=Y *(S-E(L, M)-2 * V(L, M))-U * R(I, M)$

640 Go TO 660

$650 T(L, M)=Y *(E(I I, M)-E(L, M)-2 * V(L, M))-U * R(L, M)$

$660 I(L, M)=R(I, M)$

$670 A(L, M)=T(L, M)$

$680 P(L, M)=(2 * C I / D) * E(I, M)+B(I, M)$

$690 B(L, M)=-P(L, M)-(2 * C I / D) * E(I, M)$

700 NEXT I

710 FOR N=1 to 9

$720 \mathrm{~N} 1=\mathrm{N}+1$

730 IF N1=10 THEN 760

$740 \mathrm{C}(\mathrm{N}, \mathrm{M})=\mathrm{A}(\mathrm{N} 1, \mathrm{M})$

750 GO TO 810

$760 \mathrm{R} 2=\mathrm{Y} * \mathrm{E}(9,1)+\mathrm{A} 1$

$770 \mathrm{~V} 1=\mathrm{V} 1+(\mathrm{D} /(2 * \mathrm{C})) *(\mathrm{I} 1+\mathrm{R} 2)$

$780 A 1=Y *(E(9, M)-2 * V 1)-U * R 2$

$790 \quad \mathrm{I} 1=\mathrm{R} 2$

$800 \mathrm{C}(9, \mathrm{M})=\mathrm{A} 1$

810 NEXT N

$8202(1,1)=Y * E 1$

$830 \mathrm{~K} 1=\mathrm{J}-1$

$840 T 1=K 1 * D$

850 PRINT T1,I $(9,1), E(9,1)$ 
860 NEXT J

870 DATA 1E-7,2E-9,1.

880 DATA $1, .5 \mathrm{E}-6,15 \mathrm{E}-9,1 \mathrm{E}-11, .0, .0, .0$

999 END

This program was executed by.G.E. MARK II in basic language.

The result is shown on the next page. 


$$
\Delta t=1 \text { nsoc. }
$$

\section{TIME}

\section{0}

$1 \cdot E-9$
$2 \cdot E-9$
$3 \cdot E-9$
$4 \cdot E-9$
$5 \cdot E-9$

6.E-9

7. E-9

8.E-9

9. E- 9

1. $E-8$

1. $1 E-8$

1. $2 E-8$

1. $3 E-8$

1. $4 E-8$

1. $5 E-8$

1. $6 E-8$

1. $7 E-8$

1. $8 E-8$

1. $9 E-8$

$2 \cdot E-8$

2. $1 E-8$

2. $2 E-8$

$2 \cdot 3 E-8$

$2 \cdot 4 E-8$

$2 \cdot 5 E-8$

$2 \cdot 6 E-8$

2. $7 E-8$

2. $8 E-8$

2. $9 E-8$

3. $E-8$

$3.1 F-8$

$3 \cdot 25-8$

3. $3 E-8$

3. $4 E-8$

$3 \cdot 5 E-8$

3. $6 E-8$

3. $7 E-8$

3. $8 E-8$

3. $9 E-8$

$4 \cdot E-8$

4. $1 E-8$

$4 \cdot 2 F,-8$

$4 \cdot 3 F_{1}-8$

$4 \cdot 4 E-8$

$4 \cdot 5 E-8$

$4 \cdot 6 E-8$

\section{CURRENT TO 10 VOLTAGE AT 10}

\section{0}

$1.83314 E-14 \quad 0$

$5.88344 E-13 \quad 1.66487 E-12$

9.3562?E-12 5.46451E-11

$9.83733 E-11 \quad 8.89194 E-10$

. $7.69899 \mathrm{E}-10$

4. $78733 E-9$

9.57107E-9

$7.6715 E-8$

4. $88698 E-7$

2. $57863 E-6$

1. $15968 E-5$

4. $53916 E-5$

1. $57112 E-4$

4. $86907 \mathrm{E}-4$

1. $36457 \mathrm{E}-3$

3. $48603 E-3$

8. $17068 \mathrm{E}-3$

: 1.76621E-2

3. $53576 \mathrm{E}-2$

0.065759

0.113879

0.183878

0.276932

0.388708

0.507324

0.613001

0.680521

0.684931

0.609648

0.4154632

0.241327

1. $12219 \mathrm{E}-2$

$-0.183325$

$-0.29445$

$-0.295591$

$-0.193238$

$-2.78355 E-2$

0.138319

0.243057

0.248175

0.155202

$5.53983 \mathrm{E}-3$

$-0.136309$

$-0.210143$

$-0.186373$

$-7.92247 \mathrm{E}-2$

5. $97903 E-2$.

0.165742 


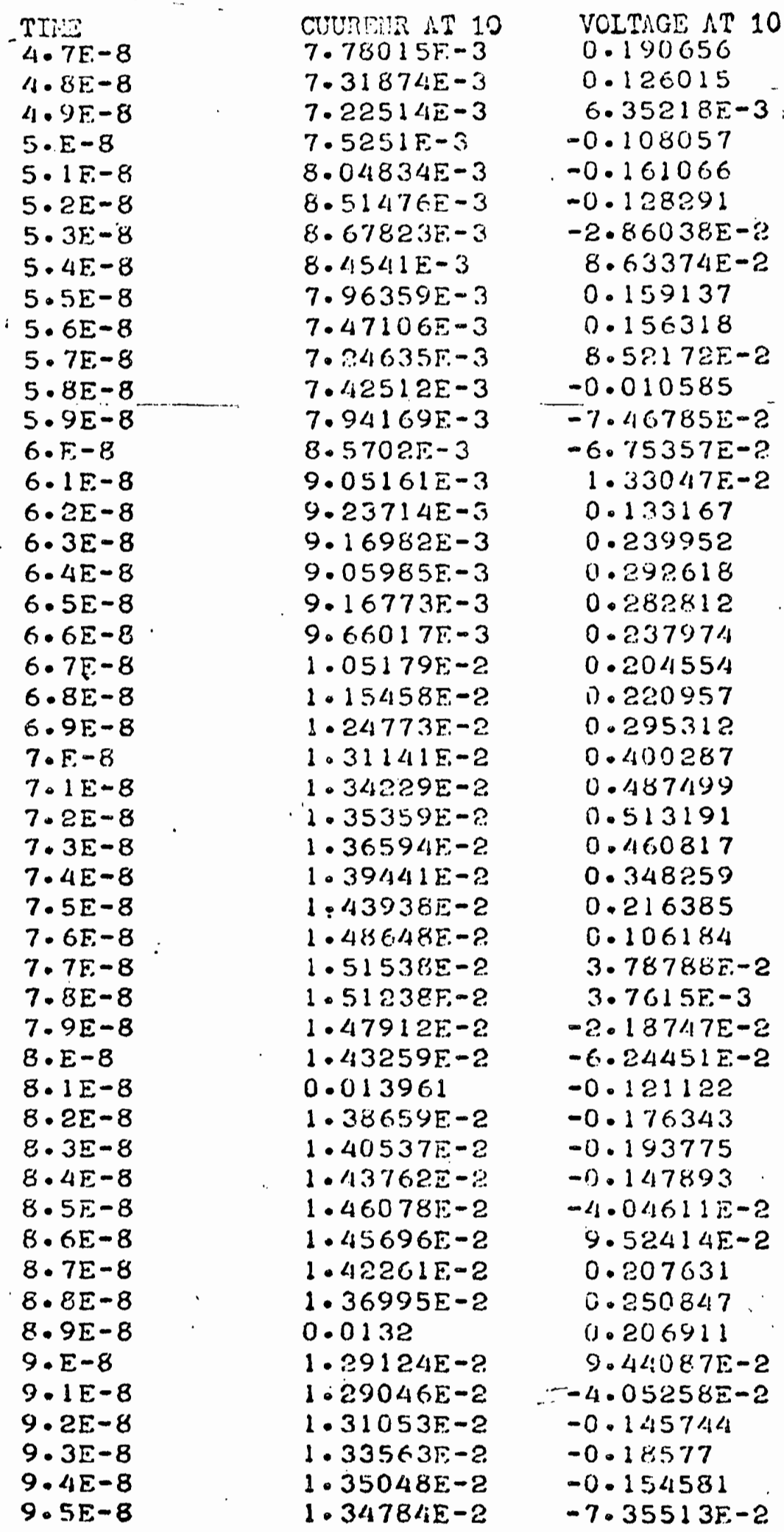




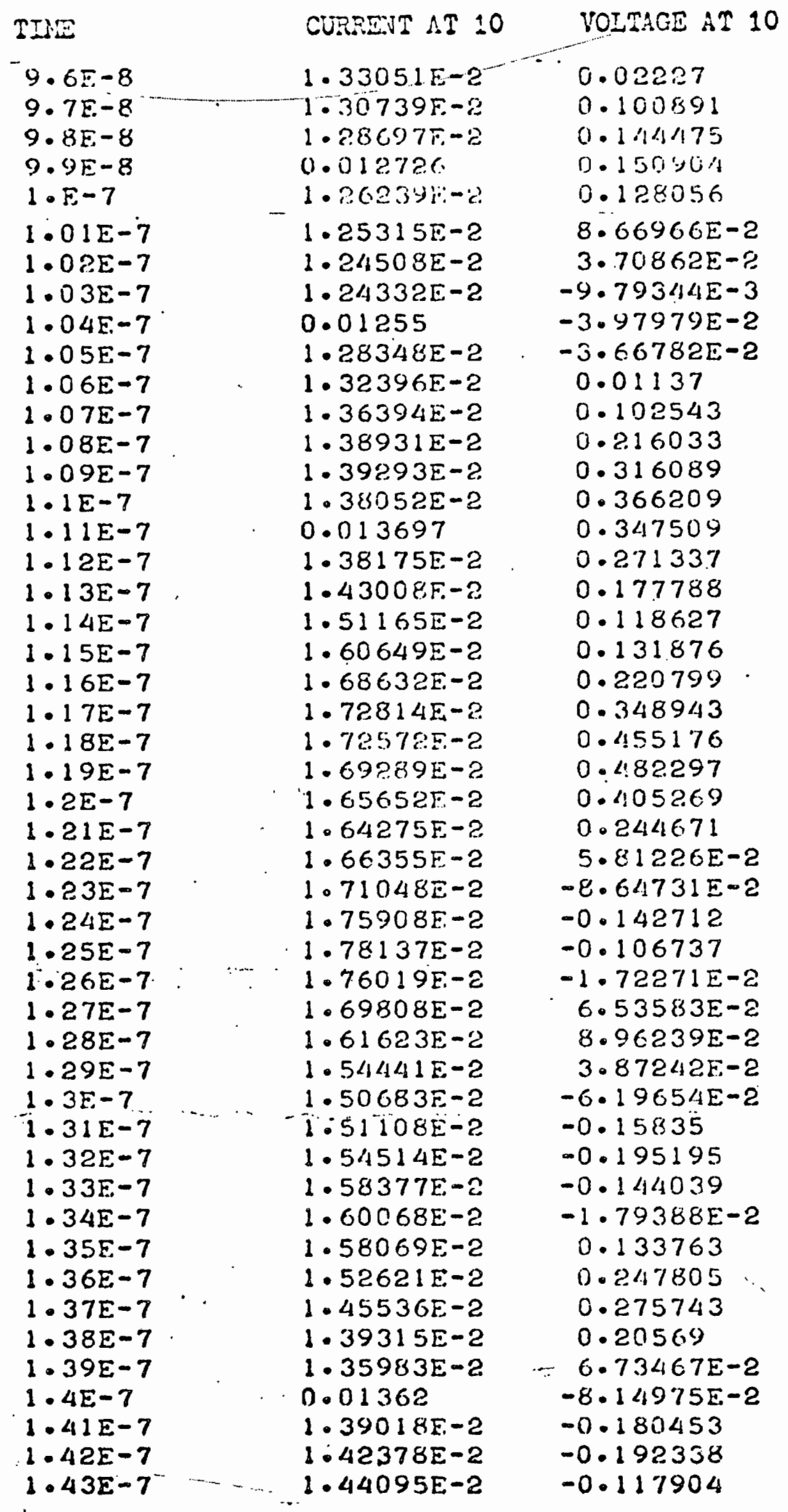




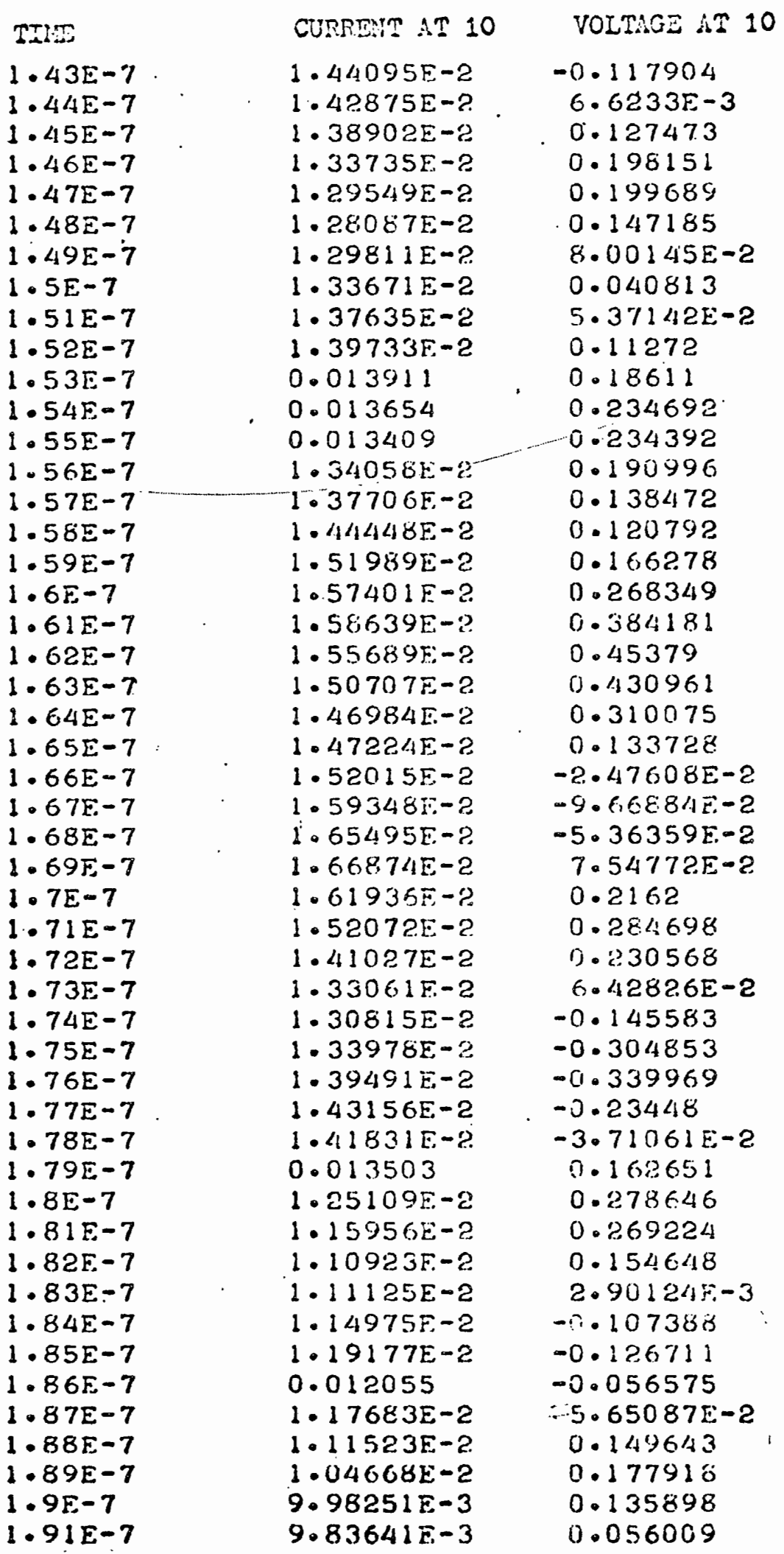


TINE

$$
\begin{aligned}
& 1 \cdot 92 E-7 \\
& 1 \cdot 93 E-7 \\
& 1 \cdot 94 E-7 \\
& 1 \cdot 95 E-7 \\
& 1 \cdot 96 E-7 \\
& 1 \cdot 97 E-7 \\
& 1 \cdot 98 E-7 \\
& 1 \cdot 99 E-7 \\
& 2 \cdot E-7 \\
& 2 \cdot 01 E-7 \\
& 2 \cdot 02 E-7 \\
& 2 \cdot 03 E-7 \\
& 2 \cdot 04 E-7 \\
& 2 \cdot 05 E-7 \\
& 2 \cdot 06 E-7 \\
& 2 \cdot 07 E-7 \\
& 2 \cdot 08 E-7 \\
& 2 \cdot 09 E-7 \\
& 2 \cdot 1 E-7 \\
& 2 \cdot 11 E-7 \\
& 2 \cdot 12 E-7 \\
& 2 \cdot 13 E-7 \\
& 2 \cdot 14 E-7 \\
& 2 \cdot 15 E-7 \\
& 2 \cdot 16 E-7 \\
& 2 \cdot 17 E-7 \\
& 2 \cdot 18 E-7 \\
& 2 \cdot 19 E-7 \\
& 2 \cdot 2 E-7 \\
& 2 \cdot 21 E-7 \\
& 2 \cdot 22 E-7 \\
& 2 \cdot 23 E-7 \\
& 2 \cdot 24 E-7 \\
& 2 \cdot 25 E-7 \\
& 2 \cdot 26 E-7 \\
& 2 \cdot 27 E-7 \\
& 2 \cdot 28 E-7 \\
& 2 \cdot 29 E-7 \\
& 2 \cdot 3 E-7 \\
& 2 \cdot 31 E-7 \\
& 2 \cdot 32 E-7 \\
& 2 \cdot 33 E-7 \\
& 2 \cdot 34 F-7 \\
& 2 \cdot 35 E-7 \\
& 2 \cdot 36 E-7 \\
& 2 \cdot 37 E-7 \\
& 2 \cdot 38 E-7
\end{aligned}
$$

CURRIN AT 10

$$
\begin{aligned}
& \text { 9. } 97531 E-3 \\
& 1.02118 E-2 \\
& 1.03503 E-2 . \\
& 1.03026 E-2 \\
& 1.01256 E-2 \\
& 9.9635 F-3
\end{aligned}
$$$$
9.93917 \mathrm{E}-3
$$$$
1.0067 \%-c \text {. }
$$$$
\text { 1.02488E-2. }
$$$$
\text { 1. } 0348.8 E-2
$$$$
1.02774 E-2
$$$$
\text { 1. } 01135 \mathrm{E}-2
$$$$
1.00194 \mathrm{E}-2 \text {. }
$$$$
\text { 1. } 01638 E-2 \text {. }
$$$$
\text { 1. } 05921 \mathrm{E}-2
$$$$
\text { 1.11669E-2 }
$$$$
\text { 1.16195E-? }
$$$$
0.011694
$$$$
\text { 1. } 13024 E-2
$$$$
\text { 1.05976E-? }
$$$$
\text { 9.91028E-3 }
$$$$
\text { 9.5751\% }-3
$$$$
9.73901 \mathrm{~F}-3
$$$$
1.02614 \mathrm{E}-2 \text {. }
$$$$
\text { 1.07728E-? }
$$$$
\text { 1. } 08678 \bar{E}-2
$$$$
1.03311 \mathrm{E}-2
$$$$
9.26931 \mathrm{E}-3
$$$$
\text { 8.07045E-3 }
$$$$
7 \cdot 20369 F-3
$$$$
6.96648 \mathrm{E}-3
$$$$
7.31796 \mathrm{~F}-3
$$$$
\text { 7. } 89525 E-3
$$$$
8.20916 E-3
$$$$
7.91513 E-3
$$$$
\text { 7. } 00975 \mathrm{r}-3
$$$$
\text { 5. } 84081 \mathrm{E}-3
$$$$
4.92032 \mathrm{E}-3
$$$$
4 \cdot 64045 \mathrm{E}-3
$$$$
\text { 5. } 04901 \mathrm{E}-3
$$$$
5.81197 \mathrm{E}-3
$$$$
\text { 6. } 38899 \mathrm{E}-3
$$$$
6.32 .962 \mathrm{E}-3
$$$$
5.52831 \mathrm{~F}-3
$$$$
\text { 4. } 2953.3 E-3
$$$$
\text { 3. } 19973 E-3
$$$$
\text { 2. } 7651 \mathrm{~F}-3
$$

VOLTAGE $A T 10$

$$
\begin{aligned}
& -1.29586 E-2 \\
& -3.34913 E-2 \\
& 2.67175 E-3 \\
& 0.074962 \\
& 0.150127 \\
& 0.20259 \\
& 0.226348 \\
& 0.232335 \\
& 0.235097 \\
& 0.239353 \\
& 0.23642 \\
& 0.213164 \\
& 0.166859 \\
& 0.114489 \\
& 8.79079 E-2 \\
& 0.115498 \\
& 0.200722 \\
& 0.311877 \\
& 0.392215 \\
& 0.38779 \\
& 0.278866 \\
& 9.65193 E-2 \\
& -8.72938 \mathrm{E}-2 \\
& -0.193623 \\
& -0.177587 \\
& -5.42053 E-2 \\
& 0.106545 \\
& 0.214718 \\
& 0.207844 \\
& 8.52919 E-2 \\
& -8.98885 E-2 \\
& -0.223844 \\
& -0.242508 \\
& -0.132497 \\
& 5.05415 E-2 \\
& 0.211483 \\
& 0.267608 \\
& 0.194388 \\
& 3.95428 E-2 \\
& -0.103124 \\
& -0.146251 \\
& -0.058286 \\
& 0.114315 \\
& 0.276272 \\
& 0.331236 \\
& 0.239825 \\
& 4.45249 E-2 \\
&
\end{aligned}
$$




\begin{tabular}{|c|c|c|}
\hline TIS:S & CURREIT AT 10 & VOLTAGE AT 10 \\
\hline $2 \cdot 39 E-7$ & $3.182175-3$ & -0.149612 \\
\hline $2 \cdot 4 F-7$ & $4.19587 E-3$ & -0.230145 \\
\hline $2 \cdot 41 E-7$ & $5 \cdot 23213 E-3$ & -0.138557 \\
\hline $2 \cdot 42 E-7$ & $5.69991 E-3$ & $9.48079 E-2$ \\
\hline $2 \cdot 43 E-7$ & $5.307915-3$ & $0.36798 ?$ \\
\hline $2.44 E-7$ & $4 \cdot 22535 I-3$ & 0.536008 \\
\hline $2 \cdot 45 E-7$ & $2.99889 E-3$ & 0.528482 \\
\hline $2 \cdot 46 E-7$ & $2 \cdot 26741 E-3$ & 0.345266 \\
\hline $2 \cdot 47 E-7$ & $2.425 .38 E-3$ & $8.07246 E-2$ \\
\hline $2 \cdot 48 E-7$ & $3.412 E E-3$ & -0.128808 \\
\hline $2 \cdot 49 E-7$ & $4.74278 E-3$ & -0.17491 \\
\hline $2 \cdot 5 E-.7$ & $5 \cdot 75176 F-3$ & $-3.29946 E-2$ \\
\hline $2.51 E-7$ & $5 \cdot 94051 E-3$ & 0.224853 \\
\hline $2 \cdot 52 E-7$ & $5 \cdot 2274 E-3$ & .0 .466737 \\
\hline $2.53 E-7$ & $3.98376 \mathrm{~F}-3$ & 0.568315 \\
\hline $2.54 E-7$ & $2.83635 E-3$ & 0.475838 \\
\hline $2 \cdot 55 E-7$ & $2.34293 F-3$ & 0.832651 \\
\hline $2.56 E-7$ & $2.71001 E-3$ & $-4 \cdot 382.58 E-2$ \\
\hline $2 \cdot 57 E-7$ & $3.69574 E-3$ & -0.222117 \\
\hline $2.58 E-7$ & $4 \cdot 7419 E-3$ & -0.222588 \\
\hline $2.59 E-7$ & $5 \cdot 26087 E-3$ & $-5 \cdot 59017 E-2$ \\
\hline $2 \cdot 6 E-7$ & $4.92 .751 E-.3$ & 0.184502 \\
\hline $2.61 E-7$ & $3.82 .96 E-3$ & 0.370802 \\
\hline $2.62 E-7$ & $2.40819 E-3$ & 0.404667 \\
\hline $2 \cdot 63 E-7$ & 1. $22764 E-3$ & 0.264509 \\
\hline $2 \cdot 64 E-7$ & $6.9781 .1 E-4$ & $1.35849 E-2$ \\
\hline $2 \cdot 65 E-7$ & $8.876715-4$ & -0.233296 \\
\hline $2 \cdot 66 E-7$ & $1.51552 \mathrm{E}-3$ & -0.366309 \\
\hline $2.67 E-7$ & $2.10889 E-3$ & -0.331969 \\
\hline $2 \cdot 68 E-7$ & $2 \cdot 24461 E-3$ & -0.155012 \\
\hline $2 \cdot 69 E-7$ & 1. $74704 E-3$ & $7 \cdot 77309 E-2$ \\
\hline 2. $7 E-7$ & $7.52774 E-4$ & 0.2 .61284 \\
\hline $2.71 E-7$ & $-3 \cdot 78213 F-4$ & 0.32162 \\
\hline $2 \cdot 72 E-7$ & $-1 \cdot 24915 E-3$ & 0.2 .46 .578 \\
\hline $2 \cdot 73 E-7$ & $-1.6135 E-3$ & $8.57488 E-2$ \\
\hline $2.74 E-7$ & $-1.47411 E-3$ & $-7 \cdot 78279 F-2$ \\
\hline $.75 E-7$ & $-1.056365-3$ & -0.16847 \\
\hline
\end{tabular}


$\Delta t=2$ ussoc.

TIME

$$
0
$$

$2 \cdot E-9$

$4 \cdot E \cdot-9$

$6 \cdot E-9$

$8 \cdot E-9$

1. $E-8$

1. $2 E-8$

1. $4 E-8$

1. $6 E-8$

1. $8 E .-8$

$2 \cdot E-8$

2. $2 E-8$

$2 \cdot 4 E-8$

$2 \cdot 6 E-8$

2. $2 E-8$

$3 \cdot E-8$

3. $2 E-8$

3. $4 E-8$

$3 \cdot 6 E-8$

3. $8 E-8$

$4 \cdot E-8$

$4 \cdot 2 E-8$

$4 \cdot 4 E-8$

$4 \cdot 6 E-8$

$4 \cdot 8 E-8$

$5 \cdot E-8$

$5 \cdot 2 E-8$

$5 \cdot 4 E-8$

$5 \cdot 6 E-8$

$5 \cdot 8 E-8$

$6 \cdot E-8$

6. $2 F .-8$

6. $11 E-8$

$6 \cdot 6 F-8$

6. $8 E-8$

$7 \cdot E-8$

7. $25-8$

7. 4 F. -8

7. $6 E-8$

$7 \cdot 8 E-8$

$8 \cdot E-8$

$-8 \cdot 2 \pi-8$

CURRENT TO 10 VDLTAGE AT 10

0 .

3. $95973 \mathrm{~F}-10$

1. $0477 \mathrm{Fi}-8$

1. $34.325 \mathrm{E}:-7$

1. $11072 \bar{x}-6$

6. $65004 E-6$

$3.0673 E-5$

$1.131955-4$

$3.42545 E-4$

$8.64058 E-4$

1. $83661 \mathrm{E}-3$

3. $31295 E .-3$

$5.09707 \mathrm{E}-3$

$6.72 \% 86 E-3$

$\% .71656 \mathrm{E}-3$

$7.93802 \mathrm{E}-3$

$7.806995-3$

$7.936065-3$

8. $49512 \mathrm{E}-3$

$8.97341 \vec{F}-3$

$8.75759 \mathrm{E}-3$

$7.96458 \mathrm{E}-3$

$7.45813 \%-3$

$7.84149 E-3$

$8.61651 \mathrm{E}-3$

Ö. $72201 \mathrm{E}-3$

$\% .92955 E-3$

$7.25074 \mathrm{E}-3$

7. 648921:-3

8.70909E-3

9. $180 \cap / F-3$

8. $78844 \mathrm{E}-3$

8. $686.16 E-3$

9. $\$ 775 E-3$

$1.16978 \%-$ ?

1. $37014 \mathrm{E}-2$

$1 \cdot 27081 \mathrm{~F}-2$

1.29361F-2.

$1.42314 \mathrm{~F}-2$

1. $53735 \mathrm{E}-2$

1. $51042 E-2$

0.013891
0

0

5. $0.474 E-8$

1. $5024 \mathrm{E}-6$

1.9.34 $26 \mathrm{E}-5$

1 - $60.32 \mathrm{eE}-4$

$9.59736 E-4$

$4.41043 E-3$

$1.61338 E-2$

$4.80359 E-2$

0.117875

0.839446

0.400804

0.543031.

$0.50976 / 1^{\prime}$

0.408546

$9.72993 E-2$

$-0.192367$

$-0.263324$

$-7.58422 E-2$

0.177954

0.235732

$3.90044 \mathrm{E}-2$

$-0.18547$

$-0.174086$

$5.55022 \mathrm{E}-2$

1).214789

0.105492

$-0.116265$

$-0.137492$

$9.1594 \times E-2$

0.085833

0.220399

1 . $997075-2$

$8.79326 \mathrm{E}-2$

0.34225

0.491865

0.340043

$=9.99076 \mathrm{~F}-2$

$7.32841 \mathrm{E}-2$

0.201004

0.166064 


\begin{tabular}{|c|c|c|}
\hline $\begin{array}{l}8 \cdot 4 E-8 \\
8 \cdot 6 E-8 \\
8 \cdot 8 E-8 \\
9 \cdot E-8 \\
9 \cdot 2 E-8 \\
9 \cdot 4 E-8 \\
9 \cdot 6 E-8 \\
9 \cdot 8 E-8 \\
1 \cdot E-7\end{array}$ & 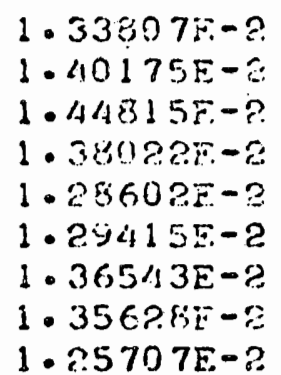 & $\begin{array}{l}-0.098411 \\
-0.274474 \\
-0.122471 \\
0.153095 \\
0.197307 \\
1.459415-2 \\
-7.686085-2 \\
3.581135-2 \\
0.119463\end{array}$ \\
\hline
\end{tabular}

The curves are shown on the following page. 


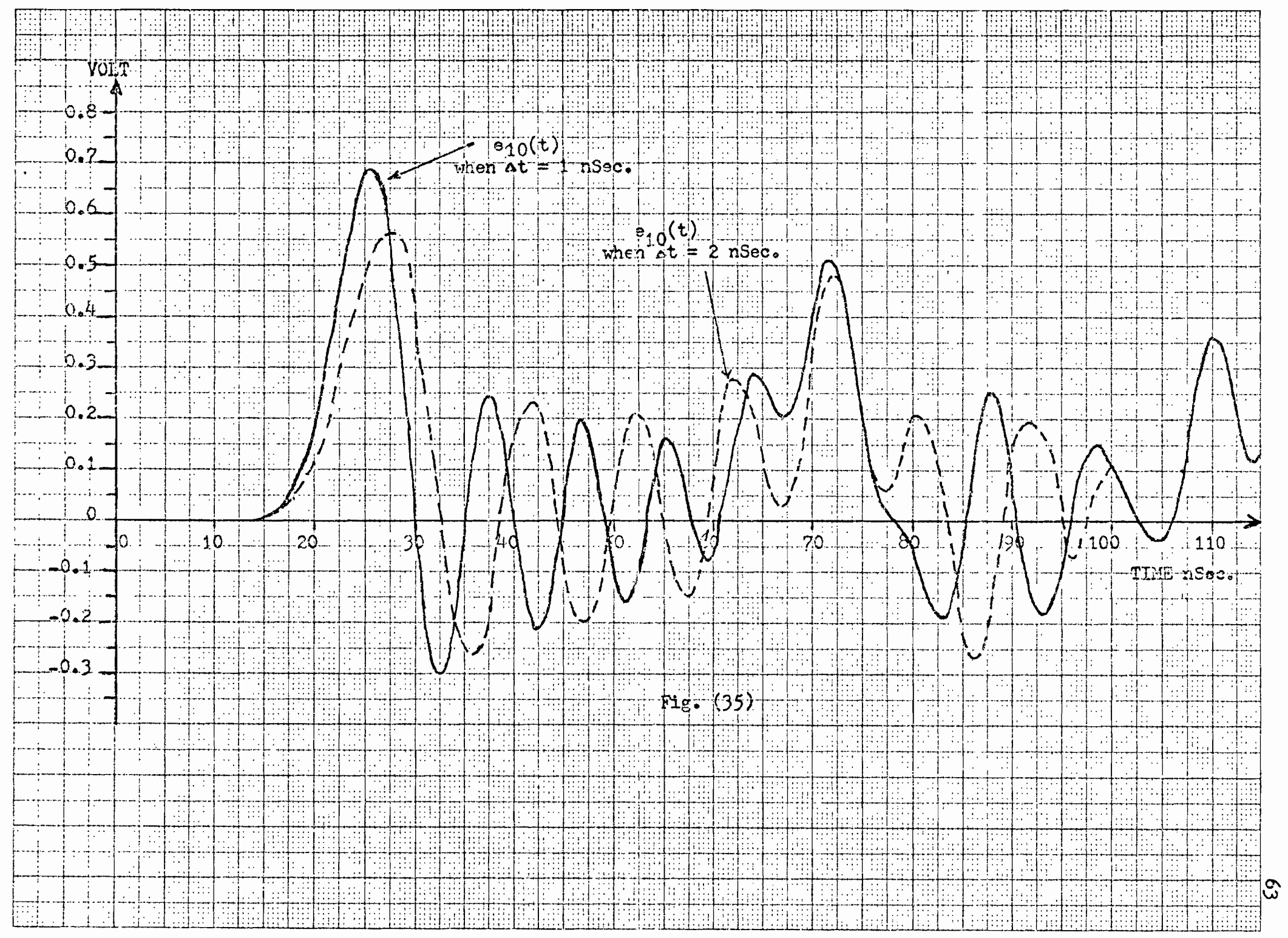




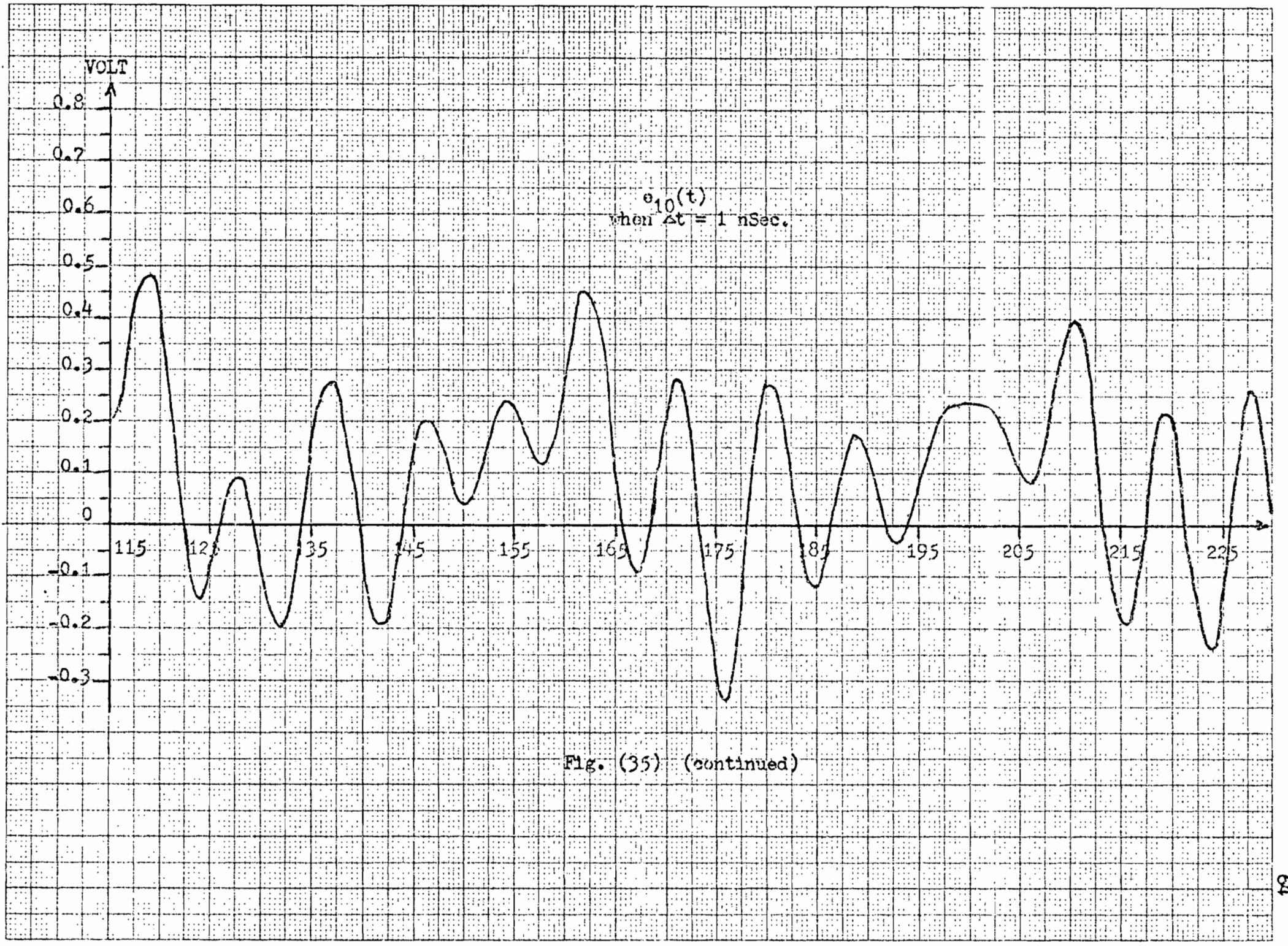




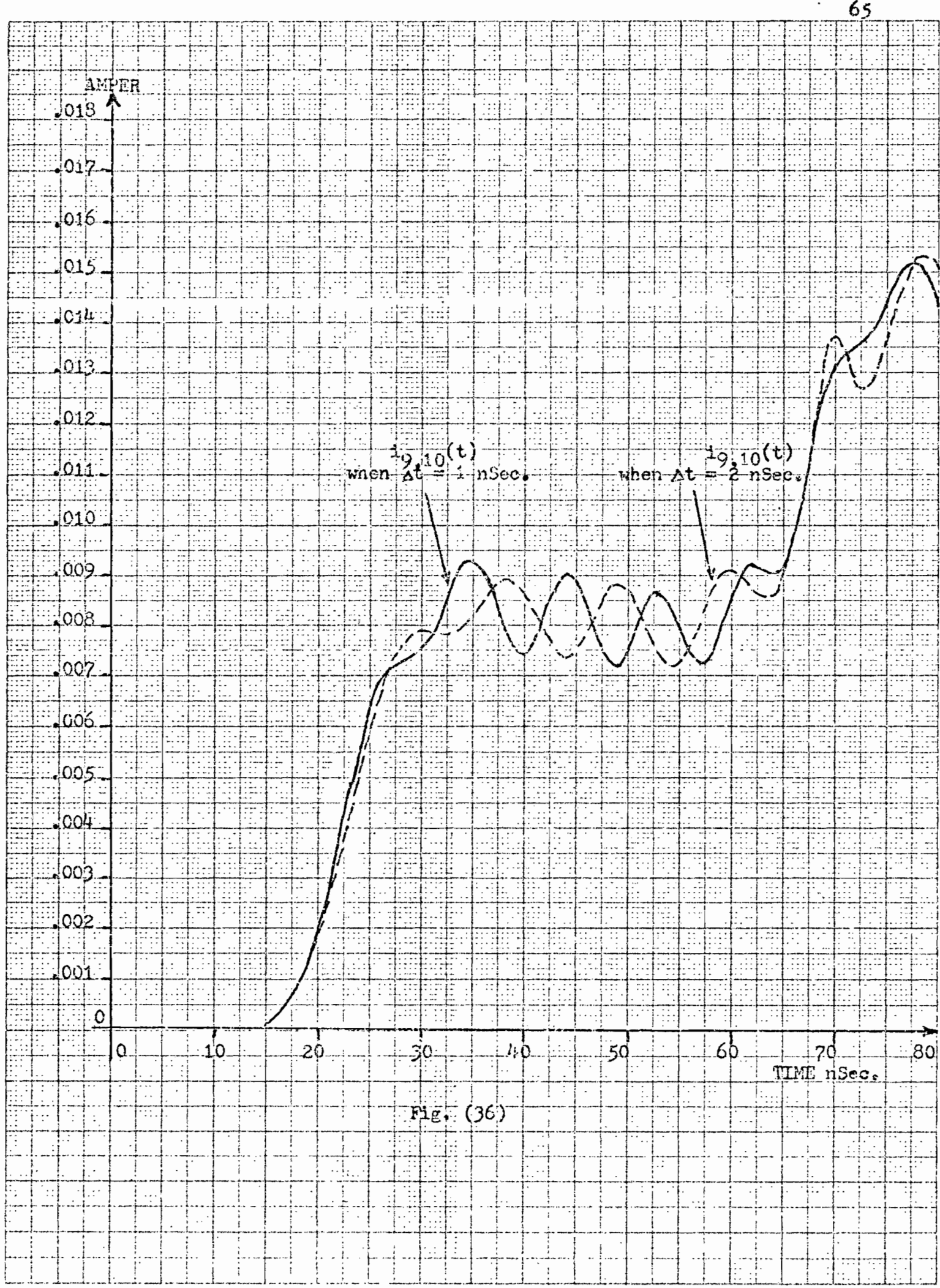


66

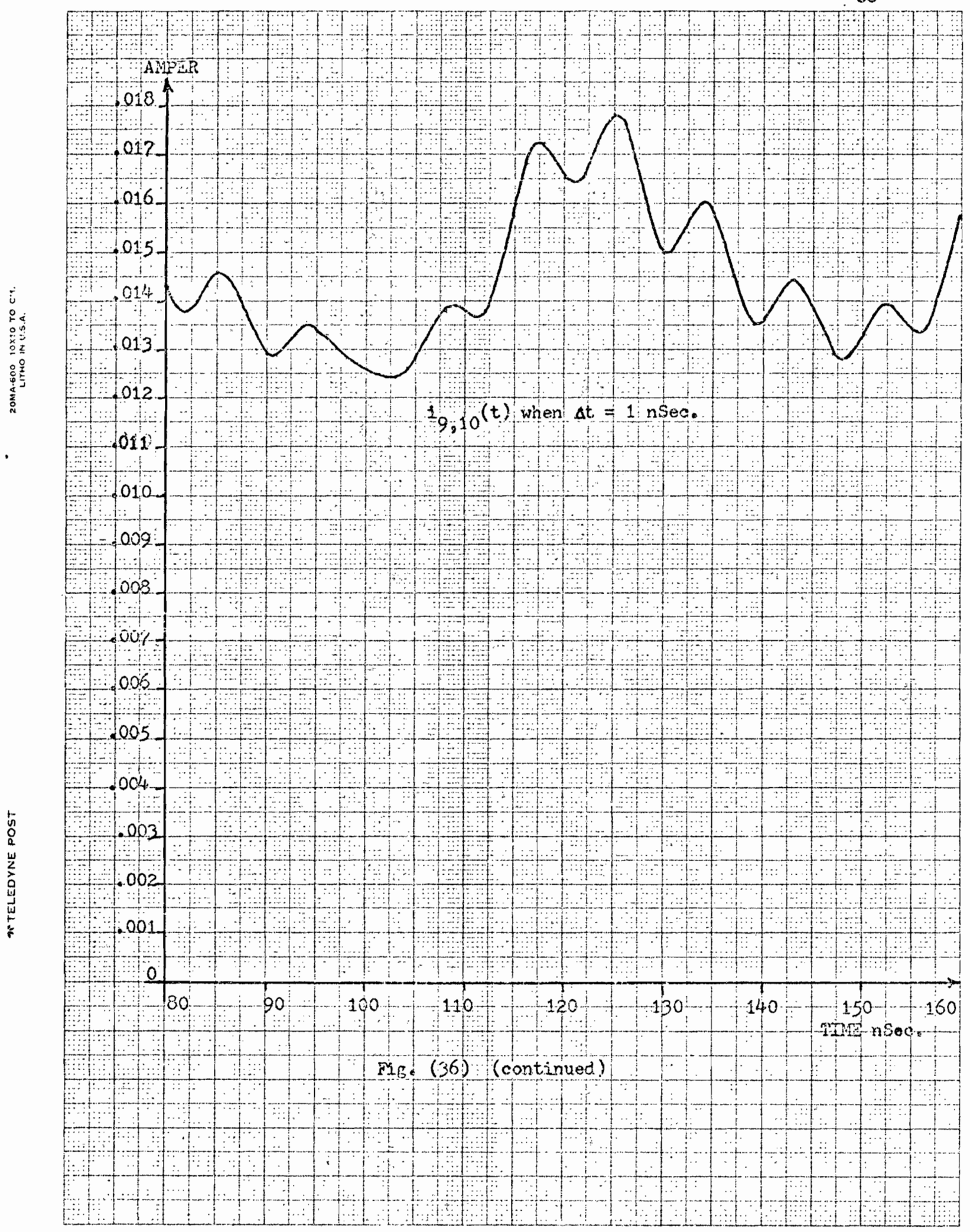




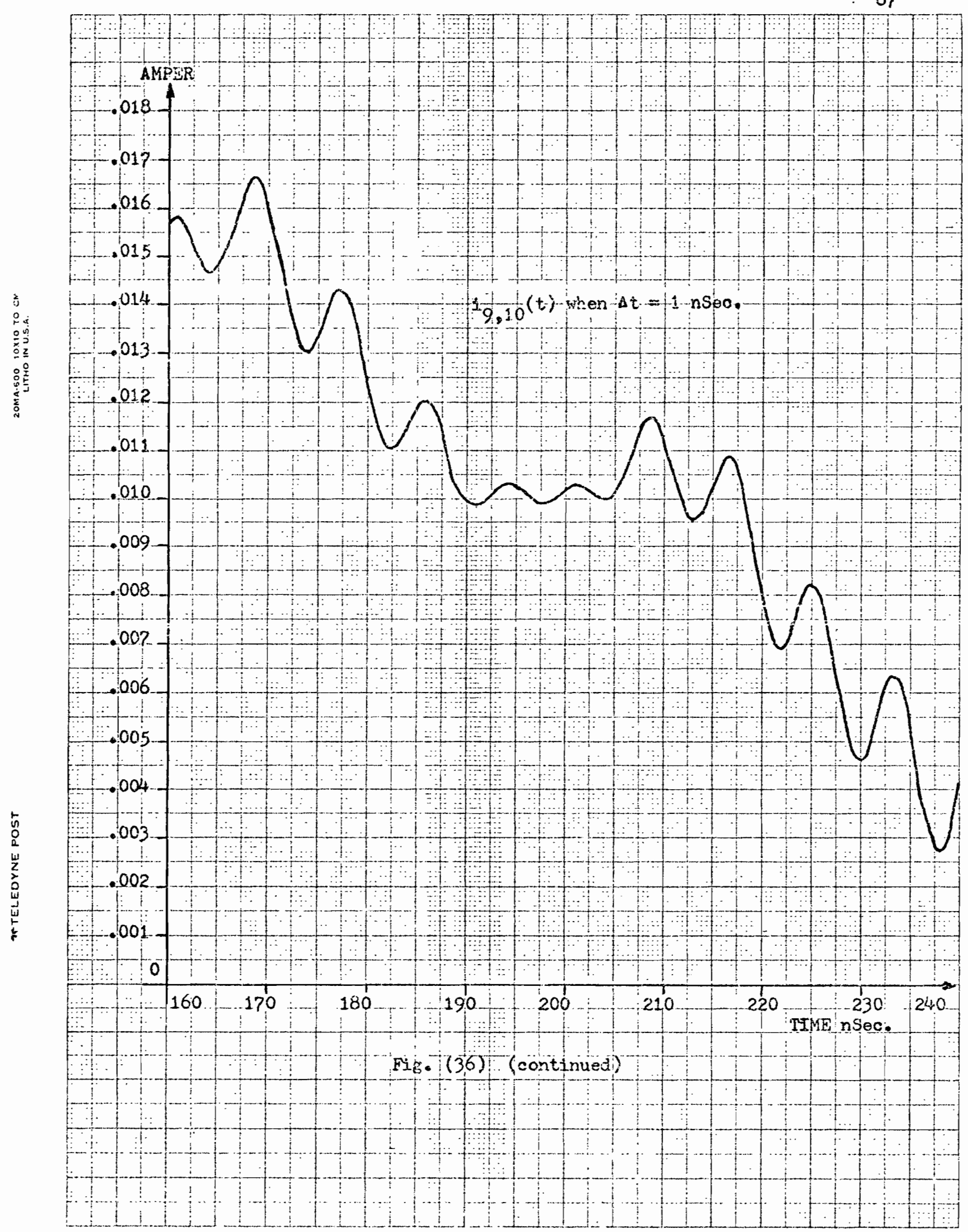


Voltage at node $10\left(e_{10}(t)\right)$ and current from node 9 to node 10 (i $9,10(t)$ ) were plotted in fig. (35), where first $t$ was selected I nSec. and then 2 nSec. From these figures, the significance of selection of $\Delta t$ appears. The peak value of elo(t) is 0.6849 . Volt ; ... at $t=26$ sec. and .5697 Volt.: at $t=26$ Sec. when $t$ is 1 nSec. and $2 \mathrm{n}$ Sec., respectively. This shows that during time $26 \mathrm{nSec}$. and $28 \mathrm{nSec}$. that is $t=27$ nSec., one point has been ignored in fig. (35) and this is because of selection of $t=2$ nSec. This difference is the same for ${ }^{1} 9,10(t)$, which becomes clearer by studying the two curves.

From the above discussion, we note that the smaller $\Delta t$ is the more accurate of the calculated data.

Nonlinear and Time-Varying Parameters

Nonlinear and time-varying parameters can be handled as well as linear parameters. However, when there is only one nonlinear parameter in a system, the solution is still linear and when there is more than one nonlinear parameter, the entire system becomes nonlinear and thus the solution gets very complicated.

Consider equation (6I), when there is one nonlinear parameter, it is not included in matrix $[Y]$. To find an equation describing the relation of voltage and current, $i_{a, b}$ can be considered as two currents with two additional nodes:

$$
i_{b}=i_{a, b} \text { and } i_{a}=-i_{a, b}
$$

The equation consists of two parts; Iinear and nonlinear. By superimposing the two additional currents $i_{a}=-i_{b}=-i_{a, b}$, equation (6I) 
can be written in the form of:

$$
\theta_{U}(t)=\underbrace{e_{U}(t)}_{\text {Linear part }}+\underbrace{2 \cdot 1_{a, b}(t)}_{\text {nonlinear part }}
$$

The linear part is computed by ignoring the nonlinear part. Matrix $[2]$ is the precalculated difference of ath and bth columns of [YUU $]^{-1}$. By considering the two simultaneous equations derived by the linear network equation and the nonlinear equation, which is the characteristic of the nonlinear element, current $1_{a, b}(t)$ can be found $a s$ follows:

$$
\theta_{a}(t)-\theta_{b}(t)=\underbrace{\theta_{a}(t)-\theta_{b}(t)}_{\text {linear part }}+\underbrace{\left(z_{a}-z_{b}\right) \dot{i}_{a, b}(t)}_{\text {nonlinear part }}
$$

Let us put equation (62) in a general form as follows:

$$
\theta(t)=A-B i_{a, b}(t)
$$

The nonlinear equation in the form of given characteristics is:

$$
\left.\theta_{a}(t)-\theta_{b}(t)=f\left(\dot{i}_{a, b} t\right)\right)
$$

The nonlinear characteristic can be presented point by point and by each set of points, a linear equation is made and all equations are plotted as piecewise linear; then the result will be the characteristic of the nonlinear element shown as a curve. This is represented by Bonneville Power Adninistration's program.

Now consider fig. (37), where the characteristic of a nonlinear element as piecewise linear and a linear network equation in the form of equation (63) are plotted. The intersection of these two curves gives the value of $i_{a, b}(t)$. For each step, when $t$ changes the linear. network line moves parallel with the latter one and every time a new 
value is found for $i_{a, b}(t)$. When $i_{a, b}(t)$ is known, it can be used in equation (62) and solved for $\theta(t)$.

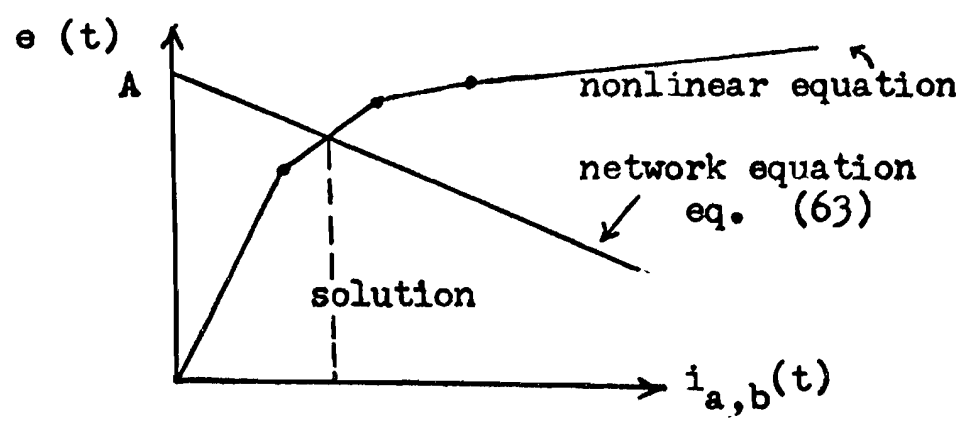

FIg. (37) Solution for nonlinear parameter.

A nonlinear characteristic can represent any type of nonlinear element. In the case of a lightning arrester, since there should be a certain voltage $\left(V_{\text {breakdown }}\right)$ until the current be discharged, $i_{a, b}(t)$ remains zero until voltage breakdown and in the case of a system with one lightning arrester, the entire system is really linear until voltage breakdown.

When a nonlinear element is a time varying resistance, equation (64) becomes simpler. Since resistance is a function of time, equation (64) can be written in the following form:

$$
\theta_{a}(t)-\theta_{b}(t)=R\left(t_{R}\right) \cdot i_{a, b}(t)
$$

When a nonlinear element is an inductance, the characteristic is usually defined ass

$$
\psi=f\left(i_{a, b}\right)
$$

and the total flux is:

$$
\psi(t)=\left(\theta_{a}(t)-\theta_{b}(t)\right) d t+\psi(0)
$$

Now when the trapezoidal rule of integration is applied to equation (65), it gives: 


$$
e_{a}(t)-e_{b}(t)=(2 / \Delta t) f\left(i_{a, b}(t)\right)-c(t-\Delta t),
$$

- $c(t-\Delta t)$ can be considered as initial condition or past history and for time zero and $(t-\Delta t)$, it is respectively as follows:

$$
\begin{gathered}
c(0)=(2 / \Delta t) \psi(0)+e_{a}(0)-\theta_{b}(0) \\
c(t-\Delta t)=c(t-2 \Delta t)+2\left(\theta_{a}(t-\Delta t)-\theta_{b}(t-\Delta t)\right)
\end{gathered}
$$

When a system consists of nonlinear elements, the time of study may not be the same as the time-varying of nonlinear elements. Therefore, it may be more than one time-varying and this makes the program longer.

In order to see how a system with one nonlinear element can be solved by digital computer, an example is illustrated on the next page. 
Test Case No. 3

Consider a system having a nonlinear element (lightning arrester) shown on fig. (38). A lightning stroke hits a line close to a substation, which can be considered as a current impulse with a characteristic as shown in fig. (39). The voltages at nodes $1,2,3,4,8$, and discharge current at lightning arrester are to be found.*

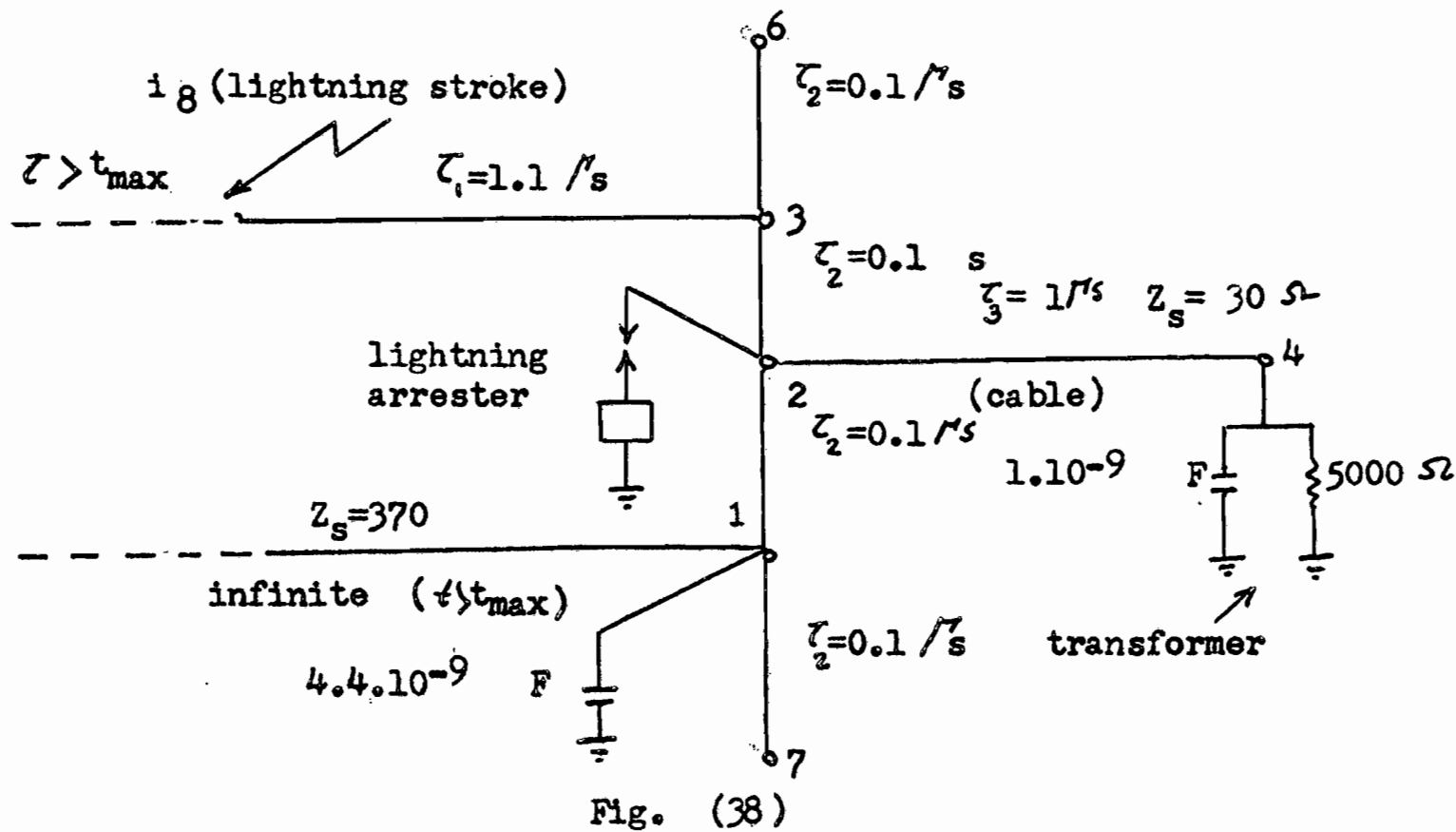

Given:

$z_{s}=370$ sall lines except the line from 2 to 4 which is $30 \mathrm{ohm}$ $t=$ time of study $=. I \Gamma_{\text {sec. }}$, which is the smallest wave travel time on line. This can be smaller, but not more than .I sec.

* This problem is taken from Hermann W. Dammel, Habilitation Thesis, submitted to the Munich Institute of Technology, May, 1970, p. 37. 
Characteristics of the lightning arrester:

$\mathrm{V}_{\text {breakdown }}=610 \mathrm{~V}$
\begin{tabular}{l|l|l|l|l|l|l|l} 
current i in $\mathrm{KA}$ & 0 & .5 & 1 & 1.5 & 2.5 & 3 & 10 \\
\hline voltage e in $\mathrm{KV}$ & 0 & 440 & 510 & 540 & 580 & 590 & 660
\end{tabular}

Characteristic: of the lightning surge is shown in fig. (39).

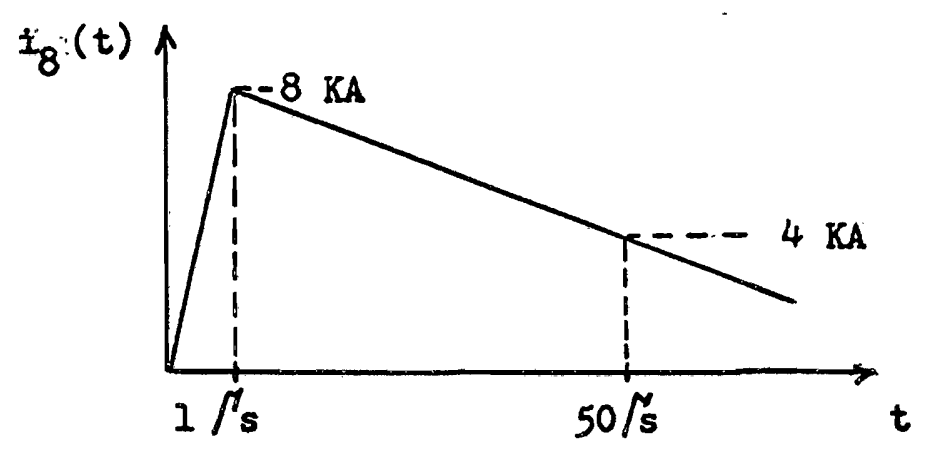

FIg. (39)

Solution:

The equivalent impedance network of the system is shown on the next page.

Let: $T=$ wave travel time on a line

$$
\Delta t=\text { time of study }
$$

The node equations can be written as follows:

Node 8:

$$
\begin{aligned}
& i_{1}(t)+i_{83}(t)-i_{8}(t)=0 \\
& (1 / 370) \theta_{8}(t)+(1 / 370) e_{8}(t)+I_{A 8}\left(t-\tau_{8}\right)-i_{8}(t)=0 \\
& \theta_{8}(t)=(370 / 2)\left(i_{8}(t)-I_{A 8}\left(t-\tau_{8}\right)\right)
\end{aligned}
$$

Node 3:

$$
\begin{aligned}
& i_{38}(t)+i_{32}(t)+i_{36}(t)=0 \\
&(1 / 370) e_{3}(t)+I_{B 3}\left(t-\tau_{1}\right)+(1 / 370) \theta_{3}(t)+I_{A 3}\left(t-\tau_{2}\right)+(1 / 370) \\
& \theta_{3}(t)+I_{C 3}\left(t-\tau_{2}\right)=0 .
\end{aligned}
$$


*

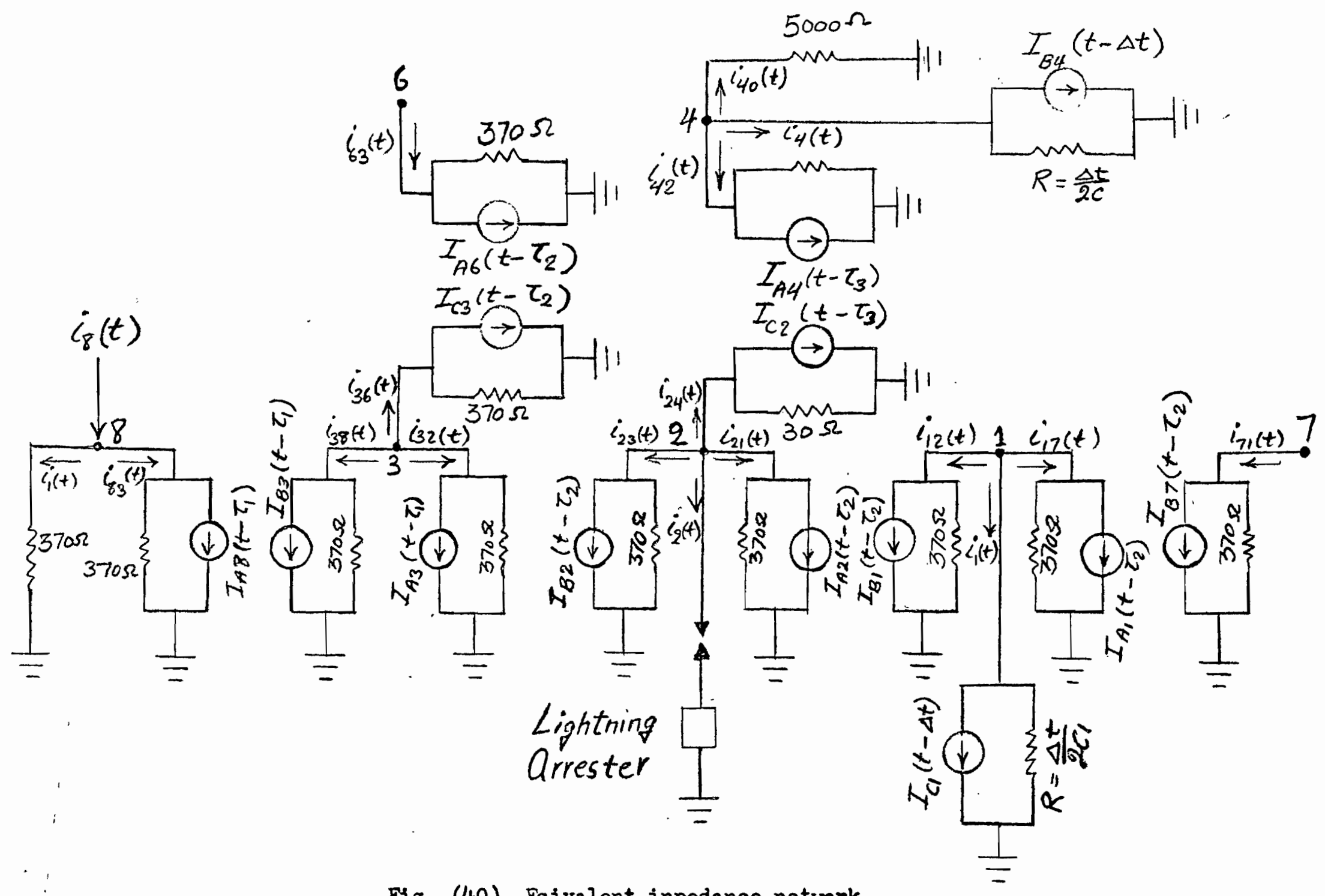

Fig. (40) Eqivalent inpedance network 


$$
e_{3}(t)=(-370 / 3)\left(I_{B 3}\left(t-\tau_{1}\right)+I_{A 3}\left(t-\tau_{3}\right)+I_{C 3}\left(t-\tau_{2}\right)\right)
$$

Node 28

$$
\begin{aligned}
& \text { Before } v_{\text {breakdown }}=610 \mathrm{~V} \text { : } \\
& i_{23}(t)+i_{21}(t)+i_{24}(t)=0 \\
& (1 / 370) e_{2}(t)+I_{B 2}\left(t-\tau_{2}\right)+(1 / 370) e_{2}(t)+I_{A 2}\left(t-\tau_{2}\right)+ \\
& (I / 30) \theta_{2}(t)+I_{C 2}\left(t-\tau_{3}\right)=0 \\
& e_{2}(t)=(-1110 / 43)\left(I_{B 2}\left(t-\tau_{2}\right)+I_{A 2}\left(t-\tau_{2}\right)+I_{C 2}\left(t-\tau_{3}\right)\right)
\end{aligned}
$$

At and after Vbreakdown:

$$
\begin{aligned}
& i_{23}(t)+i_{21}(t)+i_{24}(t)+i_{2}(t)=0 \\
& e_{2}(t)=(-1110 / 43) \underbrace{\left(I_{B 2}\left(t-\tau_{2}\right)+I_{A 2}\left(t-\tau_{2}\right)+I_{C 2}\left(t-\tau_{3}\right)\right.}_{\text {linear part }}-i_{8}^{i_{8}}(t))
\end{aligned}
$$

This also can bo written in the following form:

$$
\theta_{2}(t)=\theta_{12}(t)-1110 / 43 i_{8}(t)
$$

Node 1:

$$
\begin{aligned}
& i_{12}(t)+i_{1}(t)+i_{17}(t)=0 \\
& (1 / 370) \theta_{1}(t)+I_{B 1}\left(t-\tau_{2}\right)+(2 c / \Delta t) \theta_{1}(t)+I_{C 2}\left(t-\tau_{3}\right)+ \\
& \quad(1 / 370) e_{1}(t)+I_{A 1}\left(t-\tau_{2}\right)=0 \\
& e_{1}(t)=(-1 /(2 / 370 * 2 C / \Delta t))\left(I_{B 1}\left(t-\tau_{2}\right)+I_{C 1}(t-\Delta t)+I_{A 1}\left(t-\tau_{2}\right)\right)
\end{aligned}
$$

Node 4:

$$
\begin{aligned}
& I_{42}(t)+I_{4}(t)+i_{40}(t)=0 \\
& (1 / 30) e_{4}(t)+I_{A 4}\left(t-\tau_{3}\right)+(2 c / \Delta t) e_{4}(t)+I_{B 4}(t-\Delta t)+ \\
& (1 / 5000)_{\theta_{4}}(t)=0 \\
& \theta_{4}(t)=(-1 /(1 / 30+2 c / \Delta t+1 / 5000))\left(I_{A 4}\left(t-\tau_{3}\right)+I_{B 4}(t-\Delta t)\right)
\end{aligned}
$$

Nodes 6 and 7:

$$
\begin{aligned}
& \theta_{6}(t)=-370 I_{A 6}\left(t-\tau_{2}\right) \\
& \theta_{7}(t)=-370 I_{B 7}\left(t-\tau_{2}\right)
\end{aligned}
$$


Considering the lightning surge characteristics, in flg. (39), current $1_{8}(t)$ can be determined in the following form:

$$
\begin{array}{ll}
i_{8}(t)=8 t & \text { for } 0<t \leqslant 1 \\
i_{8}(t)=(-4 / 49) t+396 / 49 & \text { for } 1<t<50
\end{array}
$$

The characteristic curve of the lightning arrester is plotted in fig. (41) by having 7 points given in characteristic of the lightning arrester. Equation of the line between each two points is as follows:

$$
\begin{array}{llrl}
e_{2}(t)=880 i_{2}(t) & \text { for } & 0 \leqslant e_{2}(t) \leqslant 440 \\
e_{2}(t)=370+140 i_{2}(t) & \text { for } & 440 \leqslant e_{2}(t) \leqslant 510 \\
e_{2}(t)=450+60 i_{2}(t) & \text { for } & 510 \leqslant \theta_{2}(t) \leqslant 540 \\
e_{2}(t)=480+40 i_{2}(t) & \text { for } & 540 \leqslant e_{2}(t) \leqslant 580 \\
e_{2}(t)=530+20 i_{2}(t) & \text { for } & 580 \leqslant \theta_{2}(t) \leqslant 590 \\
e_{2}(t)=560+10 i_{2}(t) & \text { for } & 590 \leqslant \theta_{2}(t) \leqslant 660
\end{array}
$$

Now consider equation (68) which is:

$$
e_{2}(t)=e_{I 2}(t)-(1110 / 43) \cdot 1_{8}(t)
$$

Let us find the intersection of this line with nonlinear segments of the lightning arrester as show in fig. (41).
1) $\left.i_{2}(t)=e_{L 2}(t) / 880+1110 / 43\right)$
for $i_{2}(t) \leqslant .5$
2) $i_{2}(t)=\left(e_{I 2}(t)-370\right) /(140+1110 / 43)$ for $i_{2}(t) \leqslant 1.0$
3) $i_{2}(t)=\left(\theta_{I 2}(t)-450\right) /(60+1110 / 43)$ for $i_{2}(t) \leqslant 1.5$
4) $i_{2}(t)=\left(\theta_{I 2}(t)-480\right) /(40+1110 / 43)$ for $i_{2}(t) \leqslant 2.5$
5) $i_{2}(t)=\left(e_{L 2}(t)-530\right) /(20+1110 / 43)$ for $i_{2}(t) \leqslant 3.0$
6) $i_{2}(t)=\left(\theta_{I 2}(t)-560\right) /(10+1110 / 43)$ for $i_{2}(t) \leqslant 10$

As was mentioned before, the system is linear up to voltage breakdown and therefore $e_{2}(t)=e_{I_{2}}(t)$. once. $\theta_{L_{2}}(t)$ reaches $v_{\text {breakdown }}$, $i_{2}(t)$ is computed by first equation derived from the intersection of linear equation and nonlinear segments as above. If the computed value 


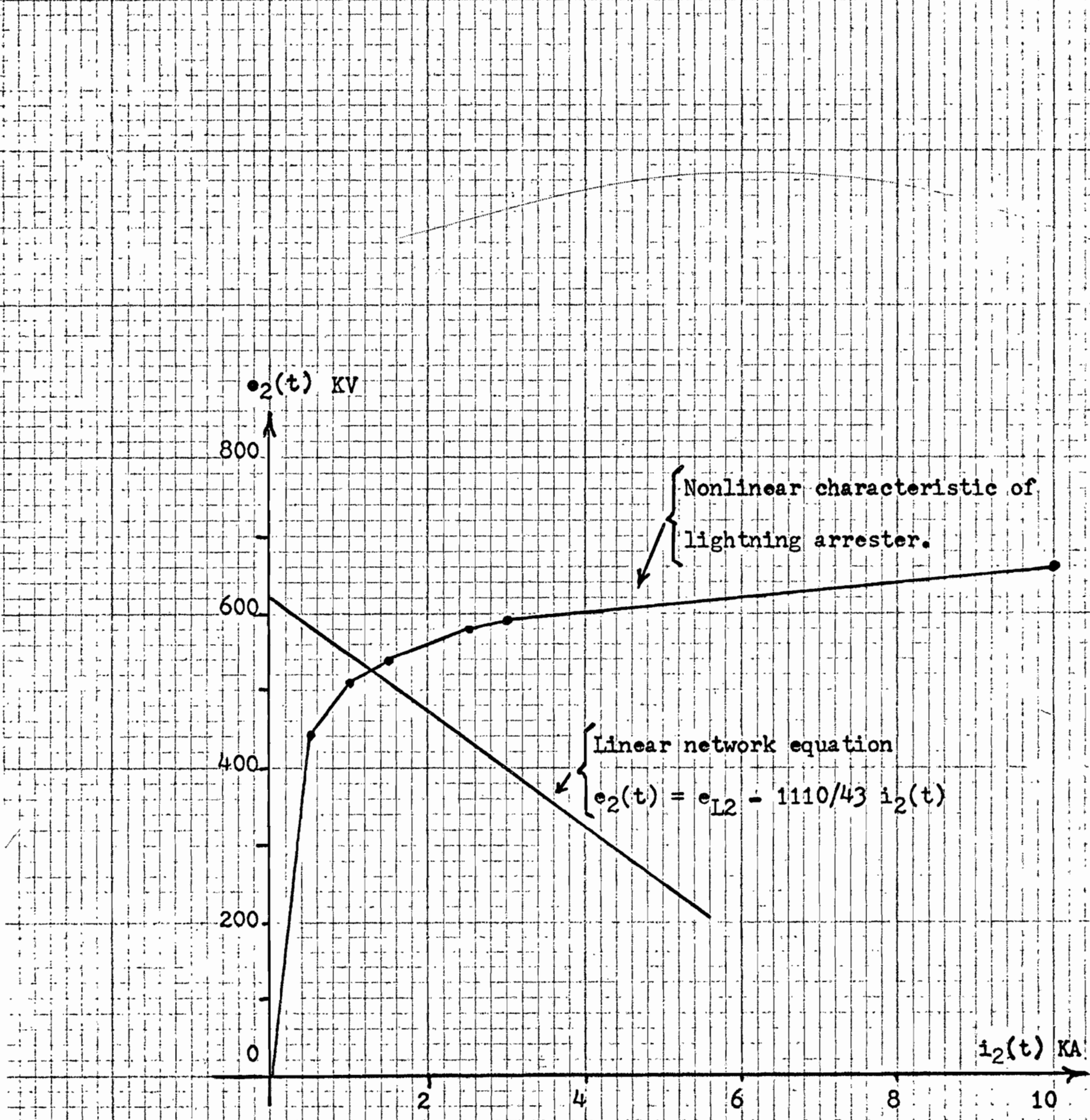

$1+1$

FIg. (41). Characteristic curvo of tho Ijghtning arrester. 
of $i_{2}(t)$ corresponds to the given value of $i_{2}(t)$, it is accepted, otherwise the next equation should be used. For example, if the first equation is used, the computed value of $i_{2}(t)$ is $6 \cdot 5, i_{2}(t)$ is accepted, otherwise the second or further equations should be used. The same procedure should be followed for all equations until the computed value of $i_{2}(t)$ meets the corresponding equation condition.

Once an accepted computed $i_{2}(t)$ is found, $\theta_{2}(t)$ can be computed by equation (67). For the next step the same procedure is used and $\theta_{2}(t)$ does not have to reach or to be more than voltage breakdown, because after Voreakdown the lightning arrester still discharges current.

The past history currents $I_{A 8}, I_{B 3}, I_{A 3}, I_{A 2}, I_{B 1}, I_{A 1}, I_{A 1}, I_{C 1}$, $I_{A 6}, I_{A 4}$, and $I_{B 7}$ are computed by means of equations $(35),(37)$, and (56).

Now all equations are set and we are ready to write a digital computer program.

Let us define the symbols used in the program.

$$
\begin{aligned}
& D=\Delta t \\
& T 1=\text { maximum time } \\
& C 1 \text { and } C=\text { capacitance } \\
& E(8, I)={ }_{8}(t) \\
& E(2, I)=\theta_{2}(t) \\
& \cdot \cdots \\
& A(8, I)=I_{A 8}(t) \\
& B(3, I)=I_{B 3}(t) \\
& C(2, I)=I_{C 2}(t)
\end{aligned}
$$




$$
\begin{aligned}
& R(8, I)=i_{83}(t) \\
& P(3, I)=i_{38}(t) \\
& I 8=i_{8}(t) \\
& I 2=i_{2}(t)
\end{aligned}
$$

I is a reference for first nonlinear computed $e_{2}(t)$.

A flow chart and digital computer program are on the next page. 


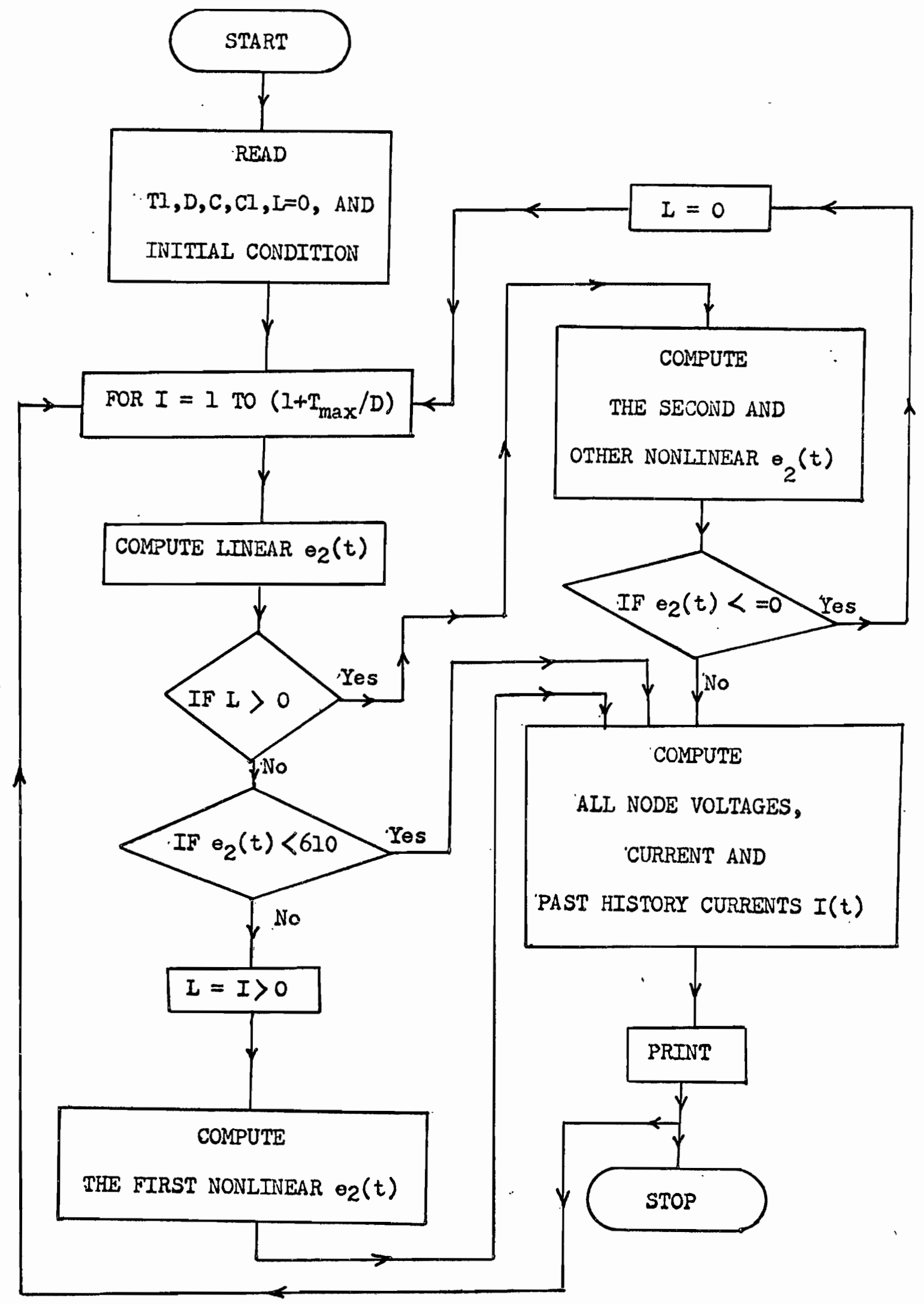


81

\section{Computer program:}

$100 \operatorname{DIM} E(8,100), A(8,100), B(8,100), C(8,100)$

$105 \operatorname{DIM} R(8,100), P(8,100), Q(8,100)$

110 READ TI,D

120 READ $C, C 1$

$130 \operatorname{READA}(8,1), R(8,1), B(3,1), P(3,1), \cap(3,1), R(3,1), B(4,1)$

$140 \operatorname{READ} C(3,1), A(3,1), B(2,1), P(2,1), R(2,1), Q(2,1), Q(4,1)$

$150 \operatorname{READ} C(2,1), A(2, I), B(1, I), P(1,1), Q(1, I), R(1, I), P(4, I)$

$160 \operatorname{READ} A(1,1), C(1,1), B(7,1), P(7,1), P(6,1), A(6,1), A(4,1)$

165 PRINT "TIME", "VOLTAGE AT 4", "VOLTAGE AT 8","DISCHARGE CURRENT AT 2" 166 PRINT

$170 \mathrm{~L}=0$

$180 \mathrm{II}=1+\mathrm{T} I / \mathrm{D}$

190 FOR $I=2$ TO II

$200 \mathrm{~T}=\mathrm{D} *(I-I)$

210 IF T $>1$. THEN 240

$220 \mathrm{I} 8=8 * \mathrm{~T}$

230 GO TO 250

$240 I 8=-(4 / 49) * T+396 / 49$

$250 \mathrm{~K}=\mathrm{I}-\mathrm{II}$

$260 \mathrm{~N}=\mathrm{I}-\mathrm{I}$

$270 M=I-10$

280 IF T) 1. THEN 320

$290 \mathrm{~K}=1$

$300 \mathrm{~N}=1$ 
$310 M=1$

$320 E(8, I)=(370 / 2) *(I 8-A(8, K))$

$330 E(3, I)=(-370 / 3) *(B(3, K)+\mathrm{A}(3, N)+C(3, N))$

$340 \mathrm{P}(3, I)=(1 / 370) * E(3, I)+B(3, K)$

$350 \mathrm{~A}(8, I)=-(1 / 370) * E(3, I)-P(3, I)$

$360 R(8, I)=(I / 370) * E(8, I)+A(8, K)$

$370 B(3, I)=-(1 / 370) * E(8, I)-R(8, I)$

$380 E(2, I)=(-1] 10 / 43) *(B(2, N)+A(2, N)+C(2, M))$

390 IF L > 0 THEN 420

400 IF $E(2, I)<610$ THEN 660

$410 \mathrm{~L}=1$

$420 I 2=E(2, I) / 880+1110 / 43)$

430 IF $12>.5$ THEN 450

440 GO TO 580

$450 I 2=(E 2, I)-370) /(140+1110 / 43)$

460 IF I2 $>1$. THEN 480

470 GO TO 580

$480 I 2=(E(2, I)-450) /(60+1210 / 43)$

490 IF I2>1.5 THEN 510

500 GO TO 580

$510 I 2=(E(2, I)-480) /(40+1110 / 43)$

520 IF I $>2.5$ THEN 540

530 GO TO 580

$540 I 2=(E(2, I)-530) /(20+1110 / 43)$

550 IF I2 $>3$. THEN 570

560 GO TO 580 
$570 I 2=(E(2, I)-560) /(10+1110 / 43)$

- $580 E(2, I)=(-1110 / 43) *(B(2, N)+A(2, N)+C(2, M)+I 2)$

590 IF $E(2, I)>.0$ THEN 660

$600 \Sigma=0$

610 GO TO 390

$660 P(2, I)=(I / 370) * E(2, I)+B(2, N)$

$670 \mathrm{~A}(3, I)=-(I / 370) * \mathrm{E}(2, I)-\mathrm{P}(2, I)$

$680 R(3, I)=(I / 370) * E(3, I)+A(3, N)$

$690 B(2, I)=-(I / 370) * E(3, I)-R(3, I)$

$700 \mathrm{E}(6, I)=-370 * \mathrm{~A}(6, \mathrm{~N})$

$710 \mathrm{Q}(3, I)=(I / 370) * \mathrm{E}(3, \mathrm{I})+\mathrm{C}(3, \mathrm{~N})$

$720 \mathrm{~A}(6, I)=-(I / 370) * \mathrm{E}(3, I)-Q(3, I)$

$730 P(6, I)=(I / 370) * E(6, I)+A(6, N)$

$740 \mathrm{C}(3, I)=-(I / 370) * E(6, I)-P(6, I)$

$750 E(4, I)=(-I /(I / 30+2 * C / I E-7+I / 5000)) *(A(4, M)+B(4, N))$

$760 P(4, I)=(I / 30) * E(4, I)+\mathrm{A}(4, M)$

$770 \mathrm{C}(2, I)=-(I / 30) * \mathrm{E}(4, I)-P(4, I)$

$780 Q(2, I)=(I / 30) * E(2, I)+C(2, M)$

$790 \mathrm{~A}(4, I)=-(I / 30) * \mathrm{E}(2, I)-Q(2, I)$

$800 Q(4, I)=(2 * C / I E-7) * E(4, I)+B(4, N)$

$810 \mathrm{~B}(4, I)=-Q(4, I)-(2 * \mathrm{C} / \mathrm{IE}-7) * \mathrm{E}(4, I)$

$820 E(I, I)=(-1 /(2 / 370+2 * C I / I E-7)) *(B(I, N)+C(I, N)+A(I, N))$

$830 P(I, I)=(I / 370) * E(I, I)+B(I, N)$

$840 \mathrm{~A}(2, I)=-(I / 370) * E(I, I)-P(I, I)$

$850 \mathrm{R}(2, I)=(I / 370) E(2, I)+\mathrm{A}(2, \mathrm{~N})$

$860 \mathrm{~B}(I, I)=-(I / 370) * E(2, I)-R(2, I)$ 
84

$870 Q(2, I)=(2 * C 1 / 1 E-7) * E(1, I)+C, N)$

$$
\begin{aligned}
& 880 \mathrm{C}(1, I)=-Q(1, I)-(2 * C I / I E-7) * E(1, I) \\
& 890 \mathrm{E}(7, I)=-370 * B(7, N) \\
& 900 \mathrm{P}(7, I)=(I / 370) E(7, I)+B(7, N) \\
& 910 \mathrm{~A}(I, I)=-(1 / 370) * E(7, I)-P(7, I) \\
& 920 \mathrm{R}(I, I)=(I / 370) * E(I, I)+A(I, N) \\
& 930 \mathrm{~B}(7, I)=-(I / 370) * E(I, I)-R(I, I)
\end{aligned}
$$

940 PRINT T,E(4,I),E(8,I),I2

950 NEXT I

960 DATA 8,.1

970 DATA IE-9,4.4E-9

$980 \mathrm{DATA} .0, .0, .00, .0, .0, .0, .0$

$985 \mathrm{DATA} .0, .0, .0, .0, .0, .0, .0$

990 DATA $.0, .0, .0, .00, .0, .0, .00$

995 DATA $.0, .0, .0, .0, .0, .00, .0$

999 END

The result is printed on the next page. 
TiviF.

- 0.1

0. .

i). 3

0.1

0.5

0.6

0.7

0.3

0.9

1

l. 1

1.?

1. 3

1. 4

1. 5

i. 6

1. 7

1.8

1.9

2

$2 \cdot i$

$2 \cdot ?$

$2 \cdot 3$

2.4

2.5

2.6

2.7

2.8

2.9

3

$3 \cdot i$

$3 \cdot 2$

$3 \cdot 3$

.3. 4

$3 \cdot 5$

3.6

3. 7

3. 8

3.9

4

$4 \cdot 1$

$4 \cdot 2$

$4 \cdot 3$

1.4

$4 \cdot 5$

$4 \cdot 6$

4. 7

$4 \cdot 8$

4.9

5

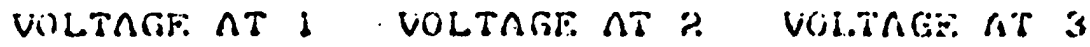

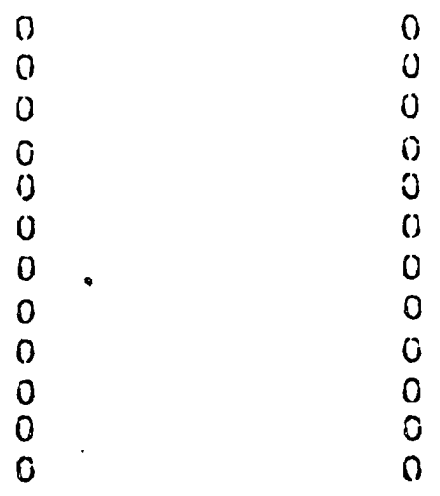

0.796727

3.09469

8.17i8i

17.1702.

$30 \cdot 5749$

48.6826

$71 \cdot 2459$

97.8337

127.88

160.689

194.686

$228 \cdot 379$

259.62

$286.417 \%$

307.718

$322 \cdot 1149$

330.441

$331 \cdot 831$

327.052

316.82

$302 \cdot 355$

286.1432

$271 \cdot 456$

260.767

$2.56 \cdot 943$

261.231.

274.619

297.042

$328 \cdot 2.48$

367.519

$413 \cdot 735$

464.032

515.914 .

565.884

611.293

650.716

683.037
0

0

0

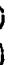

0

0

0

0

0

13.76714

$27.53 / 9$

$52.6,106$

77.9137

95.7314

$114 \cdot 2.67$

127.957

142.908

159.182

177.105

182.25

$18 \% .2 .12$

104.665

181.6188

$-186 \cdot 377$

191.829

202.553

2.13 .011

222.078

229.999

242.073

274.432

$304 \cdot 268$

347.879

382.989

101.608

423.078

435.337

453.264

472.31

490.177

487.468

491.87

4) 81.781

$484 \cdot 684$

504.415

$52 / 137.3$

553.991
0
0
0
0
0
0
0
0
0
0
0

98.6667

$19 \% .333$

3) 5.178

413.023

1106.036

399.183

$391 \cdot 8411$

$385 \cdot 1$ i 3

408.147

433.054

355.806

280.291

187.119

95.8327

121.981

149.782

180.961

213.013

214.599

215.938

218.74

220.308

$2.33 \cdot 574$

$260 \cdot 281$

287.287

337.1111

370.146

408.871

437.549

4411.406

$454 \cdot 8.18$.

4611.731

479.084

458.67

499.065

407.212

487.314

$490.54 \%$

$502 \cdot 323$ 
TIME

$5 \cdot 1$

$5 \cdot 2$

$5 \cdot 3$

5.4

$5 \cdot 5$

$5 \cdot 6$

$5 \cdot 7$

5.8

$5 \cdot 9$

6

$6 \cdot 1$

$6 \cdot 2$

$6 \cdot 3$

6.4

$6 \cdot 5$

6.6

0.7

E. 8

6.9

7

$\% \cdot 1$

7.2

7.3

$7 \cdot 4$

$7 \cdot 5$

$7 \cdot 6$

$7 \cdot 7$

$7 \cdot 8$

$7 \cdot 9$

8

VOLTAGE AT 1 VOLTAGE AT 2 VOLTAGE AT 3

579.998

604.708

569.382.

5811.556

599.1194

007.914

617.804

622.544

$621 \cdot 226$

625.106

625.315

624.938

625.452

623.154

618.682

615.56

612.78

613.197

619.353

623.485

631.564

637.167

637.983

616.838

$625 \cdot 272$

$623 \cdot 342$

622.709

$621 \cdot 63$

623.038

625.572
539.173

569.782

604.02 .1

594.725

509.091

585.296

$589.31 \%$

609.243

613.248

628.895

$631 \cdot 302$

$625 \cdot 919$

624.919

620.186

. 617.6

616.755

613.476

61.0 .219

609.278

611.81

615.936

626.512

$633 \cdot 315$

638.401

626.664

629.305

$611 \cdot 654$

615.16

617.066

$6 ! 6 \cdot 703$ 
TIME:

0.1

0.0

0.3

$0 \cdot$ it

0.5

0.6

0.7

0.8

0.9

1

$1 \cdot 1$

$1 \cdot 2$

1. 3

1.4

i. 5

1.6

1. 7

1.8

1.9

2

2. 1

$2 \cdot 2$

2. 3

2. 4

2. 5

a. 6

2. 7

2. 8

?. 9

;

3. 1

3.2

$3 \cdot 3$

$3 \cdot 4$

3.5

$3 \cdot 6$

3. 7

3.8

3.9

4

1] 1

1. 2.

11.3

1.1 .1

1. 5

1. 6

4.7

4.8

$4 \cdot .9$

5

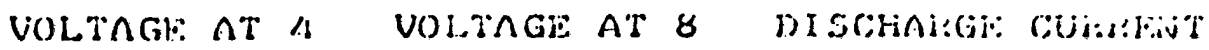

$1 / 18$

?ง

$1 / 11$

59?

$74 i j$

888

1036

1184

13.32

1430

1478.49

1476.98

1475.47

1473.96

$1472 \cdot 45$

$1470 \cdot 94$

1469.43

$146 \% .92$

11166.11

$14640^{\circ} 9$

1463.39

1401.88

1411.03

1360.19

1318.53

1276.86

1120.36

964.004

215.818

247.09

274.85 ?

306.719

$341 \cdot 219$

361.247

$371 \cdot 2.7$

$371 \cdot 743$

$362 \cdot 203$

$366 \cdot 747$

378.277

395.506

417.529

136.277

452.693

469.236

496.023

526.961

557.21

585.594

596.603

601.359

604.312
80) $7 \cdot-147$

650.909

524.733

394.839

3a. 581

247.060

153.895

$62.608 ?$

88.7566

116.558

147.737

179.788

181.375

182.714

185.515

$18 \% .084$

$200 \cdot 649$

2.7 .056

254.062

304.187

342.922

375.6116
Ail ?

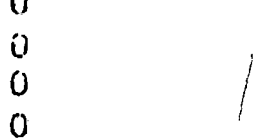


TINE

VOLTAGE AT 4

VOLTAGE AT 8

DISCHARGE CURRENT

AT 2

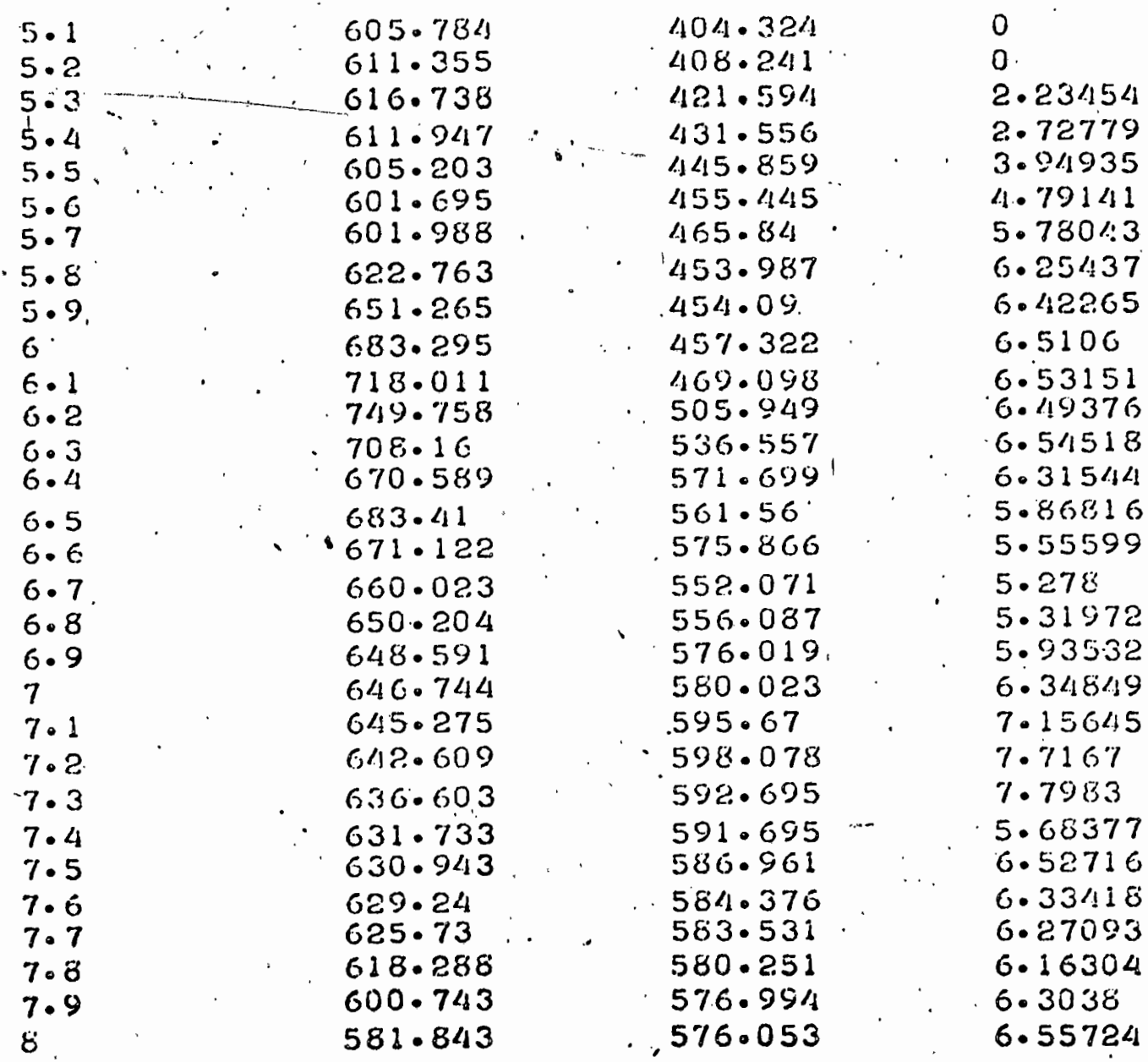

The curves are show on noxt pageo 


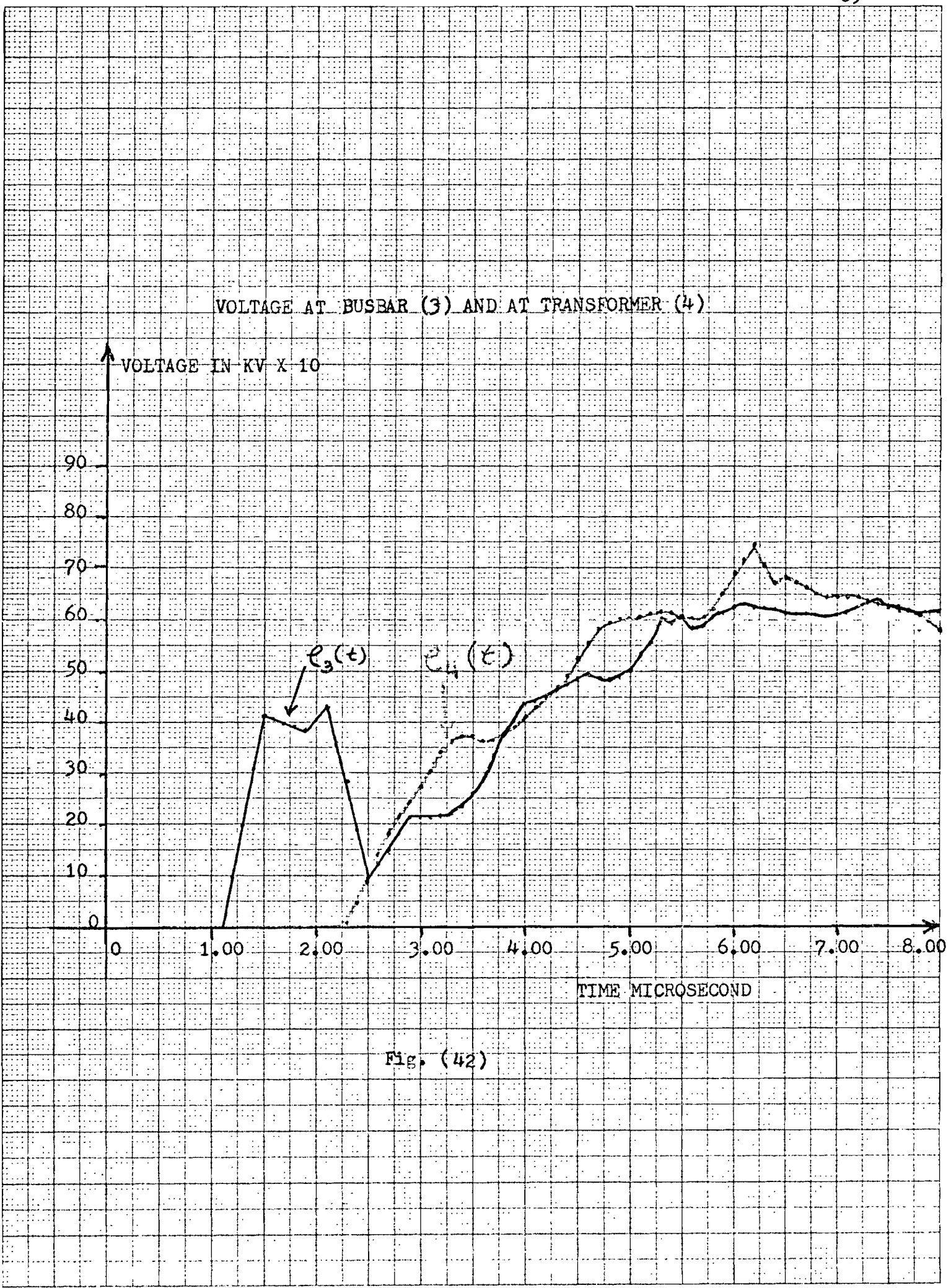




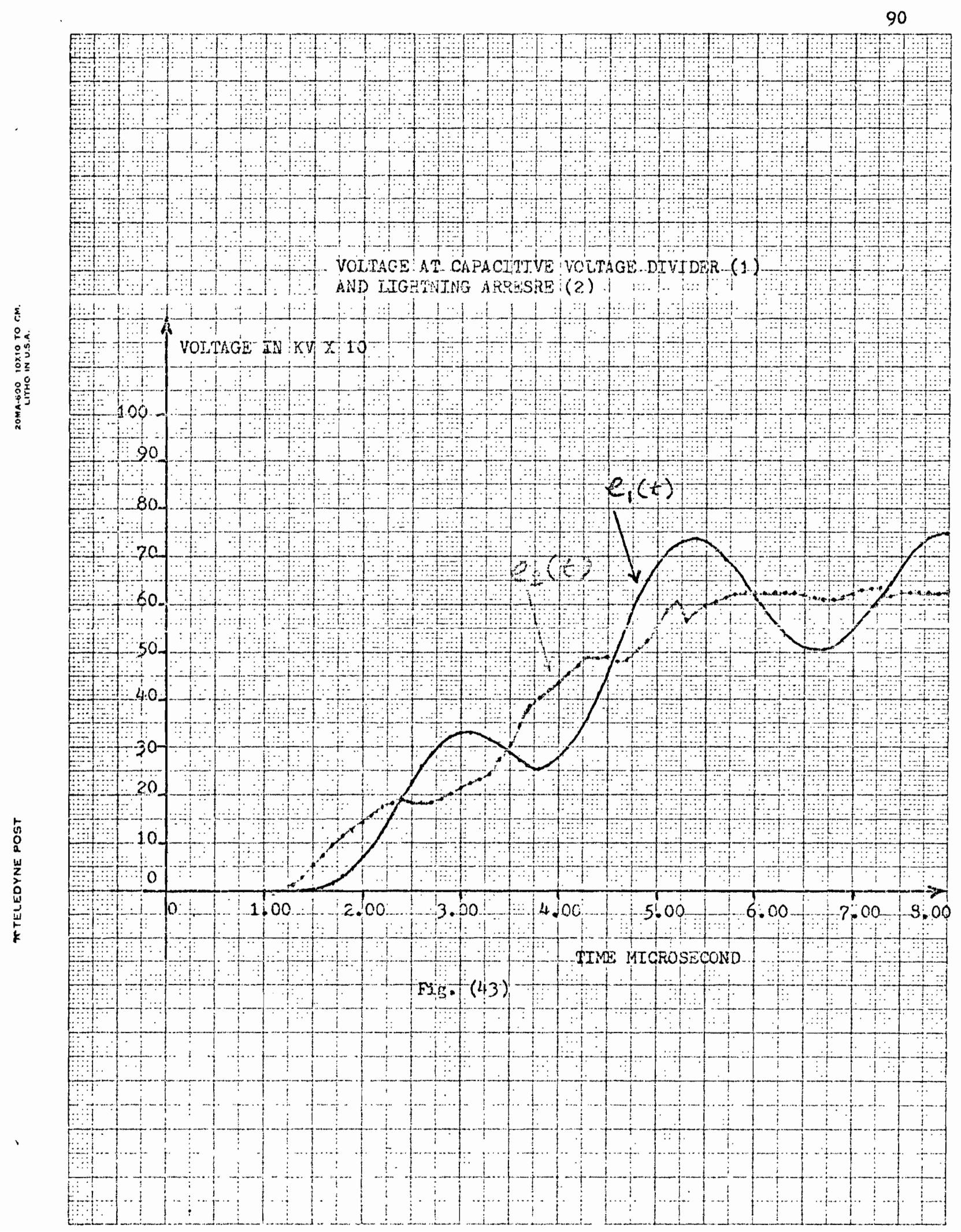




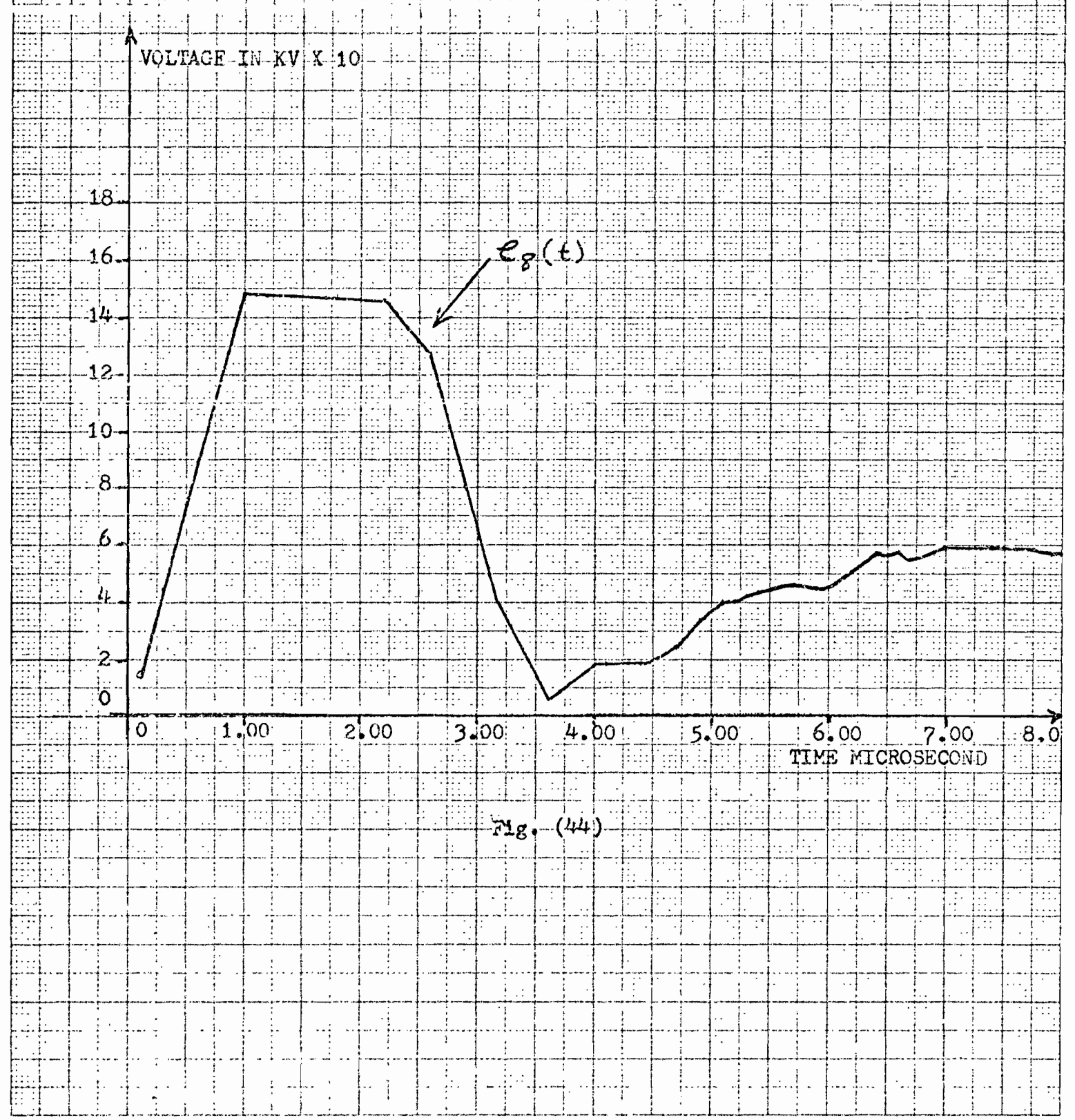




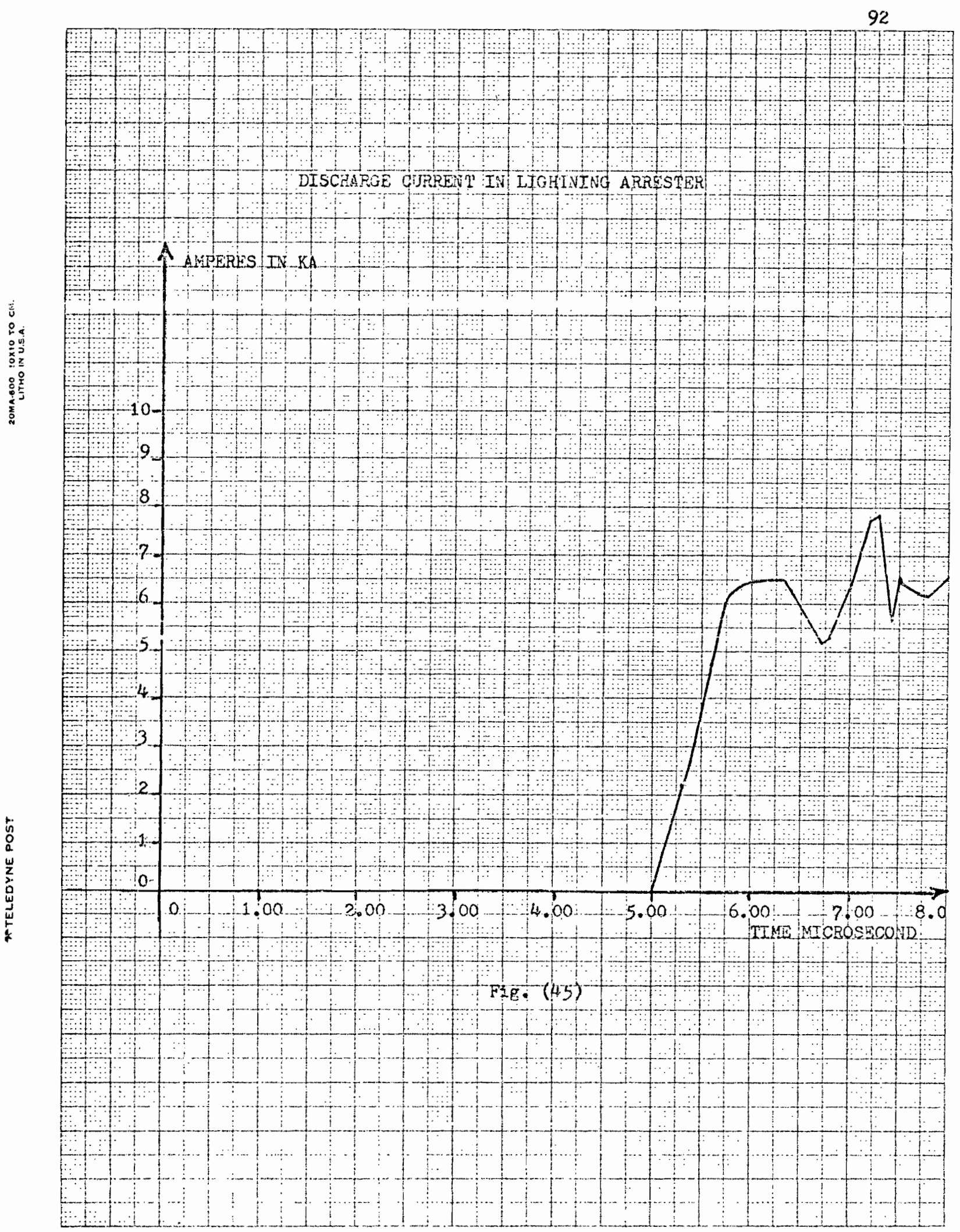




\section{Past History Current I}

In the last three examples, we saw that the past history plays an important role in digital computer solution. For each step of time the equivalent current source I has to be recorded in order to build $I_{\text {total }}$ for the next step and for each inductance and capacitance, we need to know $I_{a, b}(t-\Delta t)$. This requires a double list of $I_{a}$ and $I_{b}$. Now if the currents in equations (50) and (55) be expressed by equations (49) and $(55)$, respectively, we may find an equation describing $I_{a, b}(t-\Delta t)$ in a form in which I may be computed faster.

Let us write (49) and (50) again for the sake of convenience.

$$
i_{a, b}(t)=(\Delta t / 2 L)\left(e_{a}(t)-e_{b}(t)\right)+I_{a, b}(t-\Delta t)
$$

and at time $(t-\Delta t)$ equation (69) can be written in the form of:

$$
i_{a, b}(t-\Delta t)=(\Delta t / 2 L)\left(e_{a}(t-\Delta t)-e_{b}(t-\Delta t)\right)+I_{a, b}(t-2 \Delta t),
$$
equation (50) is:

$$
I_{a, b}(t-\Delta t)=i_{a, b}(t-\Delta t)+(\Delta t / 2 L)\left(e_{a}(t-\Delta t)-e_{b}(t-\Delta t)\right) .
$$

Find $i_{a, b}(t-\Delta t)$ from equation $(50)$ and substitute in equation (69) and reorder it; we have:

$$
I_{a, b}(t-\Delta t)=I_{a, b}(t-\Delta t)+2(\Delta t / 2 I)\left(e_{a}(t-\Delta t)-e_{b}(t-\Delta t)\right)
$$

Similarly, equations (55) and (56) give:

$$
I_{a, b}(t-\Delta t)=-I_{a, b}(t-2 \Delta t)-2(2 c / \Delta t)\left(\theta_{a}(t-\Delta t)-\theta_{b}(t-\Delta t)\right)
$$

Equations (70) and (71) could be written in a general form as follows:

$$
I_{a, b}(t-\Delta t)= \pm\left(I_{a, b}(t-2 \Delta t)+2 H(t)\right) \text {. }
$$

Where:

+ is for inductance

- is for capacitance

$$
\begin{aligned}
& H(t)=(\Delta t / 2 L)\left(e_{a}(t-\Delta t)-e_{b}(t-\Delta t)\right) \text { for inductance } \\
& H(t)=(2 c / \Delta t)\left(e_{a}(t-\Delta t)-e_{b}(t-\Delta t)\right) \text { for capacitance }
\end{aligned}
$$




\section{Accuracy}

Since approximation is made by trapezoidal rule of integration for lumped parameters, there is some error in computing voltage and current. However, as long as $\Delta t$ is selected sufficiently small, the orror in practice is completely ignorable. The result obtained by trapezoidal method is adequate for the purpose of digital computer solution. Compared with other methods, the approximation is more or as accurate as other alternative methods. As long as the oscillation of highest frequency is represented by sufficient number of points, the selection of $\Delta t$ is not too important.

Before we draw our conclusion, it would be a good idea to discuss Laplace transformation technique of the solution of electromagnetic transient or steady state in a circuit. This will show the advantages and disadvantages of both techniques.

\section{LAPIACE TRANSFORMATION TECHNIQUE}

Differential equations have been used traditionally to describe engineering and physical problems particularly in the electrical field. Since a general solution is not always avallable for differential equations, the Laplace transformation is a mathematical tool that greatly facilitates the solution of constant-coefficient linear differential equations. By Laplace transformation, a differential equation can be transferred into relatively simple algebraic equations. The complete solution of the original differential equation is obtained by transformation back. 
Laplace transformation eliminates the independent variable in differential equations and operator s takes its place. The s operator is a complex quantity and may be handled algebraicaliy in an equation.

The transformation from the real independent variable domain to the s complex variable domain is obtained by integration of the differential equation as follows:

By definition the Laplace transformation integral is:

$$
F(s)=\int_{0}^{\infty} e^{-s t} f(t) d t=\mathscr{L} f(t)
$$

where $s$ is called Laplace operator, $f(t)$ is a known function and $F(s)$ is the Iaplace form of function $f(t)$.

The inverse transformation or transformation back from s domain to the $t$ dornain is:

$$
f(t)=(1 / 2 n j) \oint F(s) e^{s t} d s
$$

of course there are numbers of books which describe the Laplace transformation and its tables to which the reader may refer for more information.*

In order to compare the first method with the Iaplace transformation technique, an example is illustrated on the next page.

Laplace transformation result is shown in figs. (47), (48), and (49). The digital computer solution result is shown in fig. (50). The two results are fairly similar to each other; the difference could be considered as the approximation used in computing voltage and current in both Iaplace and digital comouter methods. The two results are individually accepted for practical purposes.

* Foyd E. Nixon, Handbook of Laplace Transformation, $2 d$ od. (Englewood Cliffs, N. J.: 1965), pp. 21-44. 
Test case No. 4

Consider the two $R$ - I - C branches shown below. This is similar to the example of test case No. 2 with only two branches.

Let us find voltage at node 2 .

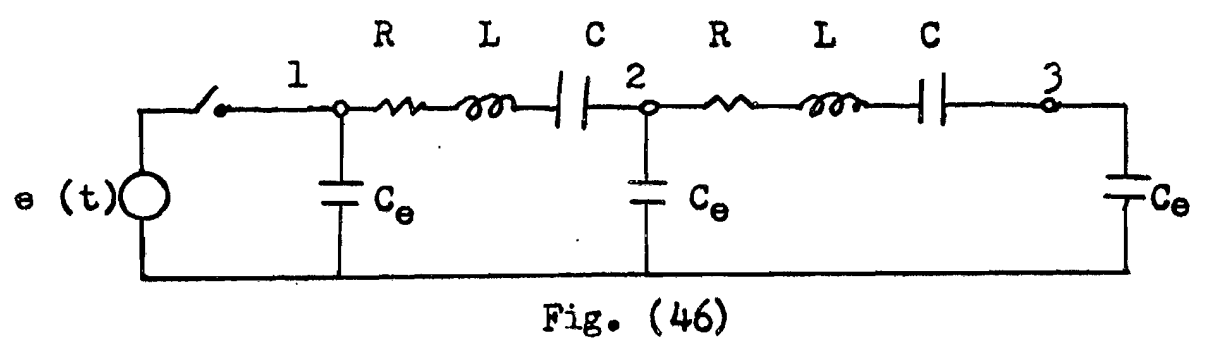

Given:

$$
\begin{aligned}
& \theta_{I}(t)=1.0 \text { for } t>0 \\
& \theta_{1}(t)=0 . \text { for } t \leqslant 0 \\
& R=1 \\
& I=.5 \mathrm{rH}_{\mathrm{H}} \\
& C=15 \mathrm{nF} \\
& C_{\Theta}=10 \mathrm{PF} \\
& t=1 \mathrm{~ns} .
\end{aligned}
$$

Solution:

First each element of the circuit is written in the Laplace transformation form, which is replaced in the circuit and then the voltage is found in $\mathbf{s}$ domain.

In Laplace transformation form each element is written as follows:

$$
\begin{aligned}
& \mathrm{C}: \longrightarrow \mathrm{I} / \mathrm{sC} \\
& \mathrm{I} \longrightarrow \mathrm{sL}
\end{aligned}
$$




$$
\begin{aligned}
& \mathrm{R} \longrightarrow \mathrm{R} \\
& \mathrm{C}_{\boldsymbol{\theta}} \longrightarrow 1 / \mathrm{sC}_{\boldsymbol{\theta}}
\end{aligned}
$$

Let the following symbols be assigned for the sake of convenience:

$$
\begin{aligned}
& A=(R+s L+1 / s C) \\
& B=\left(1 / s c_{e}\right)
\end{aligned}
$$

then voltage $e_{2}(t)$ is found as follows:

$$
\begin{gathered}
\theta_{2}(s)=e_{1}(s)(B(A+B)) /\left(A B+(A+B)^{2}\right) \\
=\theta_{1}(s) \cdot C\left(L C C_{\theta} s+R C C_{\theta} s+C+C_{\theta}\right) /\left(C C_{\theta}\left(I C s^{2}+R C+1\right)+\left(I C C_{\theta} s^{2}+\right.\right. \\
e_{1}(s)=1 / s
\end{gathered}
$$

then

$$
\begin{array}{r}
\theta_{2}(s)=(1 / s)\left(2.10^{17} s^{2}+4.10^{23} s+4.10^{34}\right) /\left(s^{4}+4.10^{6} s^{3}+\right. \\
\left.6.0027 .10^{17} s^{2}+12.10^{23} s+4.10^{34}\right)
\end{array}
$$

The roots of the polynomial of denominator are found by digital computer. Thus $e_{2}(s)$ can be written in the following form: $\theta_{2}(s)=1 / s-.3619499 /\left(s+999406-j 2.763 .10^{8}\right)-.3619599 /(s+999406+$ $\left.j 2.763 .10^{8}\right)-.131522 /\left(s+1.00059 .10^{6}-j 7.2382 .10^{8}\right)-.131522 /(s+$ $\left.1.00059 \cdot 10^{6}+7.2382 \cdot 10^{8}\right)$.

By Inverse Laplace transformation and having:

$$
e^{ \pm j a}=\cos a \pm j \operatorname{Sin} a
$$

$e_{2}(s)$ can be written in $t$ domain as follows:

$e_{2}(t)=1-.724 e^{-999406 t} \operatorname{Cos}\left(2.763 .10^{8} t\right)-.276 \theta^{-10^{6} t} \operatorname{Cos}\left(7.2382 .10^{8} t\right)$

In order to be able to compare the Iaplace transformation technique with the digital computer method by use of trapezoidal rule of integration, the above example has been solved by both techniques. 
Result of Laplace Transformation Tochnique

TIME

$1)$

$1 \cdot 1-y$

$2 \cdot n-y$

$\because \cdot \because \cdots-\cdots$

1.

$5 \cdot \vec{F}-9$

G. $F-9$

$7 \cdot 5-9$

$\mathcal{B} \cdot[-\mathrm{C}-\mathrm{Y}$

9.F.-9

1. $F-r$

$1 \cdot 1 F-8$

1. $2 E-8$

1. $3 F-8$

1. $4 \mathrm{E}-8$

1. $5 E-8$

1. $65-8$

1. $7 E-8$

1. $8 \pi-8$

1.9E- 8

2. $E-8$

2. $1=-8$

2. 2E-8

2. $3 E-8$

?. $4 \pi-8$

2. $5 F-8$

2. $6 E-8$

$\because 7 \bar{\square}-8$

2. $8 F-8$

c. $95-8$

3. $5-8$

3. $1 \mathrm{~F}-8$

$\therefore-2 \overline{-}-8$

3. $3 E-6$

3. $A \mathrm{E}-6$

3. $5 \mathrm{E}-8$

$3 \cdot 6 E-8$

3. $7 E-8$

3. $8 E-8$

3. $9 E-8$

4. $F-8$

1. $1 F-B$

$4 \cdot 2 E-8$

$4 \cdot 3 E-8$

$4 \cdot 4 \mathrm{E}-8$
VOLTAGE AT NODE 2

0

0.097563

0.351156

o. co.7500

0. $919: 3 \% 7$

$1 \cdot 10838$

$1 \cdot 16165$

1. 16043

1.1875

1. 30286

1. 5083.3

1. $\% 117 t$

1.90613

$1: 91578$

1. 74019

1. 42101

1.05462

0.748648

0.573778

0.534704

0.571165

0.607547

0.570199

0.453382

0.310584

0.230949

0.293178

0.523126

0.876582

1. 25612

1. 55393

1. 69963

1. 68944 .

1. 5828

1.46836

1. 41692

1.44501

1.50745

1. 52252

1.4168

1. 16697

0.817207

0.463112

0.209731

0.124401 
TINE

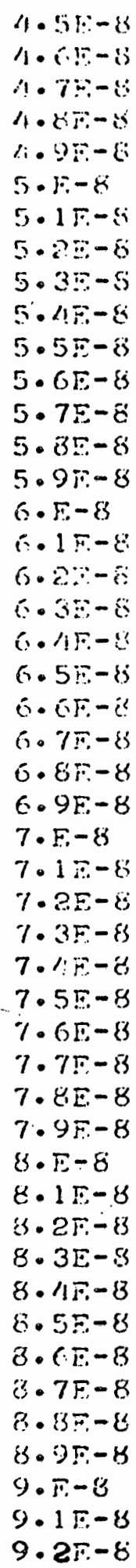

VOLTAGE AT NODE 2

0.207505

0. 395809

0.545186

0.729149

0.773219

$0.76,57857$

0.733112

$0.8 \% 5772$

1.1273

1.43639

i. 73209

1.91461

1. 92167

1. 75754

1.19016

1. 21822

1.02 .431

0.937728

0.925065

0.912868

0.830571

0.651639

0.1111900

0.195555

9. $55559 E .-2$

0.16819

0.404105

0.732339

1.04986

1. 2.1103

1. 36,357

1. 35896

1.33069

1. 35196

1.4546

1. 60999

1. 74183

1. 76437

1. 62691

1. 3422

0.984221

0.6562 .35

0.1141182

0.382401

0.436660

0.531656

0.584552

0.571909 


\section{TIME}

$$
\begin{aligned}
& 9 \cdot 3 F-8 \\
& 9 \cdot 1:-83 \\
& 9 \cdot 5 F-83 \\
& 9 \cdot 6 F-83 \\
& 9 \cdot 7 F-81 \\
& 9 \cdot 85-85 \\
& 9 \cdot 95-8 \\
& 1 \cdot 5 \cdot-7
\end{aligned}
$$

\section{VOLTAGE AT NODE 2}
0.499518
0.1110934
0.475559
0.650015
0.9199963
1. 30183
1.60396
1.7719

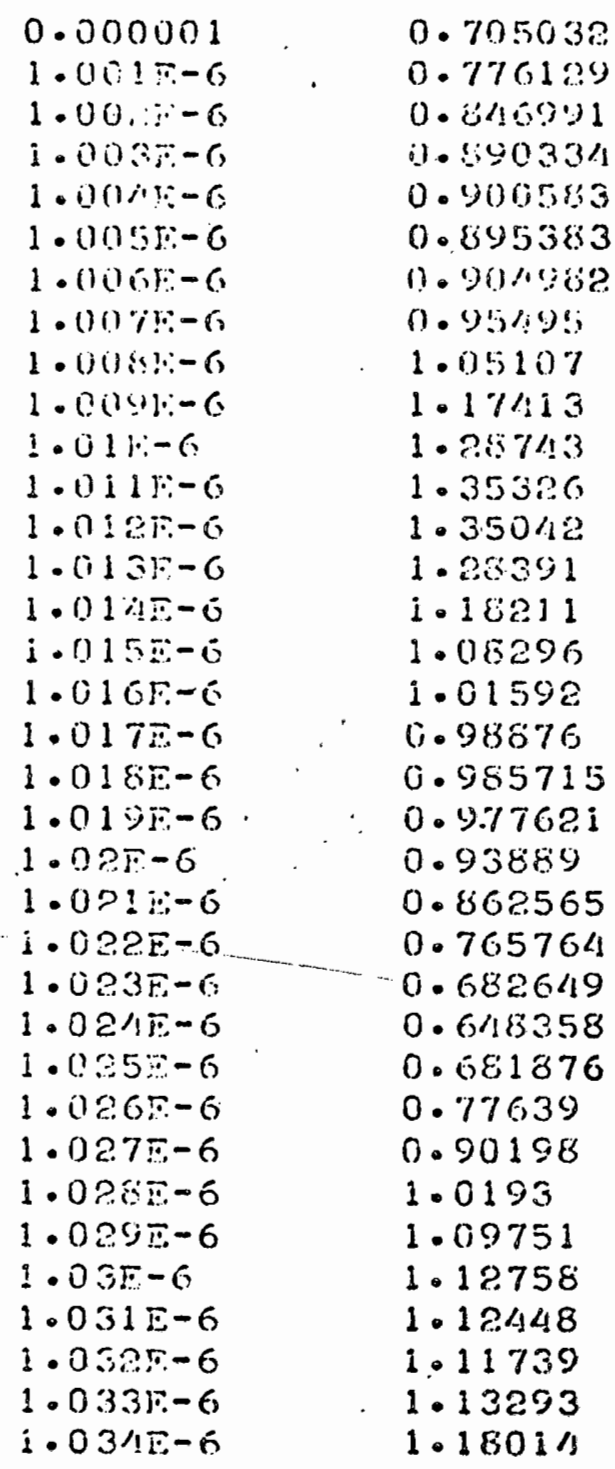


VOLTAGE AT NODE 2

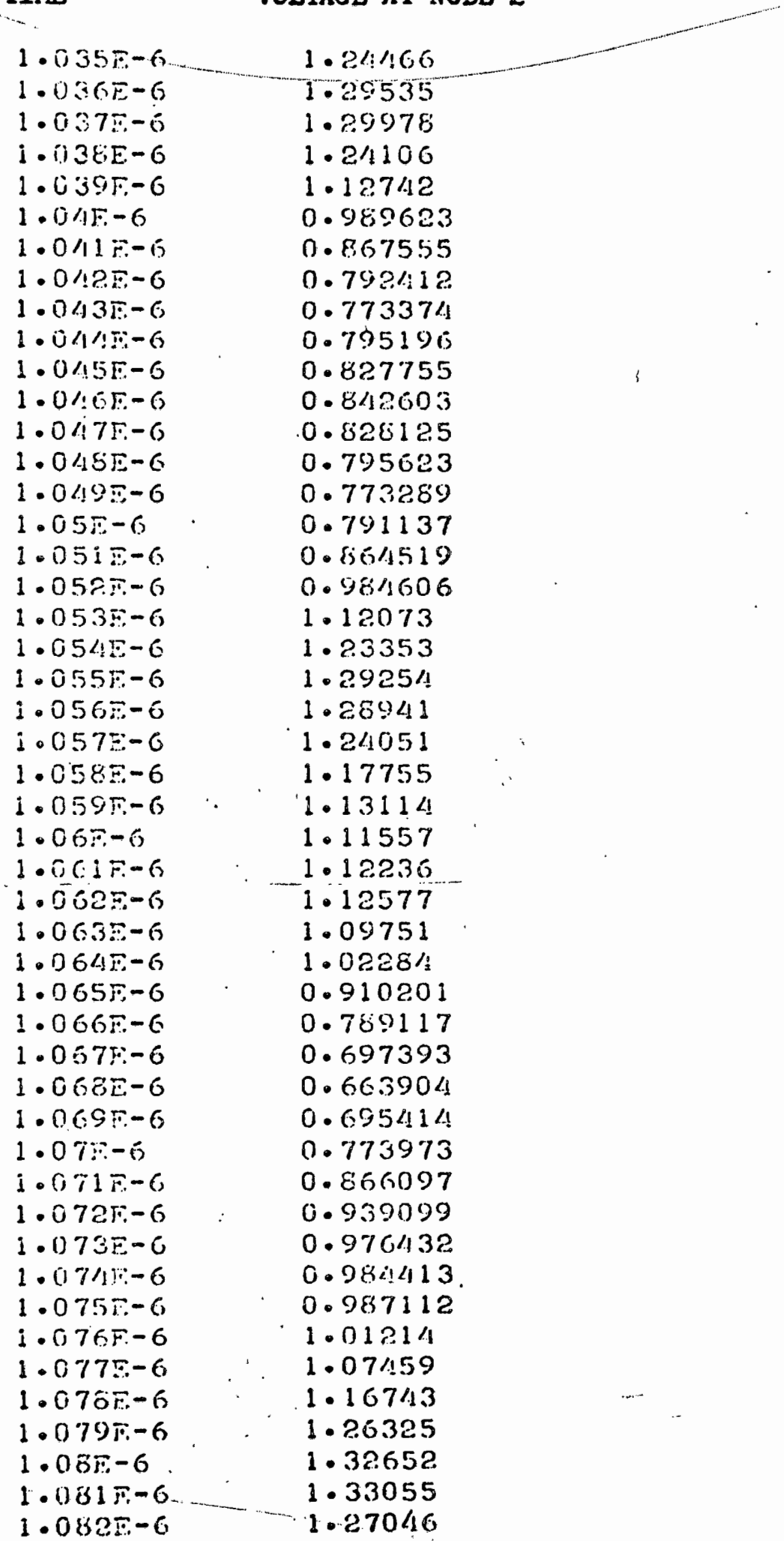


Result of Dlgital Computer Technique

TIME

()

1. $m-9$

a. $:-?$

$3 \cdot 5-9$

1.

$5 \cdot[-?$

6.

$7 \cdot 5-3$

$8 \cdot 5-9$

9. $\pi \cdot-9$

1. $F-\varepsilon^{\prime}$

1.1 $\bar{E}-8$

1. $2 \pi-4$

$1 \cdot 3:-8$

$1 \cdot 4 \pi-8$

1. $5 \bar{F}-8$

1. $G F-8$

1. $75-83$

1. $8 \mathrm{~F}-\mathrm{z}$

1. $9 \bar{r}-8$

2. $E-6$

?. $1 E-8$

2. $2 F-8$

2. $3 E-8$

2. $4 F-8$

․ $5 \bar{T}-8$

P. $6 E-8$

2. $7 F-3$

2. $3 E-8$

2. $9 \overline{2}-8$

3. $E-8$

3. $15-8$

3. $35-8$

3. $3 \bar{r}-8$

3. $45-8$

3. $5 F-8$

3. $6 F-8$

3. $7 F-8$

3. $\measuredangle E-8$

$3.9 F-8$

1! $079-8$

$4 \cdot 15-8$

$4 \cdot 2 \vec{F}-8$

$4 \cdot 3 F-8$

4. $4 \mathrm{E}-8$
VOLTAGE AT NODE 2

(1)

11. $5510: 2: i-8$

$0 \cdot\{: 11<03$

(1). 1871472

0. $751 \% 15$

1.02 .155

1. 1.5567

$1 \cdot 19091$

$1 \cdot 208381$

1.24 .493

1. 3637

i. 54554

1. 7394

1. $\$ 86 / 444$

1.85118

1.67461

1. 36804

1.01127

0.698313

0.499197

0.433227

0.465584

0.528403

0.550162

0.518692

0.43634

0.370212

0.397066

0.547964

0.832753

1.18747

1. 52125

1. 74787

1. 8206

1. 74937

1.59288

1.129119

1. 32049

1. 28294

1. 2.84 .34

1. 2.6154

$1 \cdot 15474$

0.940405

0.64762

0.349787 
TIME

$$
\begin{aligned}
& 9 \cdot 2 F-8 \\
& 9 \cdot 3 F-8 \\
& 9 \cdot 11 F-8 \\
& 9 \cdot 5 F-8 \\
& 9 \cdot 6 F-8 \\
& 9 \cdot 7 F-8 \\
& 9 \cdot 8 F-8 \\
& 9 \cdot 9 F-8 \\
& 1 \cdot F-7
\end{aligned}
$$

0.393901

1.04147

1.09906

1.11425

1.15144

$1 \cdot 25893$

1.411168

$5 \cdot 6 r-8$

$5 \cdot 7 ! \cdot-\varepsilon$

$5 \cdot 8+1 .+4$

$2 \cdot 9 ! \div-8$

6. $E-B$

$6 \cdot 1 \pi-3$

6. $2.5-8$

$6 \cdot 3 E-3$

G. $\triangle E-B$

$6 \cdot 5 \pi-8$

‥ $6 F-8$

6. $7 F-8$

$6.8 F-8$

6. $9 F-8$

7. $5-8$

.7.1F- -8

7.? $?:-8$

$7 \cdot 3 F-8$

$7 \cdot 45-8$

7. $5 E-8$

$7 \cdot 6 \cdot 5 \cdot-8$

7. $7 F-8$

7. $E E-8$

$7 \cdot 9 E-8$

$8 \cdot 5-8$

$3 \cdot 15-8$

․․ $8-8$

$6 \cdot 35-8$

i. $4 F-8$

8. $5 F-8$

8. $6 F-8$

8. $7 E-E$

$8.8 E-8$

$8.95-8$

9. $E-8$

9.1E-8

$1.0,5504$

1. 85.2 .49

1. 35 rigass

1. 75774

1. 50/121

1.17581

0.86214

0.638779

0.537508

0.537069

0. $5 \% 8177$

0.595449

0.551115

0.45465

0.359106

0.335825

0.439324

0.678778

1. 00953

1. 34885

1. 601599

1. 7326

1. 714149

1.60011

1. 26167

1. 36.329

1. 3,31383

1. 34397

1. 34372

1.26841

1.08443

0.807453

0.500316

0.248756

0.125928

VOLTAGE $A T$ NODE 2

0.161782

0.331253

0.566532

0.787605

0.937359

1.00/104

1. 02.279

1.05407

1. 15053 


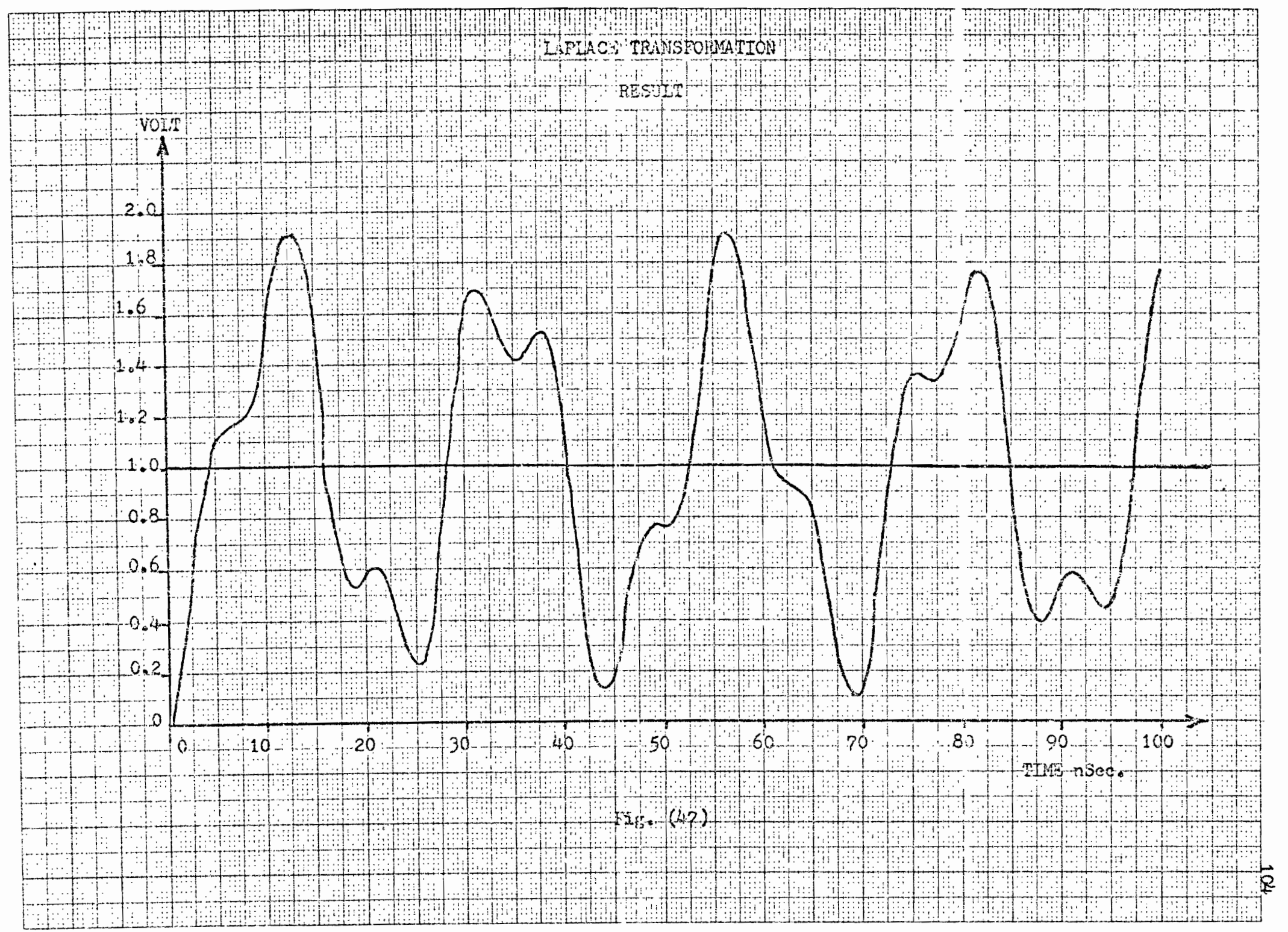




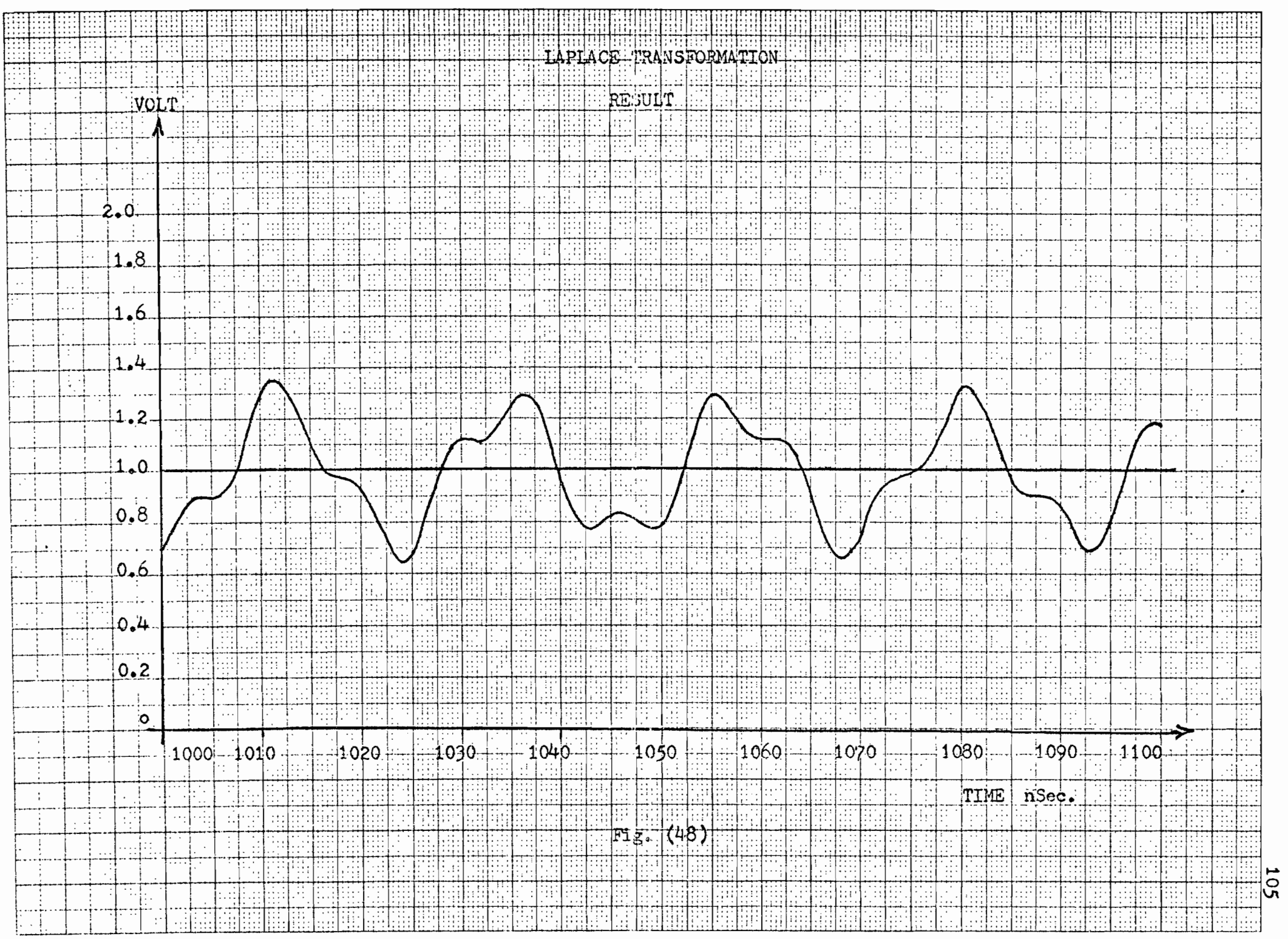




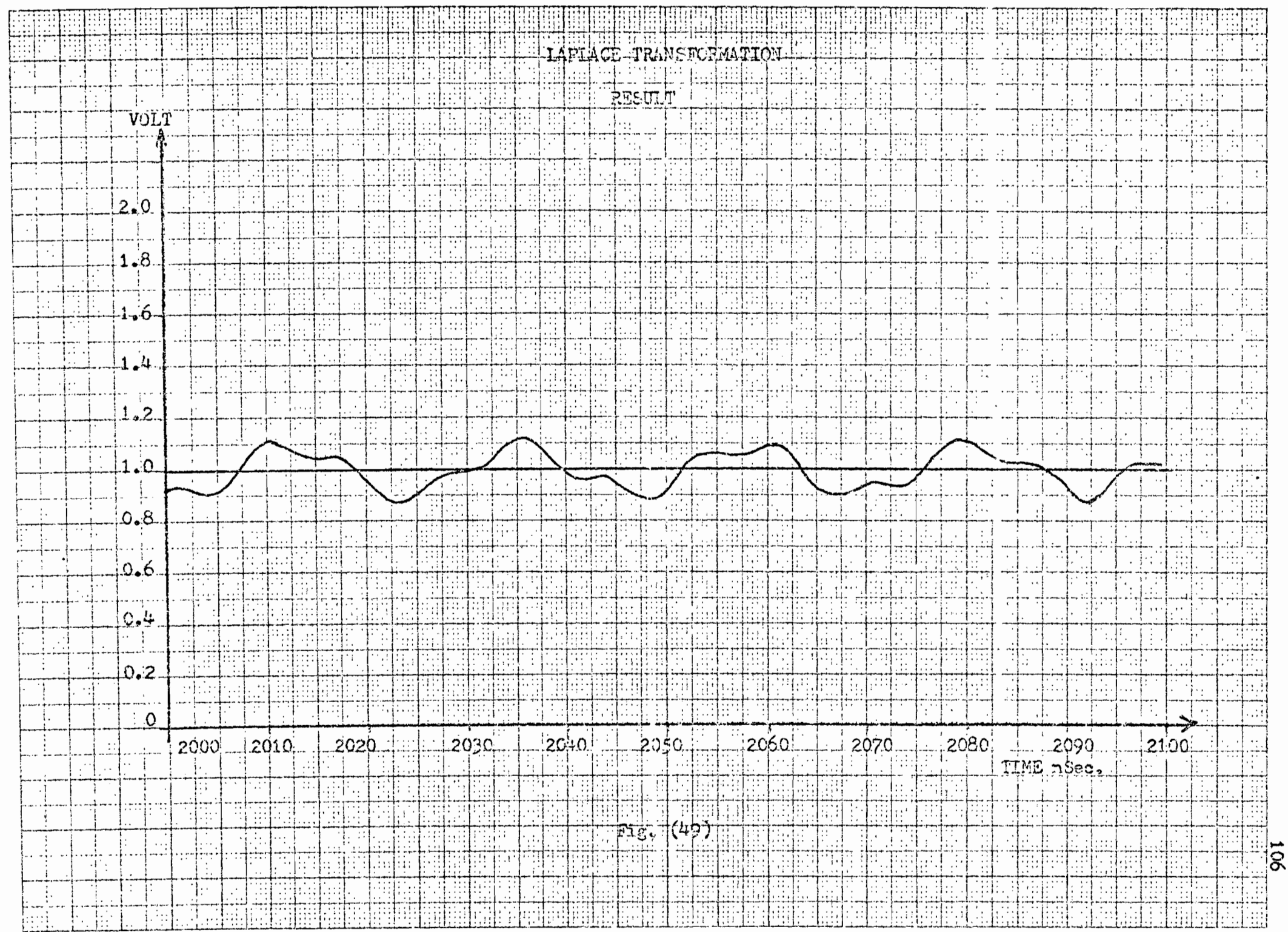




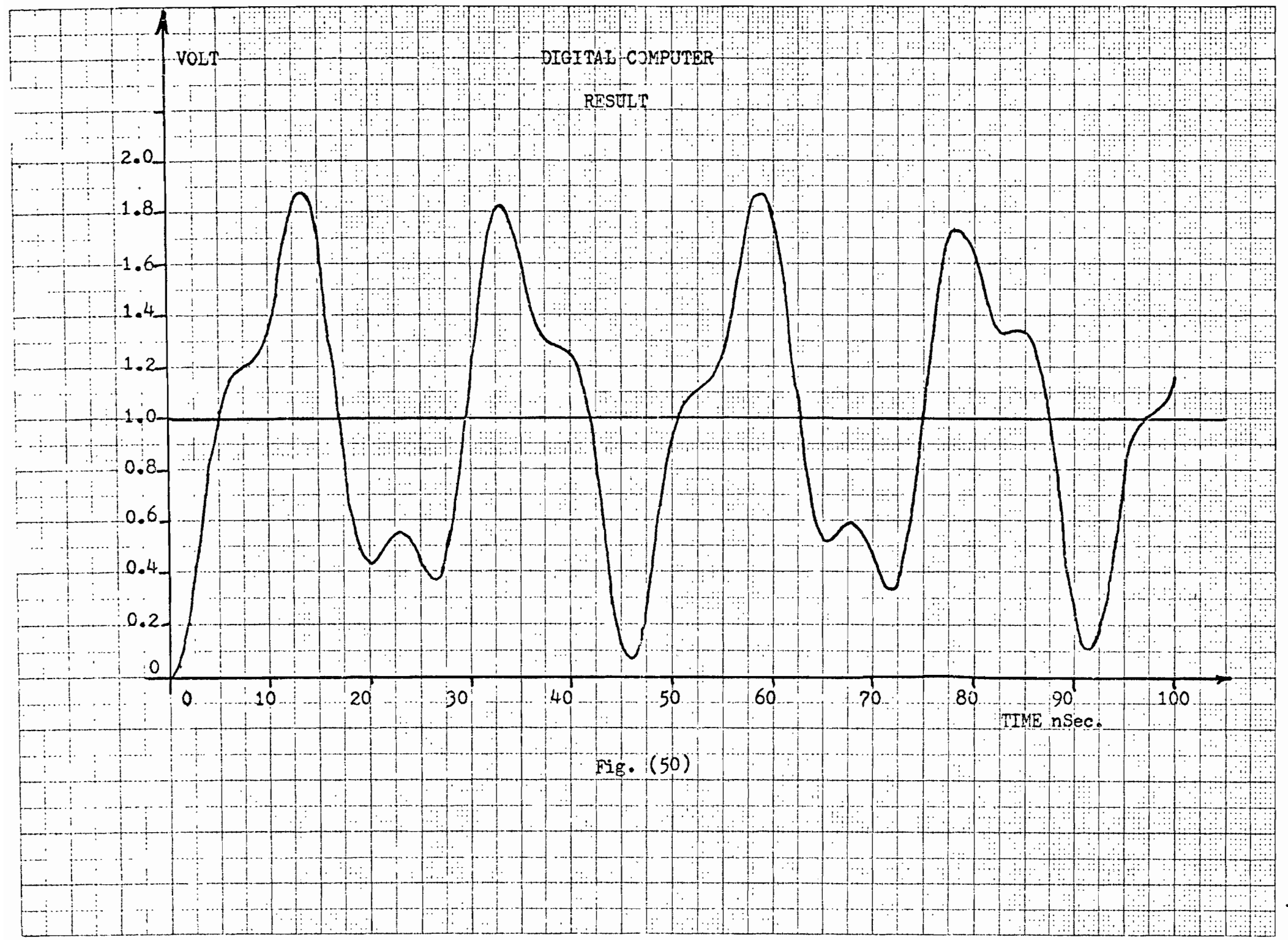


CHAPTER IV

COIMARISON AND CONCLUSION

Comparison of Both Techniques

Advantages and limitations of both of these methods are considered

in the following points:

Digital computer solution by the use of the trapezoidal mule of

integration and the Bergeron method approach:

Advantages:

1. Once current or voltage at a node is determined, all currents and voltages at all nodes can be found simultaneously. In other words, the entire picture of the circuit with its past history can be determined at the same time.

2. Voltage or current is described by a linear equation for each element. There is no need to derive a new equation for each element in a different type of circuit.

3. Complex forcing functions such as sinusoids and exponentials can be handled exactly with no approximation.

4. There is no complex number involved and there is no need to find the roots of a polynomial.

5. This technique is accurate enough for practical purposes and it can be applied to very large power systems. 
Iimitations:

1. There is no exact mathematical equation describing the nature of current or voltage at a node.

2. Initial condition or the past history is always needed.

\section{Laplace transformation technique}

Advantages:

1. There is an exact mathematical equation describing the nature of current or voltage at a node.

2. There is no need for initial condition; data can be obtained at any time easily with only one equation describing the voltage or current.

3. There is no approximation involved in deriving the equations except in computing of coefficients.

4. Laplace transformation technique is analytically and practically more precise than the first method.

\section{Limitations:}

1. All or some of the current and voltages can not be found at the same time unless for each node an equation describing voltage and current has been independently derived.

2. Complex numbers are involved and the roots of a polynomial of transfer function have to be found. When the order of the polynomial is larger than 3, the roots may be found by digital computation. However, it will be sometimes impossible to find the roots by digital computation when the order of the polynomial is too large. 
3. It is difficult and sometimes impossible to find the inverse matrix of an impedance matrix in a large power system.

4. Each forcing function must be transferred to Laplace form and this increases the order of the polynomial.

Conclusion

The graphical solution of the Bergeron method and its application to digital computer solution of electromagnetic transient for distributed parameters and the trapezoidal rule of integration for lumped parameters was discussed. The equations describing the relation of voltage and current on a lossless line and lumped parameters were found; consequently the equivalent impedance networks were drawn. Three examples showed the step by step digital computer solution and programming.

To compare this technique with another, the Laplace transformation method was introduced. An example was illustrated by both techniques and in conclusion the accuracy, advantages, and disadvantages of both methods were discussed.

The method of solving electromagnetic transient with the Bergeron method approach for distributed parameters and the trapezoidal rule of integration for lumped parameters is very efficient and capable of handling very large networks. This method may of course be used with multiphase systems as well as single-phase. 


\section{REFERENCES}

Bergeron, L., Du Coup de Belier en Hydrauligue au Coup de Foudre en Electricité, Paris: Dunod, 1949. Transl., Water Hammer in Hydraulics and Wave Surges in Electricity (Translating Committeo Sponsored by ASME), New York: Wiley, 1961.

Bewley, L. V., Traveling Waves on Transmission Systems, (New York: Dover Publications, Inc., 1951), D. 100.

Branin, F. H., Jr,"Transient Analysis of Iossless Transmission Lines," Proc. IEEE, Vol. 55, pp. 2012-2013, November, 1967 .

Dommel, H., "A Method for Solving Transient Phenomena in Multiphase System", Proc. 2nd Power System Computation Conference 1966, (Stockholm, Sweden), Rept. 5.8.

Dommel, Hermann W., "Digital Comouter Solution of Electromagnetic Transients in Single and Multiphase Networks," IEEE Transaction on Power Apparatus and Systems, Vol. PAS-88, pp. 388-399, No. 4, April 1969.

Nixon, Floyd E., Handbook of Laplace Transformation, Englowood Cliffs, N. J., 2d ed., 1965, pp. 21-44.

Prinz, H., and H. Dommel, "Überspannungsberechnung in Hochspannungsnetzen," presented at the Sixth Meeting for Industrial Plant Managers, sponsored by Allianz Insurance Company, Munich, Germany, 1964.

Tinney, W. F., and J. W. Walker, "Direct Solutions of Sparse Network Equations by Optimally Ordered Triangular Factorization," Proc. IEEE, vol. 55, pp. 1801-1809, November 1967. 